\title{
Evaluation of the Regional Choice Initiative
}

Andrea Phillips, Kun Yuan, Shannah Tharp-Gilliam

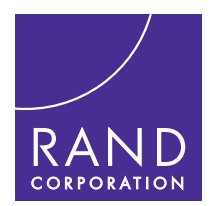


For more information on this publication, visit www.rand.org/t/rr1386

\author{
Library of Congress Cataloging-in-Publication Data \\ is available for this publication.
}

ISBN: 978-0-8330-9255-7

Published by the RAND Corporation, Santa Monica, Calif.

(C) Copyright 2016 RAND Corporation

RAND $^{\circledR}$ is a registered trademark.

\title{
Limited Print and Electronic Distribution Rights
}

This document and trademark(s) contained herein are protected by law. This representation of RAND intellectual property is provided for noncommercial use only. Unauthorized posting of this publication online is prohibited. Permission is given to duplicate this document for personal use only, as long as it is unaltered and complete. Permission is required from RAND to reproduce, or reuse in another form, any of its research documents for commercial use. For information on reprint and linking permissions, please visit www.rand.org/pubs/permissions.html.

The RAND Corporation is a research organization that develops solutions to public policy challenges to help make communities throughout the world safer and more secure, healthier and more prosperous. RAND is nonprofit, nonpartisan, and committed to the public interest.

RAND's publications do not necessarily reflect the opinions of its research clients and sponsors.

Support RAND

Make a tax-deductible charitable contribution at www.rand.org/giving/contribute

www.rand.org 


\section{Preface}

School districts in Beaver County, Pennsylvania, lost approximately 3 percent of their student population because of declines in population and school choice offerings in the state in the academic years 2005-2006 and 2006-2007. These decreasing enrollments and the associated decrease in funds for Beaver County public-school districts led administrators to work proactively to maintain the quality of their basic services for all students, as well as to increase instruction in core areas, including technology and the arts.

One of their approaches to this problem was the Regional Choice Initiative (RCI). This initiative sought to offer more public-school options to students, particularly in terms of providing opportunities for students in low-performing districts to learn in high-performing environments.

In the fall of 2007, the Beaver Valley Intermediate Unit (BVIU), the regional educationalservice agency serving schools in Beaver County, won a Voluntary Public School Choice grant from the U.S. Department of Education to fund the RCI. As part of this grant, BVIU partnered with the RAND Corporation to evaluate the RCI's processes and outcomes. This report summarizes attainment of performance goals and performance outcomes (e.g., student achievement, dropout rates) over the course of the grant.

This report should be of greatest interest to the BVIU administration; the RCI implementation team; and leadership, administrators, and staff from partnering districts. It also provides the U.S. Department of Education with information about the final performance of the grant and should be of interest to people seeking to expand school-choice programs.

This evaluation is sponsored by the U.S. Department of Education. It is being conducted within RAND Education, a research unit of the RAND Corporation. This research reflects RAND Education's mission to bring accurate data and careful, objective analyses to the national discussion on education policy. Comments are welcome and should be sent to Andrea Phillips (412-683-2300; aphillip@rand.org). 


\section{Table of Contents}

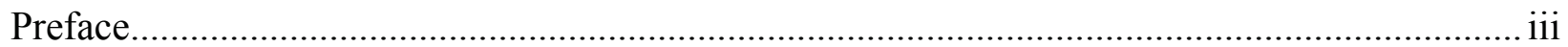

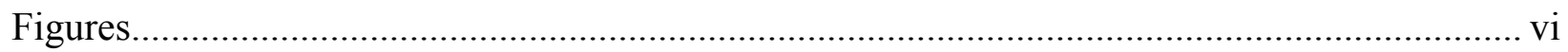

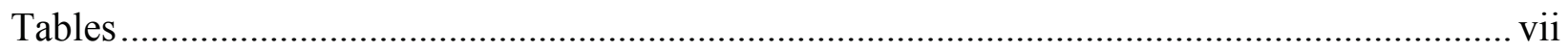

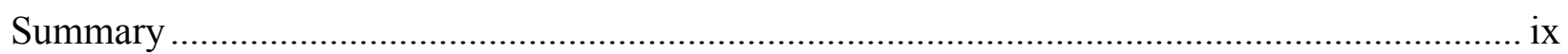

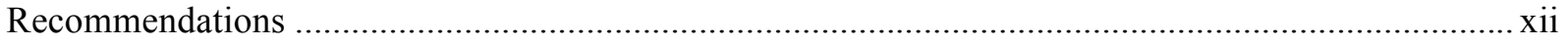

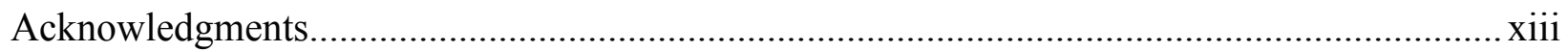

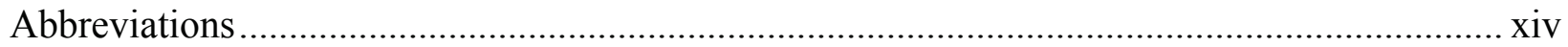

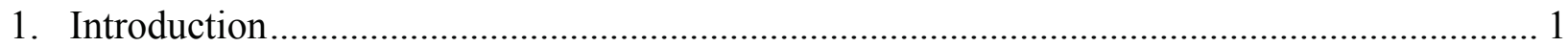

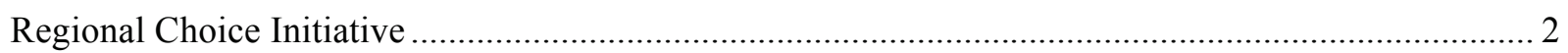

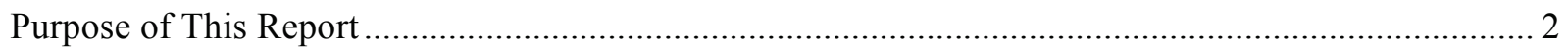

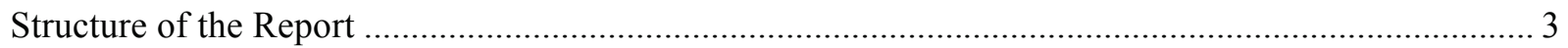

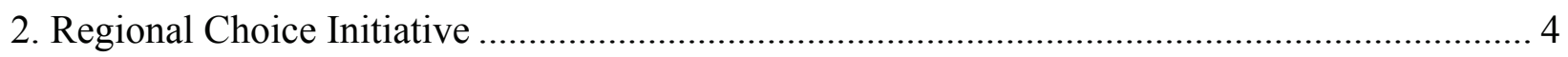

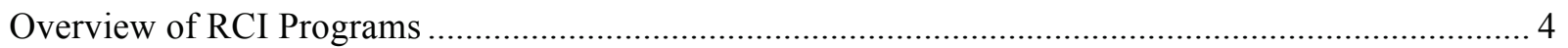

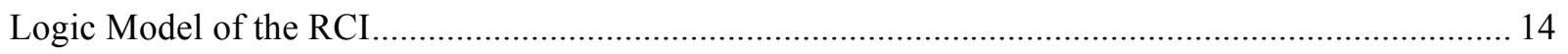

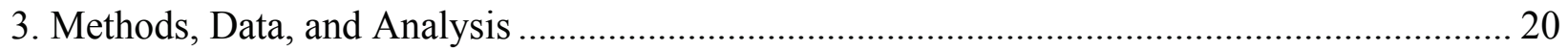

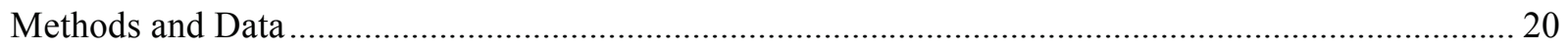

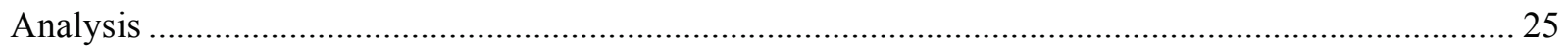

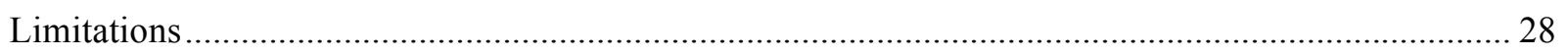

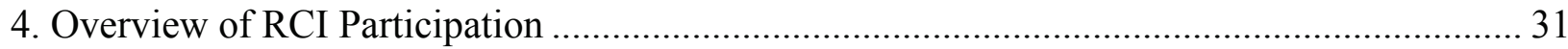

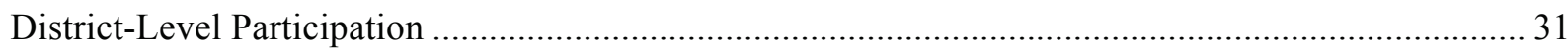

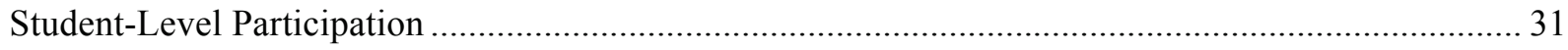

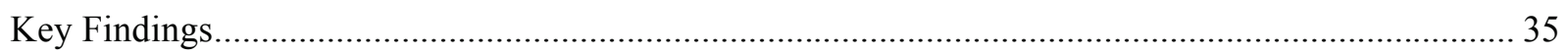

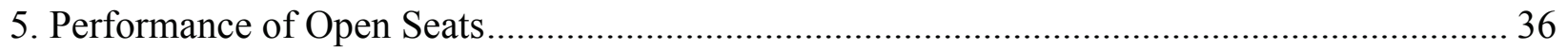

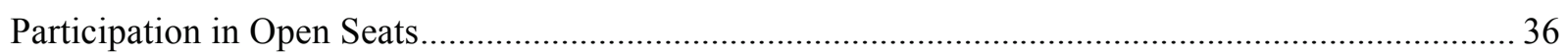

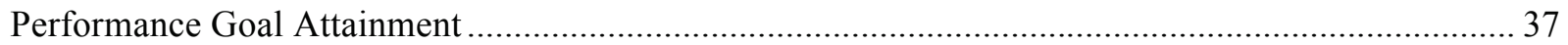

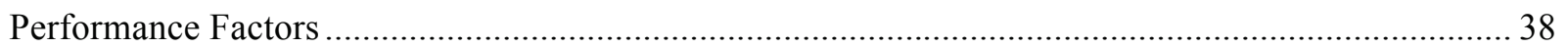

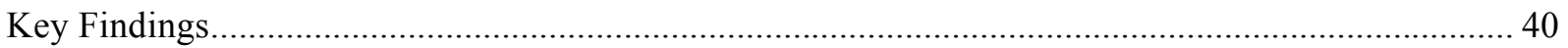

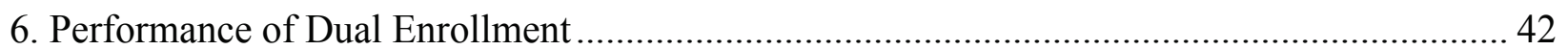

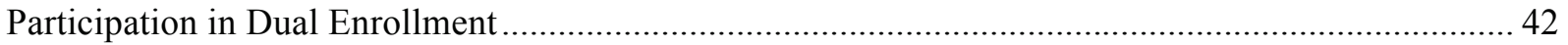

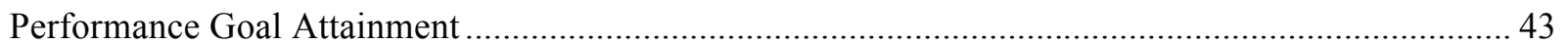

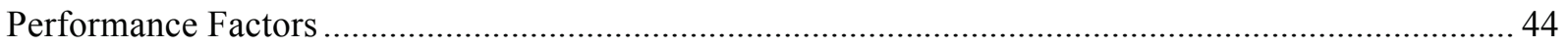

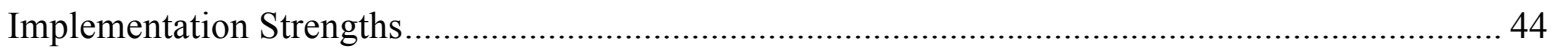

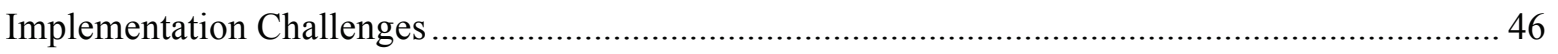

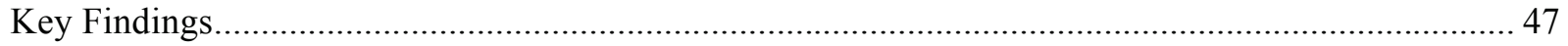

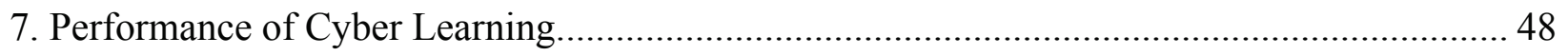

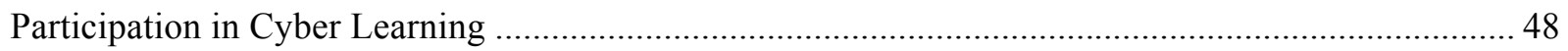

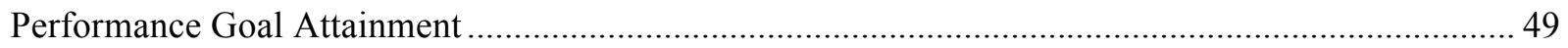




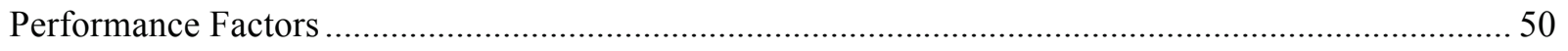

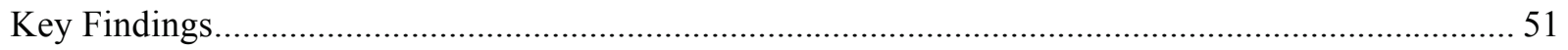

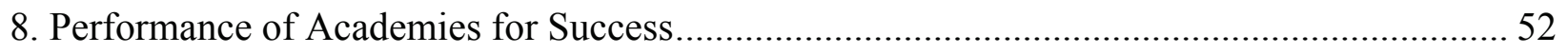

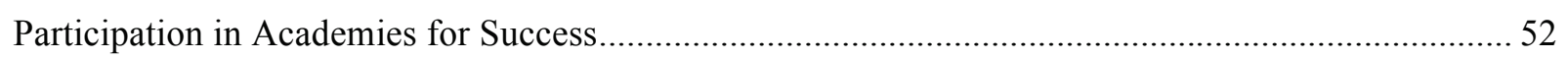

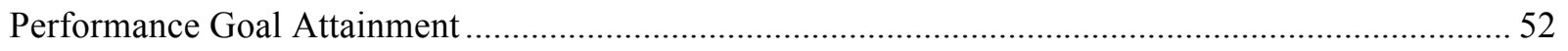

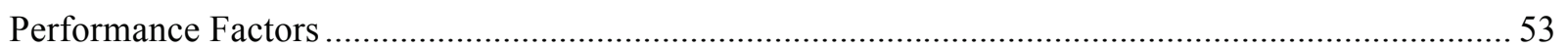

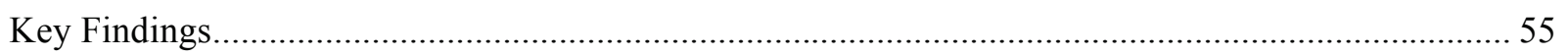

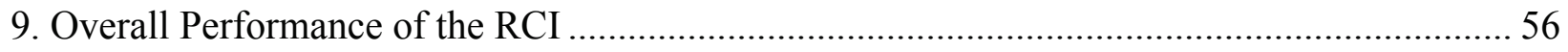

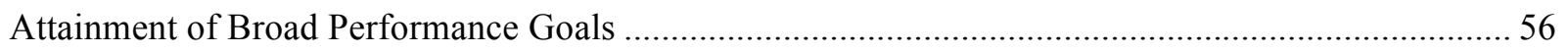

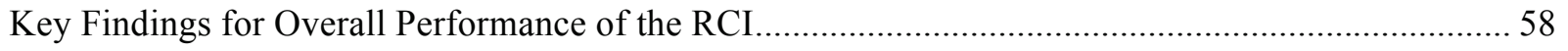

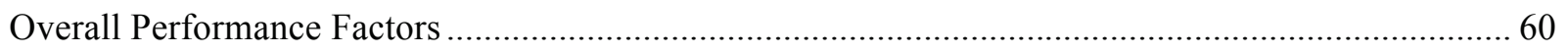

10. Relationship of Participation in the RCI to Student Outcomes ......................................... 63

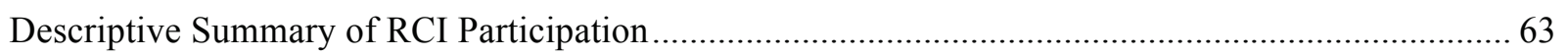

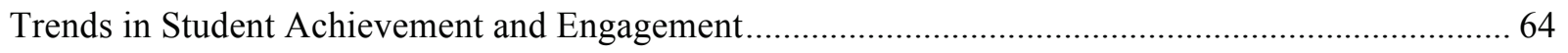

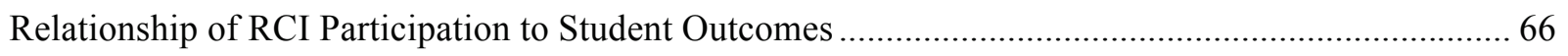

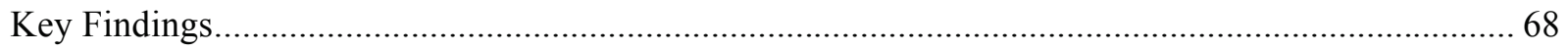

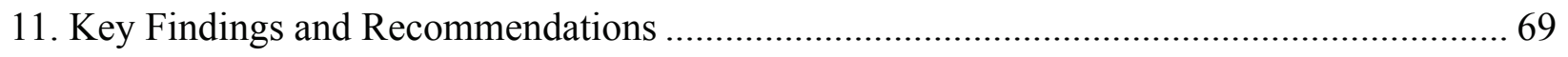

The RCI Did Not Achieve the Majority of the Performance Measures .............................................. 69

The RCI's Impact on Student Outcomes Is Not Evident in the Limited Available Data..................... 71

Stakeholders Perceive That the RCI Affected the Region ........................................................... 71

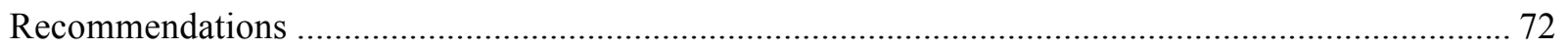

Appendix: Student Outcome Analysis Methods and Results ............................................ 74

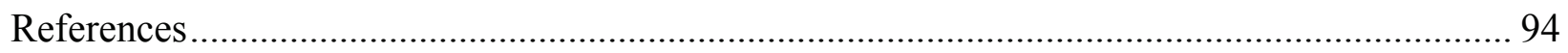




\section{Figures}

Figure 2.1. Screenshot of the RCI Website, Featuring the Open Seats Program with

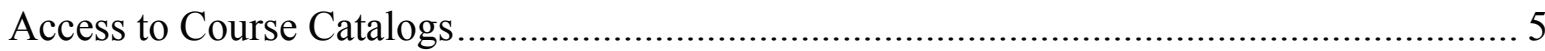

Figure 2.2. Screenshot of the RCI Website, Featuring the Dual Enrollment Program and

Links to Course Catalogs of Partnering Colleges ........................................................... 8

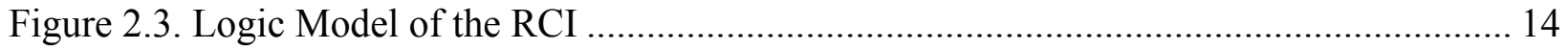

Figure 9.1. Parents' Awareness of RCI Programs ............................................................ 58

Figure 10.1. Percentage of RCI Participants by the Years Students Participated in the RCI...... 63

Figure 10.2. Percentage of RCI Participants by the Number of Programs Students

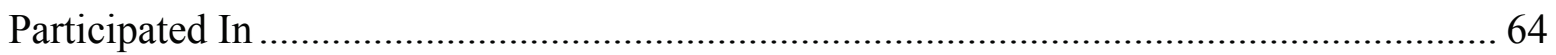

Figure 10.3. Trends in the Percentage of Students Scoring at or Above the Proficient

Level on the PSSA Mathematics and Reading Tests for RCI and Non-RCI Districts 65 


\section{Tables}

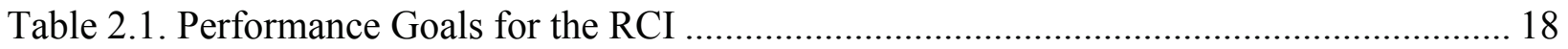

Table 3.1. Years and Grade Levels for Which Student-Level Data Were Requested

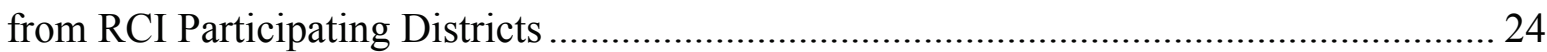

Table 3.2. Summary of Student Achievement and Engagement Measures ................................... 28

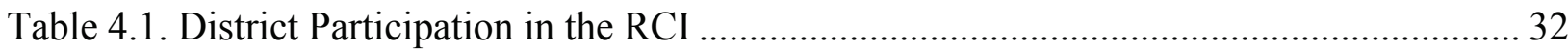

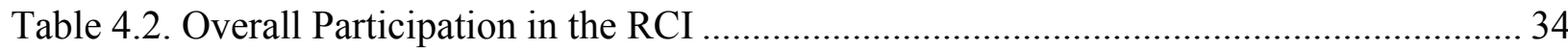

Table 5.1. Student Participation and Performance in Open Seats by Year.................................... 36

Table 5.2. Student Participation in Full-Time Transfer in Open Seats.......................................... 37

Table 5.3. Open Seats Performance Measures and Objectives......................................................... 37

Table 6.1. Student Performance in Dual Enrollment by Year ..................................................... 43

Table 6.2. Dual Enrollment Performance Measures and Objectives ............................................ 43

Table 7.1. Student Performance in Cyber Learning Courses by Year ............................................ 48

Table 7.2. Cyber Learning Performance Measures and Objectives................................................ 49

Table 8.1. Academies for Success Performance Measures and Objectives.................................. 52

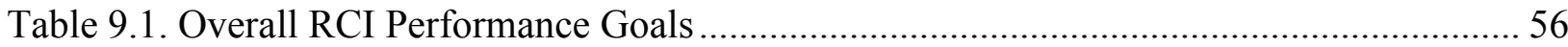

Table 9.2. Attainment of RCI Performance Measures.................................................................. 59

Table 10.1. Trends in the Percentage of 11th-Grade Student Scoring at or Above the

Proficient Level on the PSSA Mathematics and Reading Tests in RCI Districts.................. 65

Table 10.2. Trends in Dropout Rates Among Students at Grades 7-12 in RCI and Non-RCI

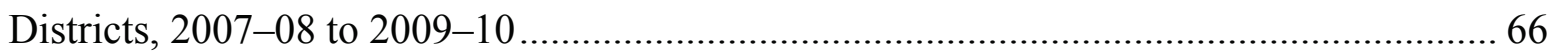

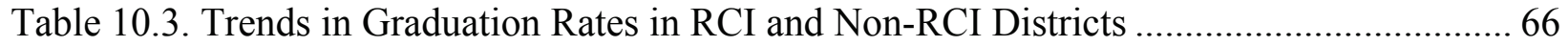

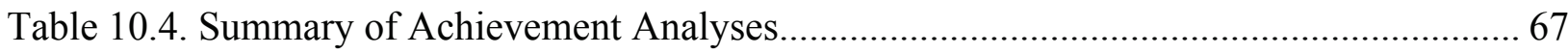

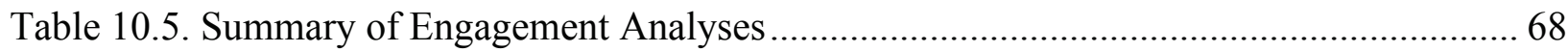

Table A.1. Equivalence Between RCI and Comparison Districts at Baseline............................... 77

Table A.2. Results of the ATT Analysis at the District Level................................................... 78

Table A.3. Equivalence Between 11th Grade RCI Participants in 2010-2011 and the

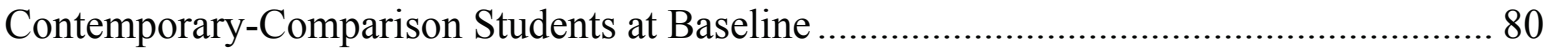

Table A.4. Equivalence Between 11th-Grade RCI Participants in 2009-2010 and the

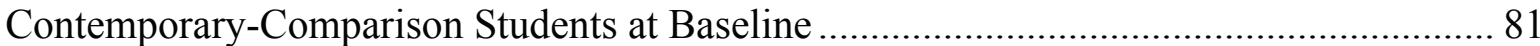

Table A.5. Equivalence Between RCI Participants in 2010-2011 and the Contemporary-

Comparison Students at Baseline for Analyses on Attendance Rate.................................. 82

Table A.6. Equivalence Between RCI Participants in 2009-2010 and the Contemporary-

Comparison Students at Baseline for Analyses on Attendance Rate 82 
Table A.7. Equivalence Between RCI Participants in 2008-2009 and the ContemporaryComparison Students at Baseline for Analyses on Attendance Rate. 83

Table A.8. Equivalence Between RCI Participants in 2007-2008 and the ContemporaryComparison Students at Baseline for Analyses on Attendance Rate 83

Table A.9. Equivalence Between RCI Participants in 2010-2011 and the ContemporaryComparison Students at Baseline for Analyses on Advanced Course Enrollment. 84

Table A.10. Equivalence Between RCI Participants in 2009-2010 and the ContemporaryComparison Students at Baseline for Analyses on Advanced Course Enrollment.. 84

Table A.11. Equivalence Between RCI Participants in 2008-2009 and the ContemporaryComparison Students at Baseline for Analyses on Advanced Course Enrollment............... 85

Table A.12. Equivalence Between RCI Participants in 2007-2008 and the ContemporaryComparison Students at Baseline for Analyses on Advanced Course Enrollment. 85

Table A.13. Equivalence Between 11th-Grade RCI Participants in 2010-2011 and the Historical-Comparison Students 86

Table A.14. Equivalence Between 11th-Grade RCI Participants in 2009-2010 and the Historical-Comparison Students 87

Table A.15. Equivalence Between RCI Participants in 2010-2011 and the HistoricalComparison Students for Analyses on Attendance Rate ..... 88

Table A.16. Equivalence Between RCI Participants in 2009-2010 and the HistoricalComparison Students for Analyses on Attendance Rate ..... 88

Table A.17. Equivalence Between RCI Participants in 2008-2009 and the HistoricalComparison Students for Analyses on Attendance Rate.... 89

Table A.18. Equivalence Between RCI Participants in 2007-2008 and the HistoricalComparison Students for Analyses on Attendance Rate..... 89

Table A.19. Equivalence Between RCI Participants in 2010-2011 and the HistoricalComparison Students for Analyses on Advanced Course Enrollment 90

Table A.20. Equivalence Between RCI Participants in 2009-2010 and the HistoricalComparison Students for Analyses on Advanced Course Enrollment 90

Table A.21. Equivalence Between RCI Participants in 2008-2009 and the Historical-

Comparison Students for Analyses on Advanced Course Enrollment 91

Table A.22. Equivalence Between RCI Participants in 2007-2008 and the HistoricalComparison Students for Analyses on Advanced Course Enrollment.... 91

Table A.23. ATT Analysis Results at the Student Level Using Contemporary-Comparison Group .92

Table A.24. Results of the ATT Analysis at the Student Level Using Historical-Comparison Group ...... 


\section{Summary}

\section{Background and Research Questions}

In an effort to improve student achievement, the Beaver Valley Intermediate Unit (BVIU), an agency serving the schools in Beaver County, Pennsylvania, launched the Regional Choice Initiative (RCI) program in the fall of 2007. The RCI aimed to expand access to diverse academic offerings for middle and high school students from low-performing districts and districts in the region that did not make Adequate Yearly Progress, as well as to provide opportunities for students in those districts to learn in high-performing environments. The RCI also aimed to expand access to academic offerings for students who were not in low-performing districts but were underperforming, referred to as low-performing or disengaged students.

The RCI consists of four programs: (1) Open Seats, which allows students in one district to take advantage of open or available seats in courses in other districts; (2) Dual Enrollment, which enables high school students to take courses at partnering institutions of higher education free of cost and receive college credit; (3) Cyber Learning, which enables students to take courses remotely through the Internet; and (4) Academies for Success, which provides specialized learning academies.

The BVIU partnered with 17 school districts for five years to provide the RCI. The program was implemented for six years, including the original planned five years from 2007-2008 through 2011-2012, with a no-cost extension in 2012-2013. The Voluntary Public School Choice (VSPC) award from the Department of Education (ED) required partnership with an external, independent evaluator. The BVIU contracted with RAND to carry out this evaluation.

As required by the VPSC program, RCI administrators developed 21 measures to assess the success of RCI programs. Among them, 15 measures specified quantifiable criteria on the number of participating students with a passing grade in courses enrolled through RCI programs or the dropout rate among participating students to measure the success of RCI programs. These measures are referred to as performance measures. Six measures described the activities that RCI administrators needed to complete independently and that did not rely on student participation. These measures are referred to as objective measures.

RAND researchers evaluated the implementation and impact of the RCI. The implementation evaluation covered six years of program implementation. The impact evaluation covered the first four years of program implementation, as defined by the original scope of work. This evaluation addressed the following three research questions:

1. To what extent did each RCI program achieve its performance and objective measures? 
2. What factors enabled or hindered each RCI program's achievement of performance measures?

3. To what extent did the overall RCI affect student engagement and achievement outcomes?

When reporting, we provide the annual participation for the program years ( 1 to 5 ; and the year 6 no-cost extension). We also aggregate participation data in the no-cost extension year with that in year 5 , as directed by the RCI VPSC program office.

\section{Methods and Data}

We took a mixed-methods, quasi-experimental approach to evaluate the implementation and impact of the RCI initiative. The implementation evaluation focused on assessing the extent to which RCI programs achieved their performance goals and objectives and identifying factors that facilitated or hindered the implementation and performance of the RCI. The impact evaluation used a quasi-experimental design to compare RCI participating students with groups of similar students on their achievement and engagement outcomes, as well as changes in these outcomes.

We collected and analyzed program documents and meeting notes, interviewed more than 60 stakeholders throughout the region, surveyed parents, and analyzed student RCI participation data and administrative data provided by participating districts and obtained from public sources, including the Common Core of Data at the National Center for Education Statistics and the Pennsylvania Department of Education.

We conducted thematic analysis on program documents, meeting notes, and interview results. We analyzed parent survey results. For the impact evaluation, we used propensity score matching to identify comparison students for RCI participants and conducted regression analyses to examine whether RCI participants outperformed their counterparts in the comparison group on engagement and achievement outcomes, as well as on changes in these outcomes.

\section{Findings}

\section{The Overall Participation in RCI Programs Was Low and Inconsistent}

In total, 4,357 students participated in four RCI programs during the six years of program implementation. The number of participants increased from 165 in year 1 to 2,063 in the final two years. The number of participants each year was less than 10 percent of the overall enrolled students at grades 7-12 in participating districts in the first four years of program implementation.

Analysis on the first four years of participation showed that most participants ( 86 percent) participated in the RCI for only one year, and more than 90 percent of participants took courses through only one RCI program; about 45 percent participated in Dual Enrollment, one-quarter 
participated in Cyber Learning, and one-fifth participated in Open Seats. Sixty-five percent of participants took mathematics or English Language Arts-related courses through RCI programs.

\section{Although RCI Met Most of Its Objective Measures, It Failed to Meet the Majority of Its Performance Measures}

The RCI achieved eight out of 21 measures set for RCI programs by the end of the funding period (i.e., at the end of year 6). Five of the eight achieved measures were objective measures. The three achieved performance measures were about the dropout rate of participating students in the Academies for Success and the number of live or online courses in the core curriculum created by the content-area faculty teams in the second and third years of the program. None of the performance measures that required a certain percentage of participating students earning a passing grade on courses enrolled through RCI programs was met.

\section{Data Available for Impact Analysis Were Limited; No Relationship Was Detected Between Participation and Student Engagement and Achievement Outcomes}

Data available for the analysis on the associations between RCI participation and student outcomes were limited for several reasons, including the lack of capacity at participating districts to provide the data required for analysis and the lack of students who participated in RCI programs for multiple years. As the result, we were unable to measure the impact of the initiative on all participants, because more than half of the participating districts did not provide studentlevel data for analysis. Insufficient data limited the statistical power of our analyses and therefore our ability to identify program effects.

Our analysis based on available data did not find any discernible relationship between participation in RCI programs and student achievement and engagement outcomes at the school or district level. However, student-outcome findings need to be interpreted with caution; they do not support any firm conclusions about the impact of RCI programs, because of limitations in the data and measures of participation available for analysis, the length of participation captured in the data, and the ability of available outcome variables to measure aspects of students' competency and behavior that might be affected by participation in the RCI.

\section{Multiple Factors Contributed to the Low Level of Participation in the RCI}

Interviews of district and school stakeholders and surveys of parents revealed that several factors might have contributed to the low level of buy-in from key stakeholders, including lack of quantifiable indicators for eligible students; school stakeholders' concerns about the potential impact of the program on students, staff, and the school; lack of compatible schedules across schools; students' unwillingness to attend courses using virtual-learning technologies available from RCI programs; and logistical constraints for students to physically transfer among schools to take courses. 


\section{Stakeholders Viewed the Impact of the $\mathrm{RCl}$ on Participating Districts and Students Positively, and Districts Decided to Sustain Most RCI Programs in the Future}

Despite the low and inconsistent participation in RCI programs, stakeholders reported that the RCI and its programs provided important opportunities to students throughout the final three years of the initiative. Stakeholders also reported that the RCI and the work of its administrators improved communication and collaboration between districts and transformed the climate and culture of the county. These stakeholders considered the transformation as one of the greatest successes of the RCI. Though districts were hesitant to participate in the RCI early on, they decided to sustain three of the four RCI programs without external funding. Such a decision represents a strong commitment to and support for RCI programs from participating districts.

\section{Recommendations}

We provide three major recommendations for the design and implementation of similar programs in the future. First, it is important to test the feasibility of designed program features and the implementation plan in advance. This feasibility study should examine the demand for the expected program, examine the readiness and capacity of participating organizations to implement the program features, and identify problems that might arise during the implementation of the program.

Second, we recommend a strong, multitiered communication strategy to communicate program information to the target student population and their parents. This would help directly recruit students for the program and could counter the potential difficulty in recruitment of students by school stakeholders. Experts in communication might support the development of effective campaigns that appeal to the target population and encourage recruitment.

Third, we recommend using a dashboard system from the beginning of the program to monitor the implementation and facilitate communication with stakeholders. This might help improve the program implementation and its potential impact. Such a dashboard system would require careful design to make sure it provides information that program administrators need to assess the implementation of the program and the evaluation of the program. It may also be designed to provide channels to solicit feedback from a large number of stakeholders in a timely manner, such as online surveys of school staff members and students. 


\section{Acknowledgments}

The RAND evaluation team acknowledges the thoughtful participation by numerous people during the period of the Beaver Valley Intermediate Unit (BVIU) Regional Choice Initiative (RCI) - including BVIU, RCI, and district leadership, as well as principals, assistant principals, guidance counselors, and teachers - who worked to implement this effort. Through the evaluation process, RAND researchers gathered information about the context, history, and progress from contributors to this report who gave of their time to provide data. We greatly appreciate their assistance and willingness to contribute. We would like to like to acknowledge the contributions of current and former RAND colleagues who contributed to the evaluation: John Engberg, Julia Kaufman, Elizabeth Steiner, James Coley, Lynette Staplefoote, Courtney Kase, Lauren Smith, and Emma Lee. Clifford Grammich supported the writing of this report, for which we are appreciative. We would also like to acknowledge Jennifer Russell at the University of Pittsburgh and John Pane and Cathy Stasz at RAND for their thorough reviews and feedback. Their reviews significantly improved the report. 


\section{Abbreviations}

$\begin{array}{ll}\text { AP } & \text { Advanced Placement } \\ \text { ATT } & \text { average treatment effect on the treated } \\ \text { AYP } & \text { Adequate Yearly Progress } \\ \text { BVIU } & \text { Beaver Valley Intermediate Unit } \\ \text { CCD } & \text { Common Core of Data } \\ \text { ED } & \text { U.S. Department of Education } \\ \text { IU } & \text { intermediate unit } \\ \text { IVC } & \text { interactive videoconferencing } \\ \text { NAEP } & \text { National Assessment of Education Progress } \\ \text { NCE } & \text { no-cost extension } \\ \text { NCES } & \text { National Center for Education Statistics } \\ \text { NCLB } & \text { No Child Left Behind } \\ \text { PD } & \text { professional development } \\ \text { PDE } & \text { Pennsylvania Department of Education } \\ \text { PSAT } & \text { Preliminary SAT } \\ \text { PSSA } & \text { Pennsylvania System of School Assessment } \\ \text { RCI } & \text { Regional Choice Initiative } \\ \text { ROTC } & \text { Reserve Officers' Training Corps } \\ \text { SAC } & \text { Superintendents' Advisory Council } \\ \text { STEM } & \text { science, technology, engineering, and } \\ \text { VPSC } & \text { mathematics } \\ & \text { Voluntary Public School Choice } \\ & \end{array}$




\section{Introduction}

Beaver County spans 434 square miles of Western Pennsylvania and comprises a number of former steel-mill communities that are home to approximately 172,500 residents and 25,000 public school students in grades K through 12. The Beaver Valley Intermediate Unit (BVIU) is one of 29 intermediate units (IUs) in Pennsylvania. It functions at a level of organization below the Pennsylvania Department of Education (PDE) and above that of the public-school districts in Beaver County that it serves. The BVIU provides programs and resources that include instructional materials and professional development (PD) services for educators, as well as training and career counseling.

Around the time of the global financial crisis, in 2008, Beaver County struggled along with the rest of the U.S. economy. Its unemployment rate increased from 5.5 percent in 2008 to 8.2 percent in 2009, which was lower than the national average during the same period (U.S. Department of Labor, 2009). Its poverty rate for children ages five to 17 living with their families increased from 12.5 percent in 2007 to 14.9 percent in 2008 , though this rate remained below the national rate of 16.5 percent (U.S. Census Bureau, 2010 [data for 2007 and 2008]; U.S. Department of Labor, 2009).

Such strains followed others that were placed on local schools in earlier years. A countywide population decrease of nearly 5 percent since 2000 also saw county school districts lose 761 students ( 3 percent) of their enrollment in the academic years 2005-2006 and 2006-2007. These decreasing enrollments and the associated decrease in funds pose a challenge to the ability of local schools to maintain high-quality basic services for all students and to provide instruction in noncore areas, including technology and the arts.

Despite these challenges, most districts in the region are meeting performance standards under the No Child Left Behind (NCLB) federal legislation (Pub. L. 107-110, 2002). In the 2005-2006 school year, Beaver County elementary and secondary students roughly matched the performance of other Pennsylvania students. For example, 75 percent of Beaver County eighth graders met proficiency standards in reading, compared with 81 percent of eighth graders across the state. Beaver County's proficiency levels for eighth-grade mathematics (61 percent) and 11 th-grade reading (65 percent) and mathematics (56 percent) were also similar to those for other Pennsylvania students. The state, in turn, had a slightly higher proportion of students scoring proficient on the National Assessment of Education Progress (NAEP) than did so nationwide in 2005 (Yell, 2006, p. 181). 


\section{Regional Choice Initiative}

Even in the midst of this relative success in the face of continuing challenges, Beaver County districts have been working to further improve student achievement by increasing students' exposure to more-rigorous courses, presumably offered in higher-achieving school districts. Accordingly, in 2007, the BVIU sought and received funding for a five-year grant under the U.S. Department of Education's (ED's) Voluntary Public School Choice (VPSC) program (BVIU, 2007).

VPSC grants, provided to a small number of sites nationally, seek to develop innovative strategies for local school districts in expanding school choice (Yin \& Ahonen, 2008). VPSC grant priorities are to (1) provide the widest-possible choice to students in participating schools, (2) promote transfers ${ }^{1}$ of students from low- to higher-performing schools, (3) form district partnerships that allow student transfers to a school in another district, and (4) require sites to use funds for student-transportation services.

The BVIU responded by developing, implementing, and evaluating the Regional Choice Initiative (RCI). The four programs of the RCI were

- Open Seats, allowing students in one district to take advantage of open or available seats in courses in other districts

- Dual Enrollment, enabling high school students to attend courses at a postsecondary institution and receive transferable course credits

- Cyber Learning, enabling students to take courses through the Internet

- Academies for Success, providing students with academic options of the highest levels of challenge and rigor, as well as educational opportunities that support direct links to postsecondary education and careers.

Together, the four RCI programs sought to expand students' access to diverse academic offerings from across the districts in the IU. The RCI was implemented for six years, including the original five years of grant (i.e., 2007-2008 to 2011-2012) and a no-cost extension (NCE) year in 2012-2013.

\section{Purpose of This Report}

The BVIU commissioned RAND to conduct a formative and a summative evaluation of the RCI programs. The formative evaluation focused on the implementation process and achievement of program performance goals. The summative evaluation studied the impact of participation in RCI programs on student outcomes. The formative evaluation covered all six

\footnotetext{
${ }^{1}$ A transfer occurs when a student goes to a different school to enroll in a single class or a full-course schedule.
} 
years of the program (i.e., school years 2007-2008 through 2012-2013), while the summative evaluation focused on the first four years of the program. ${ }^{2}$

The RAND team took a mixed-methods, quasi-experimental approach to evaluate the implementation and impact of the RCI initiative. We reviewed program documents, interviewed a number of stakeholders throughout the region, surveyed parents, and analyzed student RCI participation data and administrative data.

RAND's evaluation also adopts one of the key priorities of the VPSC program office. The VPSC program office encourages VPSC grantees to engages in outcome-based decisionmaking for education reform, which includes developing a logic model to show the link between their planned inputs, activities, and outcomes and using performance measures as benchmarks for their progress. Recognizing the importance of this directive, the RAND team worked with the RCI team and partnering superintendents to develop the RCI logic model and set up performance measures for each RCI program to guide the implementation and evaluation of the RCI.

The key questions addressed in this project include:

1. To what extent did each RCI program achieve its performance and objective measures?

2. What factors enabled or hindered each RCI program's achievement of performance measures?

3. To what extent did the overall RCI affect student engagement and achievement outcomes?

\section{Structure of the Report}

This report consists of 11 chapters. In Chapter Two, we describe the RCI in detail. We describe the design of the programs, literature related to the implementation and outcomes of related programs, the logic model of the overall initiative, and performance goals for implementing the RCI. The methods and data sources for the evaluation, as well as measures created for the evaluation, appear in Chapter Three. This chapter also discusses the limitations to the data and analytical approaches. Chapter Four offers an overview of participation in the RCI; the chapter describes the participating districts, target populations, and overall student participation in the initiative. Chapters Five to Nine assess the performance of the RCI using goals established prior to the start of programming. We identify implementation factors that facilitated and hindered the attainment of the performance goals. Chapter Ten presents the impact evaluation of the RCI on student outcomes. Chapter Eleven summarizes key findings for the overall evaluation and recommendations for the field.

\footnotetext{
${ }^{2}$ The initial timeline of VPSC funding and scope of work for this evaluation did not allow for inclusion of data from year 5 and the period under NCE.
} 


\section{Regional Choice Initiative}

In this chapter, we present an overview of each RCI program and reviews of prior literature on the implementation and impact of programs similar to each RCI program. We also describe the logic model for the RCI, which includes the performance measures for each program.

\section{Overview of $\mathrm{RCl}$ Programs}

As mentioned in Chapter One, the RCI includes four programs, including Open Seats, Dual Enrollment, Cyber Learning, and Academies for Success. Each program was designed to meet different needs of students and to jointly increase students' opportunities to take courses throughout the region.

\section{Open Seats}

\section{Program Description}

The RCI Open Seats program is an agreement among the consortium of school districts that is designed to expand students' course options. It does so by opening existing courses in host districts (i.e., the school district where the course materials and instructor originate) to students in grades 7 to 12 from partnering districts elsewhere in the county. Participants remain enrolled in their home district (i.e., the school district in which the student is officially enrolled) while taking part in Open Seats courses by (1) physically traveling to the host district or (2) using interactive videoconferencing (IVC) services to attend a class virtually. The Open Seats program facilitates physical or virtual travel between home and host districts by providing bus transportation, reimbursing mileage for students who use their own transportation between host and home districts, or providing IVC equipment. Any course can qualify as an Open Seats course if there is space for at least one additional student. Figure 2.1 shows Open Seats information and links to course catalogs. 
Figure 2.1. Screenshot of the RCI Website, Featuring the Open Seats Program with Access to Course Catalogs

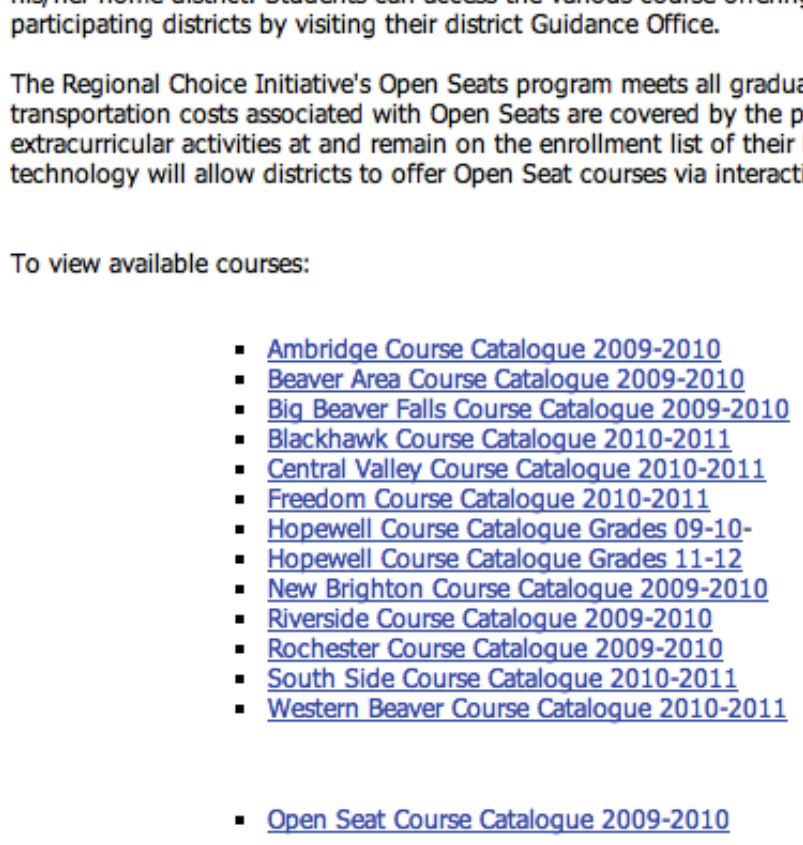

To view available courses:

- Ambridge Course Cataloque 2009-2010

- Beaver Area Course Cataloque 2009-2010

- Biq Beaver Falls Course Cataloque 2009-2010

- Blackhawk Course Cataloque 2010-2011

- Central Valley Course Cataloque 2010-2011

- Freedom Course Catalogue 2010-2011

- Hopewell Course Cataloque Grades 09-10-

- Hopewell Course Cataloque Grades 11-12

- New Brighton Course Catalogue 2009-2010

- Riverside Course Cataloque 2009-2010

- Rochester Course Cataloque 2009-2010

- South Side Course Cataloque 2010-2011

- Western Beaver Course Catalogue 2010-2011

- Open Seat Course Catalogue 2009-2010

The Regional Choice Initiative's Open Seats program meets all graduation requirements for each participating district. All transportation costs associated with Open Seats are covered by the program. Students taking part in Open Seats participate in extracurricular activities at and remain on the enrollment list of their home district. In the near future, state-of-the-art technology will allow districts to offer Open Seat courses via interactive video conferencing.

NOTE: This screenshot was taken on June 22, 2010, at the end of program year 3.

\section{Findings from Prior Studies on Similar Programs}

No other studies have examined the implementation and impact of the RCI's Open Seats program. However, a similar program, called Open Enrollment, has been widely implemented and studied. According to the Education Commission of the States Open Enrollment 50-State Report (Education Commission of the States, 2013), 21 states currently have mandatory interdistrict open transfer policies, and 22 states have mandatory intradistrict open transfer policies. These programs require a full transfer of students from their home districts to participate in classes at another school or district.

Results from prior studies on the implementation and impact of Open Enrollment programs are mixed. For instance, such programs have been shown to increase student outcomes, such as higher graduation rates (Cullen, Jacob, \& Levitt, 2005). However, prior studies found that such programs resulted in districts that were either "winners" or "losers" when it came to the loss of state financial support for the home district that was being exited (Jimerson, 2002). In addition, students who had to take a full transfer to a different school outside their home districts in an Open Enrollment program were barred from participating in extracurricular activities in their home districts, where friends and loyalties might have been located. 
Regarding factors that were associated with transfer decisions, district-level indicators of high educational quality - namely, high student achievement, along with racial composition and socioeconomic makeup - are key determiners for parents looking for Open Seats options for their children (Carlson, Lavery, \& Witte, 2011). Parental transfer decisions were also influenced by such factors as whether a school district has higher per-pupil spending and the availability of extracurricular opportunities (Welsch, Statz, \& Skidmore, 2010).

Across metropolitan areas, higher-income students were far more likely to take advantage of interdistrict choice and to transfer to a higher-income school district. One explanation for this trend was that open-enrollment programs have fewer supports for students from lower socioeconomic-status backgrounds (e.g., eligibility for free and reduced-price lunch, free transportation) and thus tend to have lower participation among that demographic.

Even with all of the effort to open opportunities to students for course offerings that are not available in their home districts, the impact of transfer enrollment on student outcomes is not clear. In their examination of open enrollment in the Chicago Public Schools, Cullen, Jacob, and Levitt (2005) analyzed data drawn from detailed student-level panel data for more than 60,000 students. While they observed a positive correlation between the choice to opt out of the assigned school and student outcomes (e.g., higher graduation rates), any measurable benefits for transfer students faded after controlling for difference among students related to capability and demographics. Overall, there is a lack of evidence suggesting that Open Enrollment programs have a measurable effect on the performance of transfer students compared with peers remaining at the home school.

\section{Design Rationale and Expected Benefits}

The Open Seats program was designed to fill open seats in courses running below capacity with students from other districts. It was designed with several potential benefits that may help address many of the implementation challenges found in the literature about the Open Enrollment program.

Specifically, in the RCI Open Seat program, students can attend courses not available in their home districts without leaving them. One expected benefit is that it will address financial concerns for sharing students between school districts. Participating districts and schools can retain funds that they may lose when students transfer to another district. Districts hosting students for Open Seats also benefited from payments of $\$ 600$ for each student from another district enrolled in a full-year Open Seats course.

With more opportunities for students to choose courses across participating districts, another expected benefit is that the Open Seat program may help hosting districts save courses that would otherwise be canceled because of low enrollment.

The expected benefit for participating students is that they can still enjoy other courses and extracurricular activities available from their home districts, where friends and loyalties might be located. 
Providing bus transportation and technology services to allow students to take courses in person or virtually may address concerns regarding logistics and student safety and increase the likelihood that students will participate in the Open Seat program. The availability of such services is also expected to address concerns about difficulties that economically challenged students may have in getting to a neighboring district to attend an Open Seats Course, which may affect parent and student choices on which schools or classes leave or join, based on results from prior studies (Education Commission of the States, 2013) on the Open Enrollment programs.

\section{Dual Enrollment}

\section{Program Description}

The RCI Dual Enrollment program offered tenth- to 12th-grade students opportunities to take college courses that provide credits that apply toward students' college transcripts. These courses did not substitute but rather supplemented high school courses by providing additional challenge and rigor, as well as exposure to college for low-performing and disengaged students. Because several higher-education institutions were involved, students had a comprehensive set of college courses from which to choose. Participating colleges and universities offered their courses during the regular school day, on their campuses, online, or at the high school campus. Some courses were also offered in the evenings, on weekends, or over the summer. In the later years of the RCI, some professors traveled to high schools to instruct students rather than requiring students to travel to the postsecondary campus. In some cases, the professor partnered with the high school teacher to deliver the course. Additionally, some high school teachers received accreditation to instruct at the collegiate level. These teachers modified high school courses to meet the expectations of collegiate courses and delivered these college courses to students. Figure 2.2 shows the information presented to potential participants about the program, as well as collaborating institutions.

\section{Findings from Prior Studies on Similar Programs}

Dual-enrollment programs, often called Post-Secondary Education Options (PSEO), are designed to offer opportunities that increase the likelihood for postsecondary success once students matriculate. Twenty-five years ago, Minnesota was the first state to pay for high school juniors and seniors to earn college credits that also counted toward their high school diplomas. Since Minnesota's debut, dual-enrollment options have spread to 42 states. 


\section{Figure 2.2. Screenshot of the RCI Website, Featuring the Dual Enrollment Program and Links to Course Catalogs of Partnering Colleges}

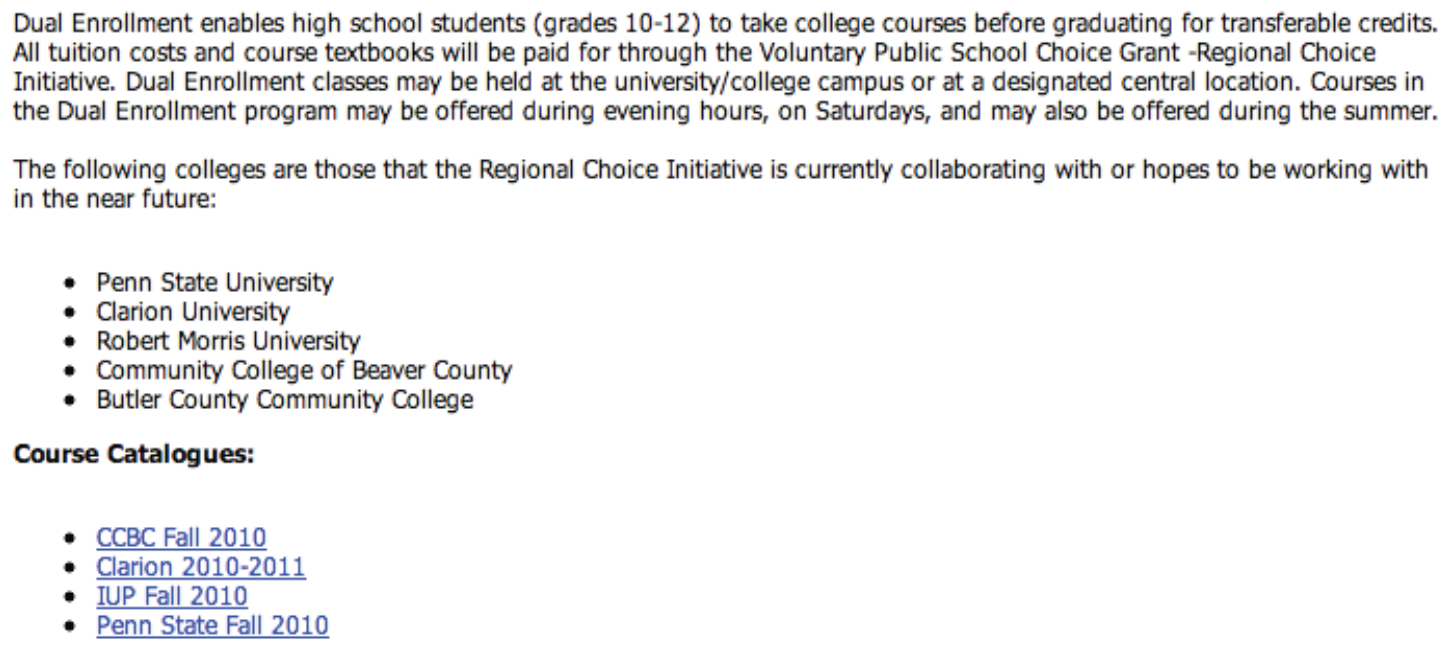

NOTE: Screenshot taken June 22, 2010, at the end of program year 3.

Research on dual-enrollment programs has shown a positive relationship between dualenrollment participants and academic success. For example, dual-enrollment participants had higher college grade point averages, were more likely to persist, and were more likely to attain their pursued degrees than nonparticipants (An, 2013).

Though the relationships between participation in dual enrollment and positive postsecondary outcomes are strong, studies suggest that dual-enrollment programs are not significantly affecting students from underperforming schools, disengaged students from high-performing schools, and students of color. For instance, Meade and Hoffman (2007) found that dualenrollment programs are often more beneficial to high-achieving students and are more likely to be accessed by white students and students of higher socioeconomic status. Conversely, these programs have thus been less beneficial, by virtue of lower participation, to minority students and those from lower economic groups.

Similarly, between 1985 and 2010, Minnesota's PSEO program graduated more than 110,000 students who attained up to two years of college credit for free while in high school. However, during that time, Minnesota struggled to address the achievement gap, because its "typical PSEO student is white, female and from a middle-class family," according to state data and other analyses (Selix, 2014).

In the state of Pennsylvania, for example, where 45 percent of postsecondary institutions use standardized test scores as a determinant of eligibility (Museus, Lutovsky, \& Colbeck, 2007), such eligibility requirements result in reduced access to dual-enrollment programs for African American and Hispanic students and students from lower economic groups. As such, dualenrollment programs typically have disproportionately high levels of participation by white and 
Asian students. Furthermore, students that come from school districts in the lowest-poverty quartile are substantially more likely than those from the two highest poverty-quartiles to participate in dual-enrollment programs (Museus, Lutovsky, \& Colbeck, 2007).

Findings from research in Florida found that dual enrollees were more likely than the population of grade 11 and 12 students (the general student population) to be women (62 percent versus 51 percent) and white (72 percent versus 51 percent) and less likely to be economically disadvantaged (e.g. free or reduced-price lunch and English language learner students (Estacion et al., 2011). Furthermore, when compared with students enrolled in Advanced Placement, International Baccalaureate, or Advanced International Certificate of Education, dual-enrollment students were less likely to be Hispanic and less likely to be enrolled in special education.

Programs involving dual enrollment in high school and college have become effective tools for preparing participating high school students for college success, decreasing the overall cost of attaining a college degree, and developing effective pipelines of college-ready students for participating colleges. However, these programs are not without challenges to recruitment and implementation. For example, while underuse among their intended audience has been a consistent theme, increased interest in these programs is often straining the system and raising questions about maintaining academic rigor and relevant course offerings - questions worth addressing as society increasingly seeks an answer to adequately preparing students for college and careers. In addition to increasing the participation of minority and low-achieving students, lack of qualified high school teachers to serve as dual-enrollment instructors for programs that provide college-level courses on-site, lack of colleges that are within reasonable geographic proximity for programs that require participation on the college campus, inadequate communication with parents, grade-point-average requirements that preclude targeted students from enrolling in college-level coursework, and inconsistent communication between college and high school personnel create challenges for dual enrollment programs (Estacion et al., 2011).

Overall, although dual-enrollment programs expand opportunities for students, research suggests that these programs have not had intended outcomes on the population targeted by the RCI. These programs are less likely to serve to students from low-performing schools or students from lower economic groups. Programs offered on the campuses of postsecondary institutions struggle to recruit students, but less than programs offered in high schools. There are a number of additional recruitment challenges for Dual Enrollment, such as the academic eligibility of students for postsecondary courses and communication.

\section{Design Rationale and Expected Benefits}

The RCI Dual Enrollment program was designed to provide students from low-performing schools and/or disengaged students with access to postsecondary education options. This access and experience are expected to increase familiarity with postsecondary education; reduce psychological barriers often reported from families of first-generation college attendees; and even result in credits toward students' college degrees before their high school graduations, 
reducing the overall cost of attaining a college education. Concomitantly, dual enrollment can include partnership and collaboration between secondary and postsecondary systems and staff that reduces or even eliminates the misalignment between academic standards enforced in secondary education and college. This misalignment in standards has been reported to result in students entering college underprepared for coursework despite meeting the standards set by their high schools (An, 2013). Because courses are often taught by teachers from the high school in partnership with college faculty, dual enrollment offers students more-rigorous academic options during their secondary education years, when credits are free and before the clock begins to tick on loan repayment. Additionally, students from low-performing schools tend to be students of color; therefore, in addition to the benefits at the level of the individual, dual enrollment programs aim to close the black-white achievement gap across the population of students.

\section{Cyber Learning}

\section{Program Description}

The RCI Cyber Learning program was designed to provide virtual learning courses to students. Students could participate in one cyber learning course or a full online course schedule. This was made possible by two conditions. One of these conditions is the BVIU's prior investment in a fiber-optic network. The fiber-optic network connections are in schools, colleges, and selected businesses in Beaver County, funded by the BVIU in 2007 using a separate funding stream. Through this high-speed data system, courses and academic programs can be transmitted to remote locations so that a student no longer had to physically leave his or her home district to attend an RCI course in a host district. Because of this initial investment, the RCI was able to develop and host the Cyber Learning program using its own resources.

Another condition was developing the digital course materials. In the first year of the RCI, Cyber Learning teachers modified courses from commercial providers. The RCI purchased the courses and paid teachers to augment commercial products to align with traditional course content and standards. Beginning in year 2 and through the end of the RCI, the BVIU purchased courses from Florida Virtual School. Each year, the BVIU augmented the new courses added to the Cyber Learning program. Teachers also adjusted their predesigned courses based on experiences with implementing them. The RCI continued to expand Cyber Learning course offerings by purchasing E2020's online courses in year 5. E2020 courses were an additional option for teachers delivering online instruction. Augmentation to E2020 courses was minor.

With these two conditions, the RCI Cyber Learning program established an array of online services that could be delivered in a student's home district (accessible anywhere with an Internet connection), featuring

- online curriculum courses that can be accessed at any time 
- an online virtual classroom environment allowing real-time communication between teachers and students.

These options were developed to provide enrichment, to extend the learning day, and to motivate underperforming students. Students who took online curricula through the Cyber Learning program received, through RCI initiative funds,

- courses, supplies, or texts-each semester, the RCI ordered course materials for every student, as specified by the district

- computer and printer - only in year 1, the RCI leased laptops and printer-scanner-copiers to schools for students, based on student need, for participation in cyber courses

- parent-student intake interview - an RCI technology coordinator discussed with parents and students how to use the equipment, navigate the courses, and use course-assignment calendars

- $\quad$ student support services - all new Cyber Learning students were provided a personalized academic support system with district personnel to monitor student progress on a weekly, interim, and final grade reporting schedule

- technology support - damage to or problems with the equipment were reported, and equipment replacements were provided to the student.

\section{Findings from Prior Studies on Similar Programs}

A recent meta-analysis and review of online learning stated that

a systematic search of the research literature from 1994 through 2006 found no experimental or controlled quasi-experimental studies comparing the learning effects of online versus face-to-face instruction for $\mathrm{K}-12$ students that provide sufficient data to compute an effect size; and a subsequent search that expanded the time frame through July 2008 identified just five published studies meeting meta-analysis criteria. (U.S. Department of Education, Office of Planning, Evaluation, and Policy Development, 2009, p. xv)

The key findings from this meta-analysis suggest mixed results between the benefits of traditional face-to-face learning environments compared with cyber programs, in which "the learning outcomes for students in purely online conditions and those for students in purely faceto-face conditions were statistically equivalent" (U.S. Department of Education, Office of Planning, Evaluation, and Policy Development, 2009, p. xv). More-recent examples of online learning include environments where students can download and read content online, submit assignments through the Internet, and use webinars as virtual classrooms (Kim, Hisook Kim, \& Karimi, 2012). Other studies have shown similar results, with online students performing better than their peers in conventional classrooms (O’Dwyer, Carey, \& Kleiman, 2007). Many schools and school districts offer high-tech, online, cyber-education options for students and families, with immense technological advancement in recent decades, coupled with a stronger push for school-choice options. 


\section{Design Rationale and Expected Benefits}

The RCI Cyber Learning program was designed to provide students with access to online learning resources and improve students' engagement in learning. The fiber-optic network was the mechanism for providing students with access to Cyber Learning courses. It has sufficient capacity to expand course offerings; the network was capable of hosting the usage of participants simultaneously or independently. The network did not limit participation of students or the number of courses that could be offered to students. Cyber Learning aimed to provide students choice on the mode for engaging with instruction. Students could opt to take a single course or an entire course schedule online. The program expects low-performing or disengaged students to participate in courses and perform better than similar peers who do not participate in Cyber Learning. Increased choice in how students receive instruction is expected to increase their engagement in courses and performance.

\section{Academies for Success}

\section{Program Description}

Academies for Success was created to meet the challenge and needs of students who are most at risk of dropping out of high school (e.g., low-performing and disengaged students). The program seeks to provide such students with direct links to postsecondary education and careers. The program objective is to increase academic achievement in mathematics and reading for participating students, to give them access to the county's existing alternative-education programs and services, and to offer a new innovative program with an array of support options.

This program aims to give students opportunities to gain employment-related skills or prepare for an associate's degree or other academic opportunities outside the four-year-college track. Three Choice Academies were initially offered: (1) agriscience and fine arts, (2) multimedia and web design, and (3) technology. One district hosted each program. Although students from the host districts enrolled in the programs, students throughout the region did not enroll in the program. Thus, no students participated in the initial Academy for Success programs.

In year 5, a fourth Choice Academy, the Leadership Academy, was added based on discussions among RCI administrators, BVIU leaders, the superintendent's Advisory Counsel and Governing Board, and students. Students in the Leadership Academy participated in all traditional Reserve Officers' Training Corps (ROTC) activities that occurred before and after school and assumed additional duties during the school day, as requested by the sergeant responsible for the academy. The Leadership Academy allowed students with strong military interest to increase engagement in and understanding of the military. Students could assume greater leadership responsibilities within the unit-upper-class students mentored under-class students. The sergeant responsible for the academy designed plans to visit students in class, check in with teachers of Leadership Academy students, and create additional service 
opportunities or responsibilities for students. Upon completion of the Leadership Academy, students could enlist in the military with increased readiness for boot camp, present as a candidate with high levels of training for college ROTC programs and scholarships, or present as a highly prepared candidate for a military academy.

\section{Findings from Prior Studies on Similar Programs}

Some schools and school districts are designing academic options of the highest levels of challenge and rigor, targeting low-achieving students. In the literature, we found a few types of programs that aligned with the design approach for delivering instruction, and we found varying approaches to delivering instruction to the target population of the RCI. One example is the STEM project-based learning approach, which typically provides students with an interdisciplinary curriculum, open-ended questions, and hands-on and interactive group activities. Research on STEM project-based learning approaches has shown that they yield positive results for low-achieving students (Capraro \& Slough, 2008; Clark \& Ernst, 2007; Dolmans et al., 2005; Han, Capraro, \& Capraro, 2014; Horan, Lavaroni, \& Beldon, 1996). Other innovative approaches, such as "assessment-based and readiness-focused differentiated instruction," have proven to be successful (Dunphy \& Hill, 2010). Career academies also appear, in the literature, to bolster graduation rates, a finding consistent with related work on the impacts of vocationally oriented academies among high-risk youth (Cullen, Jacob, \& Levitt, 2005). These authors went as far as to conclude that systematic choice within a public-school district does not seem to benefit those who participate, with the exception of career academies.

Project-based learning, a planned instructional approach for Academies for Success, has positive impacts on student achievement. In particular, results are positive for low-achieving students. The literature suggests that career academies - programs focusing on postsecondary employment - bolster graduation rates in schools among high-risk youth. However, these programs do not appear to have an effect on student achievement.

\section{Design Rationale and Expected Benefits}

The Academies for Success program aims to frame instruction around a specific interest of students. The alignment of students' interests and content is expected to increase students' engagement and persistence in courses. If students see the courses' application to jobs and future plans, then students at risk of dropping out will persist in school. Career academies are the most relevant type of program for students. Instruction focuses on the real-world application of content to students' interest and provides technical skills that benefit students in the workforce. Academics for Success also assumes that if students are more interested in instruction, they will engage more with the coursework, earning a higher grade in classes. Their buy-in to the content will result in higher performance. Similarly, the program aims to deliver instructions in methods that are more engaging to students. If the modes of instruction are more aligned with students' interests and learning styles, then academic performance will improve. 


\section{Logic Model of the $\mathrm{RCl}$}

The RAND evaluation team worked with the RCI team and partnering superintendents to develop a logic model to guide the implementation and evaluation of RCI programs. The logic model illustrates the expected mechanisms for achieving program effects, presenting inputs (e.g., adequate funding and strong leadership) and activities that support implementation, and identifying performance objectives and measures to appraise success (see Figure 2.3).

Figure 2.3. Logic Model of the RCI

\begin{tabular}{|c|c|c|c|c|}
\hline \multirow[b]{2}{*}{$\mathrm{RCI}$ Description } & \multirow[b]{2}{*}{ Inputs } & \multirow[b]{2}{*}{ Activitiesa } & \multicolumn{2}{|c|}{ Outcomes } \\
\hline & & & Performance Objective & Performance Measures \\
\hline $\begin{array}{l}\text { Open Seats } \\
\text { This initiative allows students in grades } \\
7-12 \text { across the 15-district consortium to take } \\
\text { courses in other districts while remaining } \\
\text { enrolled in their home district. A student may } \\
\text { attend the classes by traveling to the school in } \\
\text { which the course is offered or by using IVC to } \\
\text { participate remotely from their home school } \\
\text { districts. }\end{array}$ & \multirow[t]{4}{*}{$\begin{array}{l}\text { Adequate } \\
\text { funding; } \\
\text { strong } \\
\text { leadership }\end{array}$} & \multirow{2}{*}{$\begin{array}{l}\text { Facilitate } \\
\text { communication } \\
\text { among } \mathrm{RCI} \text { team } \\
\text { and partnering } \\
\text { districts } \\
\text { Facilitate } \\
\text { communication } \\
\text { among partnering } \\
\text { districts/RCI team } \\
\text { and higher } \\
\text { education facultyb } \\
\text { Provide training/ } \\
\text { PD for teachersc }\end{array}$} & $\begin{array}{l}\text { Open Seats: Provide bus } \\
\text { transportation, reimburse } \\
\text { mileage, and offer courses via } \\
\text { IVC and in person for students } \\
\text { to travel from one school to } \\
\text { another to participate in } \\
\text { courses or entire programs. }\end{array}$ & $\begin{array}{l}\text { By } 2012,10 \% \text { of BVIU's target group } \\
\text { will earn a passing grade in an Open } \\
\text { Seats course, either by participating } \\
\text { via IVC or transferring to another } \\
\text { school. }\end{array}$ \\
\hline $\begin{array}{l}\text { Dual Enrollment } \\
\text { This initiative allows students in grades } 10-12 \\
\text { to enroll in courses offered by postsecondary } \\
\text { education institutions in the Beaver County } \\
\text { region. If the student completes a course with } \\
\text { a grade of } C \text { or higher, he or she receives } \\
\text { college credit for the course. }\end{array}$ & & & $\begin{array}{l}\text { Dual Enrollment: Increase the } \\
\text { number of students successful- } \\
\text { ly completing grant-funded } \\
\text { college courses in high school } \\
\text { by offering courses provided } \\
\text { by multiple postsecondary } \\
\text { institutions. }\end{array}$ & $\begin{array}{l}\text { The number of students earning a C } \\
\text { or better in a Dual Enrollment course } \\
\text { will increase by } 150 \text { students per year } \\
\text { beginning in } 2008 \text {. }\end{array}$ \\
\hline $\begin{array}{l}\text { Cyber/Technology Learning } \\
\text { This initiative allows students in grades } 7-12 \\
\text { to participate in online courses, in combination } \\
\text { with classroom instruction in their home } \\
\text { districts. }\end{array}$ & & $\begin{array}{l}\text { Develop } \\
\text { programmatic and } \\
\text { student supports } \\
\text { Disseminate }\end{array}$ & $\begin{array}{l}\text { Cyber Learning: Utilize the } \\
\text { newly installed fiber optic } \\
\text { network to increase the } \\
\text { number of students completing } \\
\text { an online course. }\end{array}$ & $\begin{array}{l}\text { Increase the number of students } \\
\text { earning a passing grade in at least } \\
\text { one cyber learning course by } 5 \% \\
(603) \text { in } 2008 ; 25 \%(3,150) \text { in } 2009 ; \\
50 \%(6,300) \text { in } 2011 \text { and } 70 \%(8,820) \\
\text { in } 2012 \text {. }\end{array}$ \\
\hline $\begin{array}{l}\text { Academies for Success } \\
\text { This initiative is designed to provide students } \\
\text { with academic options of the highest levels of } \\
\text { challenge and rigor, as well as educational } \\
\text { opportunities that support direct links to } \\
\text { postsecondary education and careers. The } \\
\text { goal is to prepare students for success on their } \\
\text { career paths by producing skilled scholars, } \\
\text { thinkers, collaborators, and leaders. }\end{array}$ & & $\begin{array}{l}\text { programs to } \\
\text { students and } \\
\text { parents }\end{array}$ & $\begin{array}{l}\text { Academies for Success: } \\
\text { Increase academic achieve- } \\
\text { ment in math and reading for } \\
\text { students participating in } \\
\text { Academies for Success as } \\
\text { compared with their prior } \\
\text { performance in their home } \\
\text { districts. }\end{array}$ & $\begin{array}{l}\text { By } 2012,(1) \text { students who participate } \\
\text { in Academies for Success will have a } \\
\text { dropout rate of less than } 10 \% \text {; (2) } \\
100 \% \text { of students in Academies for } \\
\text { Success will reach proficiency in } \\
\text { reading and math by the } 11 \text { th grade } \\
\text { as measured by the } 4 \text { Sight exam. }\end{array}$ \\
\hline
\end{tabular}

alnputs and activities apply to all RCls unless stated otherwise.

bActivities with higher education faculty apply only to Dual Enrollment

cActivities in PD/training were not a part of Dual Enrollment or Academies for Success.

NOTES: IVC = interactive video conferencing. $\mathrm{PD}=$ professional development.

\section{Inputs}

The logic model highlights two inputs considered critical to implementing education reforms: adequate funding and strong leadership.

Education reform requires sufficient funding over the entire period needed for changes in teaching and learning to occur (Fullan \& Miles, 1992; Hedges, Laine, \& Greenwald, 1994; Louis and Miles, 1990). At the same time, school resources and per-pupil expenditures do not always increase student achievement (Hanushek, 1989, 1996). Spending to increase student achievement 
must be strategic — not only funding new jobs and buying equipment but also building capacity within schools (Louis \& Miles, 1990).

We asked the RCI team how federal funding enabled it to implement these initiatives. Members said that funding was integral for providing some key resources that the districts would otherwise not have been able to afford. Those resources include IVC monitors and cameras for Open Seats, the Florida Virtual School courses for offering Cyber Learning courses across districts, and tuition costs and training for Dual Enrollment courses. Funding was also necessary to hire additional BVIU staff (the RCI director and team) to support the RCI work and to pay the teachers for attending PD. Some of these changes can continue after funding runs out (e.g., districts will continue to use IVC equipment and Florida Virtual School courses and offer PD for improving instruction), while other funding will be needed to retain BVIU staff supporting RCI work.

Although it is difficult to demonstrate the direct effects that leadership has on reform efforts (Witziers, Bosker, \& Krüger, 2003), strong leadership has consistently been linked to the success or failure of school-reform implementation. For example, stable school leadership can motivate teachers to work toward change (Bodilly et al., 1998; Leithwood, Steinbach, \& Jantzi, 2002). Good leaders provide a consistent vision, which can help reform efforts succeed (Purkey \& Smith, 1983; Goertz, Floden, \& O’Day, 1995).

As with other large education-reform initiatives, leadership teams are at the core of RCI program implementation, with several groups providing leadership. In year 1 of the grant, the RAND evaluation team - through a series of conversations with the RCI director, meeting observations, and reviews of the RCI grant proposal - developed a description of each leadership team:

- RCI administrators. This team includes the regional choice director, assistant to the RCI director, RCI technology coordinator, and secretary to the RCI director. The four-member team is directly responsible for the RCI. The team executes all phases of the grant. Two BVIU staff members provide technical support to the RCI team.

- $\quad$ BVIU leadership and staff. This group applied for the VPSC grant. It supports the RCI team with technology and training and provides a linking and networking system to the districts.

- Design team. This group, comprising district high school principals, guidance counselors, gifted-and-talented-program coordinators, and partnering-college representatives, served as consultants to the RCI team and provided input for the initial planning and focus for the four RCI programs. Originally, the RCI team intended to include parents on the design team, but there were no parent members in the first three years of the grant. The members did not convene as a group; rather, the RCI program director met individually with members or teams of members. In later years, parents did participate in design-team focus groups.

- Superintendents' Advisory Council (SAC). This council, composed of superintendents from each district in the IU, existed before the BVIU received the VPSC grant. SAC meetings are structured to allow BVIU staff members (including the RCI director) to 
report on BVIU activity (most of which is not directly related to the RCI). At these meetings, the RCI program director provides a report on RCI implementation (e.g., instructional and technical support, curriculum, and technology and media). The SAC meets monthly.

- Governing board. Five superintendents from the SAC volunteered to function as an advisory group to provide opinions and suggestions (e.g., for dissemination) for all RCI programs. These superintendents make up the governing board. According to BVIU's proposal, the governing board was to meet twice monthly following initiation of the grant in October 2007, but it had met only once by June 2008 and did not convene twice monthly until July 2008. After the first year of the grant, the governing board met monthly and was still holding regular meetings for the period of the evaluation.

RCI stakeholders met regularly throughout all years of funding to plan and implement programs through the leadership groups listed above. Superintendents and district staff used meetings to provide feedback on program activities and their districts' perspectives.

\section{Activities}

The logic model presents program activities in four categories: communication, training, supports, and dissemination.

\section{Facilitating Communication Between the BVIU and Partnering Districts}

The RCI programs require clear communication to facilitate decisionmaking and logistics. They require numerous activities between the RCI team and districts, among partnering districts, and within a district's administration and high school staffs. Meetings among the leadership teams - including the RCI team, BVIU leadership and staff, the SAC, and the governing boardwere the key communication process for planning and implementing the RCI programs. The RCI team also met with principals, guidance counselors, and teachers to communicate key materials and information. The RCI team regularly sent updates between meetings. The Dual Enrollment program also included communication with institutions of higher education.

Providing Training and PD for Participating Teachers

During years $1-5$, the RCI offered teachers PD training in

- Moodle $\mathrm{T}^{\mathrm{TM}}$

- Florida Virtual School

- how to be an online teacher

- IVC

- Elluminate ${ }^{\mathbb{2}}$

- Teachers' Academy

- Online Design Academy.

The BVIU created the Teachers' Academy to encourage an integration of best practices into the Open Seats and Cyber Learning courses. Two cohorts of teachers across the consortium attended workshops through the Teachers' Academy annually, beginning in year 3. Teachers in 
cohorts from RCI years 3 and 4 created a professional learning community to extend their work in year 5. The Online Design Academy initiated in the fourth program year taught teachers how to align cyber courses with the traditional curriculum and state standards. The Online Design Academy is a series of trainings.

\section{Developing Programmatic and Student Supports}

In year 1, the planning year of the RCI, district staff members and the RCI team built supports for implementation. Some of these supports (e.g., a common bell schedule and providing transportation or mileage reimbursement) sought to overcome barriers to student participation, while others (e.g., developing a database for tracking student progress and participation) built programmatic capacity.

\section{Disseminating Information About the RCI to Parents and Students}

The RCI team designed dissemination plans to increase knowledge and awareness of the programs and encourage participation. The information-dissemination strategies covered all four RCI programs, and each dissemination activity typically provided information about more than one program. Processes for information dissemination included one-on-one communication with students and parents, distribution of RCI brochures created by the RCI team, and the RCI course catalog. Evaluation of these areas requires input from district leadership and staff, teachers, higher-education faculty, parents, and students.

\section{Performance Outcomes}

One of the key priorities of ED's VPSC program office is to engage in outcome-based decisionmaking for education reforms and encourage grantees to use performance measures as benchmarks to assess progress. Prior to the start of the RCI, BVIU leaders and the developers of the RCI designed 21 measures to assess the success of each RCI program and the overall RCI initiative. Among them, 15 measures specified quantifiable criteria on the number of participating students with a passing grade in courses enrolled through RCI programs or the dropout rate among participating students. These measures are referred to as performance measures. Six measures described the activities that RCI administrators needed to complete independently and that did not rely on student participation, such as providing transportation to students participating in Open Seats courses. These measures are referred to as objective measures. Table 2.1 presents the 21 measures, the type of measures, and goals specified for each measure. 
Table 2.1. Performance Goals for the RCI

\begin{tabular}{|c|c|c|}
\hline $\begin{array}{l}\text { RCI } \\
\text { Program } \\
\text { Alignment }\end{array}$ & $\begin{array}{l}\text { Type of } \\
\text { Measure }\end{array}$ & Description of Goal \\
\hline \multirow[t]{3}{*}{ Open Seats } & Performance & $\begin{array}{l}\text { One percent of eligible students ( } 125 \text { students) will earn a passing grade during the first } \\
\text { year of the grant and the second year of the grant. }\end{array}$ \\
\hline & Performance & $\begin{array}{l}\text { The number of participating students will increase so that, by } 2012,10 \text { percent of the } \\
\text { target group of students will earn a passing grade in an IVC course and/or physically } \\
\text { transfer to another school program. }\end{array}$ \\
\hline & Objective & $\begin{array}{l}\text { Provide bus transportation, reimburse mileage, and offer courses via IVC for students to } \\
\text { transfer from one school to another to participate in courses or entire programs, based } \\
\text { on students' educational needs. }\end{array}$ \\
\hline \multirow[t]{3}{*}{$\begin{array}{l}\text { Dual } \\
\text { Enrollment }\end{array}$} & Performance & $\begin{array}{l}\text { The number of eligible tenth- to 12th-grade students earning a } \mathrm{C} \text { or better in college } \\
\text { courses will increase by } 5 \text { percent in the first year of the grant. }\end{array}$ \\
\hline & Performance & $\begin{array}{l}\text { The number of students earning a C or better would increase by at least } 150 \text { students } \\
\text { per year, beginning in } 2009 \text { (year } 3 \text { ). }\end{array}$ \\
\hline & Objective & $\begin{array}{l}\text { Increase the number of students successfully completing grant-funded college courses } \\
\text { in high school by offering courses provided by multiple postsecondary institutions. }\end{array}$ \\
\hline \multirow[t]{6}{*}{$\begin{array}{l}\text { Cyber } \\
\text { Learning }\end{array}$} & Performance & $\begin{array}{l}\text { Two percent of students (in Beaver County, 252) enrolled in a course will earn a } \\
\text { passing grade in at least one cyber service choice in the first year of the grant period. }\end{array}$ \\
\hline & Performance & $\begin{array}{l}\text { Five percent of students (603) enrolled in a course will earn a passing grade in at least } \\
\text { one cyber service choice in the second year of the grant period. }\end{array}$ \\
\hline & Performance & $\begin{array}{l}\text { Twenty-five percent of students }(3,150) \text { enrolled in a course will earn a passing grade in } \\
\text { at least one cyber service choice in the third year of the grant period. }\end{array}$ \\
\hline & Performance & $\begin{array}{l}\text { Fifty percent of students }(6,300) \text { enrolled in a course will earn a passing grade in at } \\
\text { least one cyber service choice in the fourth year of the grant period. }\end{array}$ \\
\hline & Performance & $\begin{array}{l}\text { Seventy percent of students }(8,820) \text { enrolled in a course will earn a passing grade in at } \\
\text { least one cyber service choice in the final year of the grant period. }\end{array}$ \\
\hline & Objective & $\begin{array}{l}\text { Utilize the newly installed fiber-optic network to increase the number of students } \\
\text { completing a cyber course. }\end{array}$ \\
\hline \multirow[t]{4}{*}{$\begin{array}{l}\text { Academies } \\
\text { for Success }\end{array}$} & Performance & $\begin{array}{l}\text { By the end of the final year, students who participate in the Academies for Success will } \\
\text { have a dropout rate of less than } 10 \text { percent. }\end{array}$ \\
\hline & Performance & $\begin{array}{l}\text { By the end of the final year, } 100 \text { percent of the students attending the Academies for } \\
\text { Success will reach proficiency in math by the } 11 \text { th grade, as measured by the } \\
\text { Pennsylvania System of School Assessment (PSSA). }\end{array}$ \\
\hline & Performance & $\begin{array}{l}\text { By the end of the final year, } 100 \text { percent of the students attending the Academies for } \\
\text { Success will reach proficiency in reading by the } 11 \text { th grade, as measured by the PSSA. }\end{array}$ \\
\hline & Objective & $\begin{array}{l}\text { Increase the academic achievement in math and reading for students participating in } \\
\text { the Academies for Success, as compared with their prior performance in their home } \\
\text { districts. }\end{array}$ \\
\hline \multirow[t]{2}{*}{$\mathrm{RCl}$ overall } & Objective & $\begin{array}{l}\text { Professional development: Embed appropriate professional development for } \\
\text { administrators, guidance counselors, and faculty in each of the four choice programs to } \\
\text { support the development of live and cyber courses. This will be held regularly on a } \\
\text { sustained basis and will be based on state standards. }\end{array}$ \\
\hline & Performance & $\begin{array}{l}\text { Professional development: By the end of the } 2008-2009 \text { school year (year 2), the } \\
\text { content-area faculty teams will have developed a total of eight live and/or cyber courses } \\
\text { in the core curriculum. }\end{array}$ \\
\hline
\end{tabular}




\begin{tabular}{|l|l|l|}
\hline $\begin{array}{l}\text { RCI } \\
\text { Program } \\
\text { Alignment }\end{array}$ & $\begin{array}{c}\text { Type of } \\
\text { Measure }\end{array}$ & \multicolumn{1}{c|}{ Description of Goal } \\
\hline & Performance & $\begin{array}{l}\text { Professional development: By the end of the 2009-2010 school year (year 3), the } \\
\text { content-area faculty teams will have developed a total of eight live and/or cyber courses } \\
\text { in the core curriculum. }\end{array}$ \\
\hline & Objective & $\begin{array}{l}\text { Disseminating information: Conduct a countywide public-relations campaign to increase } \\
\text { parents' awareness of their school-choice options. }\end{array}$ \\
\cline { 2 - 4 } & Performance & $\begin{array}{l}\text { Disseminating information: By the end of the RCl, at least 75 percent of the total } \\
\text { number of surveyed parents/guardians in the 15 middle and 14 high schools will } \\
\text { respond affirmatively to parent awareness surveys, in the school-district newsletters } \\
\text { and websites, about school-choice options. }\end{array}$ \\
\hline
\end{tabular}




\section{Methods, Data, and Analysis}

In this chapter, we provide a detailed description of the methods, data, and analysis approaches used in this project. We also review limitations in the measures and data that could be used in the analysis.

\section{Methods and Data}

We took a mixed-methods approach to evaluate the implementation and impact of the RCI initiative. We reviewed program documents, interviewed stakeholders, surveyed parents, and analyzed student RCI participation data and administrative data. The methods and data used varied between implementation and impact evaluation. We describe them separately for each type of evaluation.

\section{Implementation Evaluation}

There are two major goals for the implementation evaluation. One is to examine the extent to which the goals for each performance measure of each RCI program is achieved. These goals address student participation and performance in RCI programs, as well as some broad activities related to implementation. ED uses these goals to measure implementation and program performance. We provide the performance measures in Chapter Two, Table 2.1. The other goal for the implementation evaluation is to understand factors that enable or hinder the achievement of these performance-measure goals for each program.

We used multiple methods to examine the implementation of RCI, including

- document analysis

- semistructured interviews of multiple stakeholders

- surveys of families with eligible students

- analysis of student administrative and program participation data.

\section{Document Analysis}

Over the period of the RCI, the evaluation team collected and reviewed program documents, including the grant proposal and documents describing the RCI and its program to ED. We use these documents as artifacts to ground descriptions and changes in the program design over time.

Throughout the project, the RAND evaluation team also collected and analyzed meeting notes about the RCI. The RAND evaluation team and the RCI director held, on average, twicemonthly conference calls or in-person meetings to discuss implementation and other activities for each program. We also collected notes from other leadership and team meetings. For instance, RAND evaluation-team members attended governing board and SAC meetings held monthly at 
BVIU offices. In years 1 to 5 (including the NCE year) of the project, ${ }^{3}$ a member of the evaluation team attended nearly 90 percent of monthly meetings and requested notes from the $\mathrm{RCI}$ director when unable to attend. During these meetings, the RCI director presented progress on each program, and the BVIU director and superintendents discussed new or ongoing issues. The RAND evaluation team also collected and analyzed meeting notes from informational meetings that the RCI team held with districts' school-staff members (i.e., principals, guidance counselors, transition coordinators, and gifted-and-talented-program coordinators). We conducted a thematic analysis of these notes to provide context to student participation and performance data sources.

\section{Stakeholder Interviews}

Interviews with stakeholders offered context into the participation and performance in the $\mathrm{RCI}$ and implementation. We conducted semistructured interviews of stakeholders in year 4 of the RCI to understand the strengths and challenges of implementation. We interviewed more than 60 stakeholders, including all RCI administrators and BVIU leaders, the superintendent, secondary-school principals, individuals responsible for coordinating data collection in each participating district, and at least one guidance counselor in every participating school. We conducted all interviews in person; interviews ranged in length from one to two hours.

\section{Survey of Families in the Region}

During the fourth year of the RCI, we conducted a survey of all Beaver County families with children ages 12 to 18 , ages associated with grade levels participating in the RCI. The survey was conducted by mail, using postcards. The postcard asked a series of brief questions to gauge awareness of the BVIU, as well as of the RCI and its programs. Parents completed the survey and mailed the prepaid, preaddressed postcard to RAND.

In total, we mailed the survey to 2,955 families with at least one child age 12 to 18 throughout the region. We mailed the survey two times, with the second mailing targeted at nonresponsive families. Households returning the survey received a $\$ 10$ gift card in honor of their time. We accepted postcards through the end of year 5. The response rate was low, at 19 percent, by the end of the initiative. Because of the low response rate, survey findings should be interpreted with great caution and are not generalizable to families with children ages 12 to 18 throughout the region.

\section{Analysis of Student Administrative and Program Participation Data}

Many of the program performance measures include specific goals, such as the percentage of students enrolled in a particular program earning a certain grade in a course. To evaluate the extent to which the RCI programs meet their specific performance goals, we requested and

\footnotetext{
${ }^{3}$ Project year 5 includes year 5 and the NCE year for the program.
} 
analyzed student administrative and program participation data from the RCI program. This data set includes the following information about each participating students:

- the unique state and district student identifier

- grade level and demographic characteristics (e.g., gender and ethnicity) of the participating student

- names and disciplines of RCI courses a student is enrolled in

- school year of RCI course enrollment

- the RCI program through which a course was enrolled

- grades on RCI courses a student enrolled in and completed

- providers of RCI courses

- the mode through which a course was taken in the RCI (e.g., physically transported to another district or through the Internet or IVC).

Such data were collected for each RCI program by year. We used information in the participation database to count the number of students participating in each RCI program and the overall RCI initiative. Grade information was standardized across districts for the purpose of quantifying the number of students earning a passing grade for the respective programs. As a note, successful completion of a course and earning a passing grade are interchangeable in the performance measures. Percentage of students earning a passing grade is a basic participation measure and required for measuring attainment of performance goals for all RCI programs. All personally identifiable information about students was deidentified before being transferred to the RAND evaluation team for analysis.

\section{Impact Evaluation}

The main goal of the impact evaluation was to examine the association between students' participation in the RCI and their engagement and achievement outcomes. We took a quasiexperimental approach to examine such associations. Specifically, we identified a group of students similar to RCI participating students, using statistical methods. We compared student outcomes between the participating and nonparticipating groups to examine whether participation in the RCI was associated with better outcomes. The outcome measures we examined in the impact evaluation included measures of students' achievement and engagement. We also collected and used student demographic characteristics to identify students similar to RCI participating students.

We requested student-level data from participating districts. We also downloaded districtlevel data from public sources, including the websites of the Common Core of Data (CCD) at the National Center for Education Statistics (NCES) and the PDE.

The student-level data requested included students' demographic, achievement, and engagement information for all students in grades 7-12 in 16 participating districts for the first 
four program years. ${ }^{4}$ Our request also included historical data for years 2002-2003 to 2006-2007 to compare RCI students with a group of similar students before the RCI was implemented (see more details of the rationale for using this comparison group in the section on analysis in this chapter). Table 3.1 shows the years and grade levels for which student-level demographic, achievement, and engagement data were requested from districts.

${ }^{4}$ The initial timeline of VPSC funding and scope of work for this evaluation did not allow for the inclusion of data from year 5 and the period under the NCE. 
Table 3.1. Years and Grade Levels for Which Student-Level Data Were Requested from RCI Participating Districts

\begin{tabular}{|c|c|c|c|c|c|c|c|c|c|}
\hline \multirow[b]{3}{*}{ Grade } & \multicolumn{9}{|c|}{ School Year } \\
\hline & \multicolumn{5}{|c|}{ Preimplementation Period } & \multicolumn{4}{|c|}{ Postimplementation Period } \\
\hline & $2002-2003$ & 2003-2004 & 2004-2005 & 2005-2006 & $2006-2007$ & $2007-2008$ & 2008-2009 & $2009-2010$ & 2010-11 \\
\hline 5 & & & & G & $\mathrm{H}$ & & & & \\
\hline 6 & & & & $\mathrm{~F}$ & G & $\mathrm{H}$ & & & \\
\hline 7 & & & & $E$ & $\mathrm{~F}$ & G & $\mathrm{H}$ & & \\
\hline 8 & A & B & C & $\mathrm{D}$ & $E$ & $\mathrm{~F}$ & G & $\mathrm{H}$ & \\
\hline 9 & & A & B & C & $\mathrm{D}$ & $E$ & $\mathrm{~F}$ & G & $\mathrm{H}$ \\
\hline 10 & & & A & $\mathrm{B}$ & C & $\mathrm{D}$ & $E$ & $\mathrm{~F}$ & G \\
\hline 11 & & & & A & B & C & $\mathrm{D}$ & $E$ & $\mathrm{~F}$ \\
\hline 12 & & & & & A & B & C & $\mathrm{D}$ & $E$ \\
\hline
\end{tabular}

NOTES: Letters in cells are cohort letters. The same cohort of students was labeled using the same letter in different years. For instance, students in cohort $A$ were at grade 8 in 2002-2003 and at grade 9 in 2003-2004. Student-level demographic, achievement, and outcome data were requested from RCI participating districts only for cells with a cohort letter. Grey cells indicate a particular grade level that was tested on PSSA in a certain year. 
Specific student-level demographic variables requested include students' gender, grade, ethnicity, English-language-learner status, eligibility for an individual education program (IEP), and eligibility for free or reduced-price lunch.

Student achievement data requested include mathematics and reading scaled scores and performance levels on the PSSA, Preliminary SAT (PSAT), SAT, or ACT, as well as course grades. Student engagement variables requested include attendance rate; courses enrolled during an academic year; and indicators of whether a course is an Advanced Placement (AP), International Baccalaureate (IB), honor, gifted, or Dual Enrollment course.

The district-level data we downloaded from public sources included district-level student demographic, achievement, and engagement data for all districts in Pennsylvania. The CCD at NCES publishes annual district-level student demographic (i.e., the percentages of students by gender and ethnicity) and enrollment data online. The PDE provides district-level measures of student performance on the PSSA mathematics and reading tests, as well as dropout and graduation rates, on its website.

\section{Analysis}

\section{Implementation Evaluation}

We assessed the attainment of the performance and objective goals based on student participation data, results of document review, stakeholder interviews, and the parent survey. We examined the number of participating students and the number of participating students earning a passing grade to evaluate whether each program met the applicable performance goals. We examined course completion by student; each student participating in a course is counted as participating. If a student participated in a course and met the criteria for earning a passing grade, we counted the course as successfully completed. Because a student may take more than one course in a program, the student successfully completes the course if at least one final grade is passing. We use the definition of passing grade established at the outset of the RCI. The number of students participating in the program and the number of students earning a passing grade in the program yields the percentage of students successfully completing a course. The goal is achieved if the actual percentage of students who passed a course through an RCI program meets or exceeds the specified goal or if we found evidence from multiple stakeholders that actions required by objective measures were carried out as planned. We use a simple yes or no to identify goal attainment.

We used results of the document review and stakeholder interviews to identify barriers and enablers to program implementation and participation. We analyzed interviews for each type of stakeholder, each RCI program, and the overall RCI to identify themes related to implementation strengths and challenges. These themes, in part, identify possible reasons for attained or missed performance goals by the end of the RCI. 


\section{Impact Evaluation}

Because RCI districts and students were not randomly assigned to participate in the program, participation in the RCI might derive from other characteristics, such as prior achievement and access to information about the program, which could affect our outcomes of interest. Although we used propensity score matching in the outcome analysis to control all observable characteristics, there is always a chance that some unobserved characteristics might have contributed to districts' and students' choice to participate in the RCI. To deal with this challenge, we used a difference-in-difference approach (Angrist \& Pischke, 2008) together with propensity score matching to examine whether RCI districts and students had greater gains in achievement and engagement than their counterparts in the comparison group. By using gains in student achievement and engagement as the outcome variable, we mitigate the effect of unobserved characteristics that might have affected RCI participation in estimating the association between RCI participation and student outcomes. Specifically, we conducted multiple district- and student-level analyses to examine the relationships between RCI participation and student outcomes.

\section{District-Level Analysis}

We conducted three types of analyses to examine the impact of the RCI on district-level student outcomes.

First, we examined the trend of dropout rates, graduation rates, and PSSA mathematics and reading proficiency rates for RCI-participating districts in the program years. We used other districts in Pennsylvania as a comparison group for RCI districts in these analyses.

Second, we identified a group of Pennsylvania districts that did not implement the RCI in these years but had student demographic, academic achievement, and socioeconomic characteristics that were similar to those of the RCI districts. We used propensity score matching to identify this group of comparison districts (Heinrich, Maffioli, \& Vazquez, 2010). We compared RCI districts with matched non-RCI districts on student achievement and engagement measures for each program year.

Third, we examined whether RCI districts had greater gains on the student-outcome measures of interest than matched non-RCI districts since the beginning of the program for each program year.

\section{Student-Level Analysis}

At the student level, we used propensity score matching to identify two comparison groups for RCI participants: one contemporary-comparison group and one historical-comparison group. RCI participants are students who ever took any courses through any of the RCI programs. The contemporary-comparison group consists of similar students who enrolled in the same school with RCI participants in a school year but did not participate in RCI programs. The historicalcomparison group includes similar students who enrolled in the same school with RCI 
participants before the implementation of the RCI. We matched each RCI participant to one or more students in the two comparison groups. We compared the RCI group with each comparison group on student achievement and engagement measures in each program year to examine whether RCI participation is associated with higher student achievement and greater engagement.

\section{Measures Used in the Analysis}

Although we requested a variety of student achievement and engagement outcome measures from participating districts, the data we received were incomplete (see more details in the limitation section). The amount of missing values ruled out some of the measures we planned to use for analysis. In the end, we used a subset of the student achievement and engagement outcome measures we requested from participating districts.

Student-level achievement measures mainly came from student test scores on the PSSA mathematics and reading exams. The PSSA is a standards-based, criterion-referenced assessment used to measure students' attainment of Pennsylvania academic standards. Individual-student performance on the test is reported as scaled scores and performance levels. Scaled scores are transformed item-response theory-based test scores and comparable across years (Data Recognition Corporation, 2011). We used PSSA scaled scores in the student-level analysis.

Performance levels indicate which level of performance a student reaches and are based on whether a scaled score exceeds the cut scores set for different performance levels. The PSSA uses four performance-level descriptors: advanced, reflecting superior academic performance; proficient, reflecting satisfactory academic performance; basic, reflecting marginal academic performance; and below basic, reflecting inadequate academic performance. We used percentages of students who scored at or above the proficient level in mathematics and reading as the outcome variable in the district-level analysis.

Student-level engagement measures included students' attendance rate in an academic year and the number of advanced courses (such as AP, IB, honors, gifted, or dual enrollment courses) available for a student in a particular school year. District-level measures of student engagement include dropout and graduation rates. Table 3.2 summarizes the student achievement and engagement measures used in the analysis.

We used information in the administrative and participation database to develop measures of individual- and district-level participation in the RCI. For individuals, we measured whether a student took any course through the RCI in a particular program year. We also considered the number of courses a student took and the number of years a student participated in the RCI, but this was not feasible given that few students took multiple RCI courses or participated in the RCI for multiple years (see the section "Descriptive Summary of RCI Participation" in Chapter Ten for detailed results). District-level participation was measured by whether a district joined the $\mathrm{RCI}$ initiative at the beginning of the project. 
Table 3.2. Summary of Student Achievement and Engagement Measures

\begin{tabular}{|c|c|c|}
\hline Level of Analysis & Student Outcome Measure & Source \\
\hline Student level & $\begin{array}{l}\text { - Scaled score on PSSA mathematics and reading tests } \\
\text { - Attendance rate in a school year } \\
\text { - The number of advanced courses a student took in a } \\
\text { school year }\end{array}$ & $\begin{array}{l}\text { Participating districts } \\
\text { Participating districts } \\
\text { Participating districts }\end{array}$ \\
\hline District level & $\begin{array}{l}\text { - Percentage of students who scored at or above the } \\
\text { proficiency level on the PSSA mathematics and reading } \\
\text { tests } \\
\text { - } \quad \text { Dropout rate for students at grades } 7-12^{\mathrm{A}} \\
\text { - } \text { Graduation rate }\end{array}$ & $\begin{array}{l}\text { PDE } \\
\text { PDE }\end{array}$ \\
\hline
\end{tabular}

\footnotetext{
A According to the PDE, a dropout student is someone who, for any reason other than death, leaves school before graduation without transferring to another school or institution. The dropout rate is calculated by dividing the total count of dropout students by the fall enrollment in seventh to 12th grades for the same school year. Dropout rates are available for the 2007-2008, 2008-2009, and 2009-2010 school years.

${ }^{B}$ PDE considers a high school graduate to be a student who has received a diploma. Students who earned high school credentials by obtaining a General Educational Development (GED) diploma are not considered graduates for the purpose of the graduate data. PDE does not provide information regarding how the graduation rate is calculated. Graduation rates are available for the 2007-2008, 2008-2009, and 2009-2010 school years.
}

\section{Limitations}

There are several limitations to the data in this evaluation, as well as to the analytical approaches. We address each of these limitations as they related to each evaluation activity.

\section{Implementation Evaluation}

We relied on surveys and interviews for information on performance measures and implementation context. Such self-report measures are vulnerable to bias if respondents forget important details or feel a desire to report them in a more favorable light. We attempt to combat this limitation by interviewing a broad range of stakeholders and at least one type of stakeholder from every district. We mainly use parent-survey data to measure a performance goal regarding parent knowledge of the RCI. The 19-percent response rate on this survey is an additional limitation. Thus, the survey results may not be representative of all families of students participating in the RCI; however, participation rates in the program overall and stakeholder interviews are consistent with the survey findings. Finally, although we interviewed many stakeholder groups to identify implementation factors that enable or hinder the attainment of performance goals, the data lack a perspective from teachers. Teachers may have offered additional perspectives on participation, as well as enablers and challenges of the RCI.

Overall, measures for program implementation are simplistic. A yes or no criterion to the attainment of performance measures is the primary mechanism for measuring implementation. We do not note partial attainment or near attainment for the final performance rating. 


\section{Impact Evaluation}

There are two types of limitations in the data available for the impact evaluation. The first type of limitation is about the data and measures of program participation. The quality of program participation data raised some concerns about the accuracy of available data, despite substantial effort to clean such data during the project. In this project, student participation was entered into the data-management system by district staff. However, staff inconsistently entered data about course enrollment, course names, course completion, and the disciplines of enrolled courses, as revealed by data checking conducted by the evaluation team. RCI administrators and the RAND evaluation team engaged in data-cleaning activities for three years to yield a data set that could be used for this report. There were numerous iterations of the database and questions about how to consistently treat data for the purpose of measuring participation over time. Even with these efforts, there is still some evidence to suggest that the final data sets received by the evaluation team are not consistent with the paper copies of data used by RCI administrators to support the data-cleaning process.

Regarding the measures of program participation data, the types of program participation measures allowed by the collected data capture only limited aspects of participation. At both the student and the district levels, the available program participation measures were dichotomous variables indicating whether an individual or a district participated in any RCI programs. Such measures do not provide information about the quality of the RCI courses individual students enrolled in or how well RCI programs were implemented in each district. However, the available data caused us to rely on dichotomous measures to examine the association between RCI participation and student outcomes. In addition, as detailed in the next chapter, the lack of students who participated in the RCI for multiple years prevented us from using cumulative participation measures.

The second type of limitation for the impact evaluation comes from the number of missing records in the student administrative database available for analysis. Nine participating districts did not provide any student-level data for evaluation, while the remaining seven varied in the specific years for which they provided such data. Although all seven districts provided studentlevel data for all preimplementation years (2002-2003 to 2006-2007), only three districts submitted data for all four postimplementation years. Altogether, seven districts provided data for the first program year, five did so for the second, and four did so for the third, and three did so for the fourth.

Districts that submitted student-level data also varied in types of data they provided by year. For instance, among the seven districts that submitted data for postimplementation years, one did not provide SAT and ACT scores for the first and second program years. Only two districts provided students' PSAT scores for the first and second program years, and only one district did so for the third and fourth program years. Graduation status is available only for three districts in the second to fourth program years. No district provided dropout-rate data for the first and 
second program years. Only one district provided dropout data for the third and fourth program years.

Even when variables are reported, data may be missing for many students. For instance, the proportion of missing values for the graduation status of 12th-grade students varied from 36 to 57 percent in program years. More than 70 percent of 11 th- and 12th-grade students did not have SAT or ACT scores. Only two districts provided PSAT scores, for about 130 students from the 2004-2005 to 2010-2011 school years. In addition, 85 to 94 percent of the students in districts that submitted student-level data for the 2009-2010 and 2010-2011 school years did not have adequate course-enrollment information, making it impossible to calculate the number of advanced courses students took in these two years.

Because of the amount of missing data in the student-level outcome database, some studentlevel achievement and engagement measures — such as PSAT, SAT, or ACT scores and graduation status of 12th-grade students - could not be used as outcome measures. We used only measures available from most districts with student-level data. Unfortunately, the number of students we could include in the analysis was not large. This posed challenges for the statistical power of our analyses.

During out interviews with stakeholders, districts reported that they could not provide the data because management systems from early years of the RCI no longer existed or district staff did not have the capacity to extract the data from the management systems. 


\section{Overview of RCI Participation}

In this chapter, we provide an overview of RCI participation at the district and student levels. We also discuss the target student populations of the RCI and the caveats in reporting RCI participation.

\section{District-Level Participation}

At the district level, 17 school districts participated in the RCI over the period of funding, including 16 districts located in Beaver County and one located in neighboring Lawrence County. Prior to the start of the third RCI year, the Center Area School District and Monaca School District merged to create the Central Valley School District. These districts experienced a decrease of 12 percent in student enrollment during the five years of the RCI, with the total enrollment of students at grades 7-12 declining from 12,288 in 2007-2008 to 10,768 in 20112012.

The RCI created academic choices for students in grades 7 to 12 in participating districts. Sixteen of the 17 participating districts serve students in grades 7 to 12 . Midland School District serves students in grades 7-8. Midland partners with a school district in the state of Ohio for grades 9-12, which did not participate in the RCI. Table 4.1 lists each district participating in the RCI, grade levels in the district that may exercise choice, and years of participation. The RCI received five years of funding (school years 2007-2008 through 2011-2012), as well as the NCE year in 2012-2013. We combined the fifth year of participation with the NCE year, following instructions from the VPSC program office.

\section{Student-Level Participation}

\section{RCI Target Student Population}

The VPSC grant sought to promote wider course offerings and transfers (single course or full course load) of students from low- to high-performing schools. Expanding course offerings and transfers of students from low- to high-performing schools required students to enroll in courses in a different public-school district. In the case of the RCI, low- and high-performing schools are synonymous with districts because there is only one school serving each grade level of students within a district. 
Table 4.1. District Participation in the RCI

\begin{tabular}{|c|c|c|c|c|c|c|}
\hline District Name & $\begin{array}{l}\text { Grade } \\
\text { Levels } \\
\text { Served }\end{array}$ & $\begin{array}{c}\text { Year 1, } \\
2007-2008\end{array}$ & $\begin{array}{l}\text { Year 2, } \\
\text { 2008-2009 }\end{array}$ & $\begin{array}{c}\text { Year 3, } \\
2009-2010\end{array}$ & $\begin{array}{c}\text { Year 4, } \\
2010-2011\end{array}$ & $\begin{array}{c}\text { Year 5, } \\
\text { 2011-2012 } \\
2012-2013,\end{array}$ \\
\hline Aliquippa School District & $7-12$ & $X$ & $\mathrm{x}$ & $x$ & $x$ & $x$ \\
\hline $\begin{array}{l}\text { Ambridge Area School } \\
\text { District }\end{array}$ & $7-12$ & $x$ & $\mathrm{x}$ & $x$ & $x$ & $x$ \\
\hline $\begin{array}{l}\text { Beaver Area School } \\
\text { District }\end{array}$ & $7-12$ & $x$ & $x$ & $x$ & $x$ & $x$ \\
\hline $\begin{array}{l}\text { Big Beaver Falls Schools } \\
\text { District }\end{array}$ & $7-12$ & $x$ & $\mathrm{x}$ & $x$ & $x$ & $x$ \\
\hline $\begin{array}{l}\text { Blackhawk School } \\
\text { District }\end{array}$ & $7-12$ & $\mathrm{x}$ & $x$ & $x$ & $x$ & $\mathrm{x}$ \\
\hline $\begin{array}{l}\text { Center Area School } \\
\text { District }\end{array}$ & $7-12$ & $\mathrm{x}$ & $\mathrm{x}$ & & & \\
\hline $\begin{array}{l}\text { Central Valley School } \\
\text { District }\end{array}$ & $7-12$ & & & $x$ & $x$ & $x$ \\
\hline $\begin{array}{l}\text { Ellwood City School } \\
\text { District }\end{array}$ & $7-12$ & $\mathrm{x}$ & $\mathrm{x}$ & $x$ & $x$ & $\mathrm{x}$ \\
\hline $\begin{array}{l}\text { Freedom Area School } \\
\text { District }\end{array}$ & $7-12$ & $x$ & $x$ & $\mathrm{x}$ & $x$ & $\mathrm{x}$ \\
\hline Hopewell School District & $7-12$ & $\mathrm{x}$ & $\mathrm{x}$ & $\mathrm{x}$ & $\mathrm{x}$ & $\mathrm{x}$ \\
\hline $\begin{array}{l}\text { Midland Borough School } \\
\text { District }\end{array}$ & $7-8$ & $\mathrm{x}$ & $\mathrm{x}$ & $x$ & $x$ & $\mathrm{x}$ \\
\hline Monaca School District & $7-12$ & $x$ & $x$ & & & \\
\hline $\begin{array}{l}\text { New Brighton School } \\
\text { District }\end{array}$ & $7-12$ & $\mathrm{X}$ & $x$ & $\mathrm{x}$ & $x$ & $\mathrm{x}$ \\
\hline Riverside School District & $7-12$ & $\mathrm{x}$ & $\mathrm{x}$ & $x$ & $x$ & $\mathrm{x}$ \\
\hline $\begin{array}{l}\text { Rochester Area School } \\
\text { District }\end{array}$ & $7-12$ & $x$ & $x$ & $x$ & $x$ & $x$ \\
\hline $\begin{array}{l}\text { South Side Area School } \\
\text { District }\end{array}$ & $7-12$ & $x$ & $x$ & $x$ & $x$ & $x$ \\
\hline $\begin{array}{l}\text { Western Beaver County } \\
\text { School District }\end{array}$ & $7-12$ & $x$ & $\mathrm{X}$ & $\mathrm{X}$ & $x$ & $X$ \\
\hline
\end{tabular}

The federal definition for a low-performing district is a district that has not met the Adequate Yearly Progress (AYP) goals on the state's assessment (in this case, the PSSA) for two consecutive years. There was only one district in the RCI meeting the criteria for a lowperforming district. As a result, RCI program developers expanded the focus of the RCI to help students from low-performing districts and underperforming districts. Underperforming districts are those met AYP but had (1) declined in performance each year and (2) were at risk for not making AYP as early as the 2007-2008 school year.

Because Beaver County had only one low-performing district, the RCI team also sought to help low-performing or disengaged students in higher-performing districts. RCI administrators developed a definition for low-performing and disengaged students and disseminated this 
definition throughout the grant period to districts. Low-performing students are those who are not progressing toward achievement and those who are falling behind. Such students may be low performing because of attendance, lack of motivation, or other disengagement issues, but the classification does not refer to students with behavioral problems. Disengaged students include those who are physically present in their classes but not connected to the learning process, either intellectually or emotionally, as well as students believed to have the ability to perform at a higher level but who appear to lack motivation to achieve in school. ${ }^{5}$ In short, though all students in participating districts are eligible to participate in the RCI, the initiatives target low- and underperforming districts, as well as low-performing and disengaged students from highperforming districts.

\section{Caveats About the RCI Target Student Population}

ED has many reporting requirements for program participation for VPSC awardees. Reporting mechanisms include the VPSC meta-analysis table for the national evaluation of VPSC and annual Government Performance and Results Act of 1993 reporting by the BVIU and RCI administrators to ED. At the annual grantee meeting in October 2008, ED VPSC program officers stated that only students transferring (single course or full course load) from a lowperforming district to a high-performing one should be counted for the national ED VPSC metaanalysis. Given that only one district in the county was low performing, and that the BVIU RCI had developed measures focusing on students who are disengaged or low performing, regardless of their districts' performance, the RCI team asked the ED VPSC program officers how to proceed. The ED VPSC program office responded that the BVIU RCI program's original research objectives and plans would be honored but that the RCI team should report outcomes that reflect students transferring from low-performing to high-performing districts and to focus on recruiting low-performing and disengaged students for the program.

Since receiving those directions, the BVIU RCI team focused on providing opportunities for students in low-performing districts and identified low-performing or disengaged students in higher-performing districts. At the same time, RCI administrators offered the RCI programs to all students and counted all participants for the federal meta-analysis and the BVIU RCI evaluation. RCI administrators relied on the expertise of school stakeholders (i.e., superintendents, principals, and guidance counselors) to determine whether students interested in RCI participation met the definitions of a low-performing or disengaged student. However, there was no formal verification process.

We calculated the number of students participating in the RCI enrolled in a low-performing district using the student-participation database. The database includes a school-district variable for each student, which allowed us to count the number of students from the low-performing

\footnotetext{
${ }^{5}$ This definition is taken from materials distributed to district and school leadership participating in the RCI. This artifact was collected on September 26, 2010, program year 4.
} 
district participating in the RCI. As noted, there are no data or indicators to identify students as low performing or disengaged. The definition for this target population does not reference specific individual-level data, nor was there a formal verification process to determine whether students participating in the RCI met the definition. As a result, we assumed that all participants met the definition of low performing or disengaged. Our reporting on participation counts all participants regardless of whether they are members of the target population.

\section{Overview of Student-Level Participation}

In total, 4,357 students participated in RCI programs from 2007-2008 to 2012-2013. Table 4.2 shows the number of students participating in all RCI programs during each year of the RCI. We count a student as participating in a school year if the student enrolled in a course for one of the RCI programs. A student is counted as participating in the school year only one time; a student is counted once if he or she participated in more than one RCI program in a particular year of the RCI. Annual participation is the number of single students regardless of the number of RCI programs the student participated in. Overall, less than 10 percent of enrolled targeted students at grades 7-12 in participating districts enrolled in the RCI in each of the four program years.

Table 4.2. Overall Participation in the RCI

\begin{tabular}{|c|c|c|c|c|c|c|c|c|}
\hline Program Year & Year 1 & Year 2 & Year 3 & Year 4 & Year 5 & Year 6 & $\begin{array}{c}\text { Years } 5 \\
\& 6^{A}\end{array}$ & $\begin{array}{c}\text { All } \\
\text { Years }\end{array}$ \\
\hline School Year(s) & $\begin{array}{c}2007- \\
2008\end{array}$ & $\begin{array}{c}2008- \\
2009\end{array}$ & $\begin{array}{c}2009- \\
2010\end{array}$ & $\begin{array}{c}2010- \\
2011\end{array}$ & $\begin{array}{c}2011- \\
2012\end{array}$ & $\begin{array}{c}2012- \\
2013\end{array}$ & $\begin{array}{c}2011- \\
2013\end{array}$ & \\
\hline $\begin{array}{l}\text { Low-performing } \\
\text { district }\end{array}$ & 0 & 5 & 34 & 35 & 43 & 33 & 76 & 150 \\
\hline All other districts & 165 & 514 & 712 & 829 & 1,057 & 930 & 1,987 & 4,207 \\
\hline Total & 165 & 519 & 746 & 864 & 1,100 & 963 & 2,063 & 4,357 \\
\hline $\begin{array}{l}\text { Percentage increase } \\
\text { in total participation } \\
\text { from the prior year }\end{array}$ & - & 215 & 44 & 16 & 27 & -12 & 139 & - \\
\hline
\end{tabular}

${ }^{A} \mathrm{RCl}$ administrators received direction from the VPSC program office to report year 5 and NCE in the aggregate. For consistency, we aggregated data from year 5 and the NCE to determine attainment of the performance measures related to annual growth and annual increases in successful course completion.

The number of RCI participants from all districts increased from 165 in the first year to 2,063 in the last two years. The largest increases in the overall participation occurred from year 1 to year 2 and from year 4 to the combined years 5 and 6 . There was a decrease in overall participation from year 5 to 6 , the year of the NCE. The number of RCI participants in the lowperforming district increased from zero in year 1 to 76 in the combined years 5 and 6 , with the largest increases in the later years of the RCI. 
The increase in the total participation from year 3 to year 4 was 16 percent, the smallest yearto-year increase. Results of stakeholder interviews showed that widespread communication from $\mathrm{RCI}$ administrators about the target population of students for the RCI contributed to the lower rate of increase in enrollment in RCI programs from year 3 to year 4 to. In their year 3 visit to VPSC grantees, federal evaluators raised concerns that insufficient numbers of the targeted students - students from the low-performing district and low-performing or disengaged students from all districts-were enrolling in the RCI. Though the federal evaluators noted that RCI administrators documented many efforts to target the low-performing district and population of students, they encouraged RCI administrators to further emphasize the target population. RCI administrators communicated the target population with all stakeholders. As a result, many guidance counselors expressed hesitancy to enroll students in the program. These guidance counselors chose to err "on the side of caution" when enrolling students for RCI programs by opting not to enroll a student if the guidance counselor was unclear whether the individual student met the definition of low performing or disengaged.

Though participation increased over time, our calculations may be an overestimate of individual students participating in the period of the RCI. We did not adjust prior participation in a program year. Meaning, a student may have participated in the RCI over a number of years, and we count the student each year.

\section{Key Findings}

Seventeen school districts participated in the RCI, with 16 districts located in Beaver County and one located in neighboring Lawrence County. In all but one district, two schools participated in the RCI. One school served students in the middle grades, while the other served students in high school. All students in grades 7 to 12 could participate in the RCI.

The RCI targeted students enrolled in low-performing districts, as well as low-performing and disengaged students irrespective of overall district performance. However, lack of clear indicators based on available student demographic and achievement data made it difficult to identify low-performing and disengaged students.

Overall, although student participation in the RCI increased annually, participation in the RCI was low. Less than 10 percent of the students enrolled in grades 7 to 12 in RCI districts participated each year in the first four years of the RCI. School stakeholders reported caution when recruiting students because of uncertainty about students' eligibility for RCI programs. 


\section{Performance of Open Seats}

This chapter describes participation and attainment of performance goals for the Open Seats program. Stakeholder interviews offer insights into the implementation strengths and challenges that affected the attainment of Open Seats performance goals. The chapter concludes with key findings for the Open Seats program.

\section{Participation in Open Seats}

The Open Seats program expanded course offerings to students throughout Beaver County. Students transfer to another district to take a single course or a full course load. Table 5.1 shows student participation in Open Seats during the period of the RCI. Overall, 1,096 students participated in the Open Seats program throughout RCI years. The number of participants increased from one student in year 1 to 554 students in year 5. The table also indicates the number and percentage of students successfully completing an Open Seats course in a given year. Successful completion of a course for the program is defined as earning a D or better as the final grade. The vast majority of students in Open Seats passed their courses. On average, 91 percent of students earned a passing grade over the period of the RCI. Across the years, passing rates ranged from 85 percent to 100 percent.

Table 5.1. Student Participation and Performance in Open Seats by Year

\begin{tabular}{|c|c|c|c|c|c|c|c|c|}
\hline Program Year & Year 1 & Year 2 & Year 3 & Year 4 & Year 5 & $\begin{array}{c}\text { Year } \\
6\end{array}$ & $\begin{array}{l}\text { Years } \\
5 \& 6^{A}\end{array}$ & Total \\
\hline School Year(s) & $\begin{array}{l}2007- \\
2008\end{array}$ & $\begin{array}{l}2008- \\
2009\end{array}$ & $\begin{array}{l}2009- \\
2010\end{array}$ & $\begin{array}{l}2010- \\
2011\end{array}$ & $\begin{array}{l}\text { 2011- } \\
2012\end{array}$ & $\begin{array}{l}2012- \\
2013\end{array}$ & $\begin{array}{l}2011- \\
2013\end{array}$ & \\
\hline $\begin{array}{l}\text { Number of students } \\
\text { participating }\end{array}$ & 1 & 87 & 245 & 209 & 361 & 193 & 554 & 1,096 \\
\hline $\begin{array}{l}\text { Number of students } \\
\text { earning a passing grade }\end{array}$ & 1 & 74 & 234 & 186 & 329 & 175 & 504 & 999 \\
\hline $\begin{array}{l}\text { Percentage of students } \\
\text { earning a passing grade }\end{array}$ & 100 & 85 & 96 & 89 & 91 & 91 & 91 & 91 \\
\hline
\end{tabular}

${ }^{\mathrm{A}} \mathrm{RCl}$ administrators received direction from the VPSC program office to report year 5 and the NCE in the aggregate. For consistency, we aggregated data from year 5 and the NCE to determine attainment of the performance measures related to annual growth and annual increases in successful course completion.

Open Seats afforded students an opportunity to effectively transfer full time to another school and, in turn, district, without moving residences. Students needing a "fresh start" could enroll in a school in a different district. These students are counted as a single student participating in Open Seats. However, ED and RCI stakeholders wanted to know how many students opted to transfer full time to another school. Full-time transfer is defined as a student who enrolls in a full course load in a different school; a full course load reflects all class periods for an academic day. 
Table 5.2 shows the number of students enrolling in a full course schedule in a different school. The number of full-time transfer students remained at zero in the first two years, and then increased from six students in year 3 to 46 students in the combined year 5 and year 6 . In total, 59 students participated in full transfer in the Open Seats program.

Table 5.2. Student Participation in Full-Time Transfer in Open Seats

\begin{tabular}{|l|c|c|c|c|c|c|c|c|}
\hline Program Year & Year 1 & Year 2 & Year 3 & Year 4 & Year 5 & Year 6 & $\begin{array}{c}\text { Years } \\
\mathbf{5} \text { \& 6 }\end{array}$ & $\begin{array}{c}\text { Total } \\
\text { School Year }\end{array}$ \\
\hline $\begin{array}{l}\text { Number of full-time } \\
\text { transfer students }\end{array}$ & $\mathbf{2 0 0 7 -}$ & $\mathbf{2 0 0 8 -}$ & $\mathbf{2 0 0 9 -}$ & $\mathbf{2 0 1 0 -}$ & $\mathbf{2 0 1 1 -}$ & $\mathbf{2 0 1 2 -}$ & $\mathbf{2 0 1 1 -}$ \\
$\mathbf{2 0 0 9}$ & $\mathbf{2 0 1 0}$ & $\mathbf{2 0 1 1}$ & $\mathbf{2 0 1 2}$ & $\mathbf{2 0 1 3}$ & $\mathbf{2 0 1 3}$ \\
\hline
\end{tabular}

${ }^{\mathrm{A}} \mathrm{RCl}$ administrators received direction from the VPSC program office to report year 5 and the NCE in the aggregate. For consistency, we aggregated data from year 5 and the NCE to determine attainment of the performance measures related to annual growth and annual increases in successful course completion.

\section{Performance Goal Attainment}

There are two performance measures and one objective for the Open Seats program. Table 5.3 lists each of these and identifies the type of measure for reporting purposes. To determine if the program attained the performance measure or objective we relied on student participation and course completion data, as well as stakeholder interview results.

Table 5.3. Open Seats Performance Measures and Objectives

\begin{tabular}{|l|l|c|}
\hline Type of Measure & Description of Goal & $\begin{array}{l}\text { Goal } \\
\text { Attainment }\end{array}$ \\
\hline Performance & $\begin{array}{l}\text { One percent of eligible students (125 students) will earn a passing grade } \\
\text { during the first year of the grant and the second year of the grant. }\end{array}$ & Not achieved \\
\hline Performance & $\begin{array}{l}\text { The number of participating students will increase so that, by 2012, 10 } \\
\text { percent of the target group of students will earn a passing grade in an } \\
\text { IVC course and/or physically transfer to another school program. }\end{array}$ & Not achieved \\
\hline Objective & $\begin{array}{l}\text { Provide bus transportation, reimburse mileage, and offer courses via IVC } \\
\text { for students to transfer from one school to another to participate in } \\
\text { courses or entire programs, based on students' educational needs. }\end{array}$ & Achieved \\
\hline
\end{tabular}

A Target group refers to students enrolled in an Open Seats course.

Prior to the start of the program, the BVIU's RCI planning team set a performance goal that 1 percent (125) of the eligible students in Beaver County would earn a passing grade in an Open Seats course during the first year and the second year of the grant. Participation data showed that the Open Seats program failed to meet this goal. Fewer than 125 students enrolled in the program during the first two years. Eighty-eight students total enrolled in Open Seats during the first and second years of the program, 1 student in the first year and 87 students in the second year (Table 5.1). The number of students enrolled in the Open Seats program was below the annual target. 
The BVIU's RCI planning team set an overall performance goal that 10 percent students in grades 7-12 would earn a passing grade (D or better) in an Open Seats course by 2012, the close of the program. That meant that 1,077 of the 10,768 Beaver County students in these grades would enroll in and pass an Open Seats course. ${ }^{6}$ The program attained 91 percent of this goal: altogether, 999 students enrolled in and earned a passing grade in an Open Seats program.

Superintendents, principals, and guidance counselors agreed that all students enrolled in Open Seats courses received transportation at no cost to the district. RCI administrators coordinated transportation for all students traveling by bus and fully covered the cost. Students who drove themselves or classmates were reimbursed with RCI funds. Open Seats achieved the objective of providing transportation.

\section{Performance Factors}

Stakeholder interviews indicated a number of strengths supporting the attainment of program measures and objectives but also challenges that prevented the program from reaching all its goals.

\section{Implementation Strengths}

Stakeholders agreed that Open Seats expanded course offerings provided "important opportunities" for students. Superintendents, principals, and guidance counselors alike perceived that students enrolled in Open Seats felt happier and more connected to school as a result of the program. One principal observed that low-performing and disengaged students participating in the program were "more engaged" in school since enrolling in courses. Open Seats students reportedly attended school more regularly and more consistently completed their assignments. Stakeholders theorized that students' behavior changed because they were able to enroll in courses that were not available at their schools and that matched their individual interests. Examples of such classes include ROTC and Mandarin Chinese, two "popular" and "high demand" courses in the Open Seats programs. Other popular courses in the later years of the RCI were SAT Prep and Transition to College, two courses focused on preparing students for college and created with RCI funds.

According to stakeholders, students recruited each other to enroll in the Open Seats program. One guidance counselor commented that a number of students in the school requested conversations to discuss participation in Open Seats courses, because students "heard about it" from a peer or a peer "said they had to do it." Student-led recruitment suggests students' satisfaction with the courses.

\footnotetext{
${ }^{6}$ BVIU data indicate that the number of seventh- to 12 th-grade students enrolled in regular and special-education classes in county districts decreased from 12,288 in year 1 to 11,541 in year 3, with continued decreases in enrollment each subsequent year. We adjusted the goal for 10-percent participation and passing to reflect enrollment numbers in year 5 .
} 
Similarly, course retention was relatively high for courses offered in a series or if students could reenroll in course. For example, most students enrolled in Mandarin Chinese I enrolled in Mandarin Chinese II. The vast majority of students enrolled in SAT Prep enrolled in Transition to College, a series of courses aimed at preparing for students life after high school.

Stakeholders identified the advanced courses offered in Open Seats as a "critical" opportunity for students. Superintendents and principals in particular noted the inability of some schools to offer advanced courses because of insufficient numbers of potential students. There is a need to offer these courses, though, to academically prepare students for college courses and help students identify areas of career interest. Leaders wanted all students to engage in rigorous coursework that pushed students "to reach their maximum potential." One superintendent from a host district commented that a top student in an advanced course was an Open Seats student; the student thanked the leader for the opportunity to enroll in the course. A superintendent from a sending school noted:

We could not afford to offer advanced courses anymore. I was upset that a few of our students who were ready for it would not be challenged. I did not want the students to be on hold in their progress until college. That is not serving our mission and vision to say, "You have to wait until college to take the course." And decide if you are interested in pursuing the field professionally. Open Seats kept those students engaged. One student decided what she wants to study in college because she took more-advanced courses. I do not want to lose [the engagement of] these students.

Stakeholders consistently identified advanced courses as a key strength of the Open Seats program. Although stakeholders perceived that advanced courses primarily benefited districts unable to offer advanced courses to students, they agreed that it was the "right thing" or "best thing" because "our kids in Beaver County are all of ours."

In year 4, RCI administrators and superintendents began sustainability planning for Open Seats. Superintendents agreed to continue the program indefinitely and set forth guidelines for continuing it. Planning for sustainability without VPSC funding occurred for two years during monthly meetings and through convening special committees. At the time of the publication of this report, Open Seats has persisted among districts in the BVIU. Sustainability without external funding demonstrates strong support for the program among districts.

\section{Implementation Challenges}

Overall, student participation was lower than planned. Principals and guidance counselors reported that the time required to travel to and from a neighboring school prohibited some interested students from participating in the program. At some schools, students could not physically transfer to other schools unless students' schedules allowed for a study hall or free period surrounding the Open Seats course. This flexible schedule was primarily possible for students in grade 11 or 12 . 
The varying design of master schedules created other challenges for Open Seats. Some districts operated block schedules, while others used traditional class periods of 45 to 60 minutes. Even ignoring travel time constraints, it was not possible for students enrolled in a traditional class-period school to enroll in a block course requiring multiple class periods, even if the course was delivered using IVC. When class-period lengths matched, students could sit in a classroom in their home school and use IVC to participate in a course in real time. Each school had an IVCcapable classroom. Instruction for the vast majority of Open Seats offerings could occur using IVC. Superintendents, principals, and guidance counselors agreed that schedule differences could make a school an unsuitable partner for Open Seats. Guidance counselors did not mention schools with incompatible schedules in conversations with students about Open Seats.

While students could enroll in foreign language and other courses using IVC, many guidance counselors reported that students were not interested in taking classes via IVC. According to counselors, students opted not to enroll in the course if was only possible through IVC. Still, at least some students enrolled in an IVC course each year, with 63 doing so in year 6.

Related to the schedule challenges is the aim of Open Seats to expand course offerings. Districts discouraged or prohibited students from enrolling in courses offered at another district if the course was available in their own. One principal said, "Open Seats was not intended for them [students] to take courses available here at another school." A superintendent from a different district agreed: "Open Seats is supposed to expand course offerings, not remove a student from a course we offer." Students could not enroll in a core course in an adjacent period to a unique Open Seats course to mitigate travel time and scheduling constraints. Limited availability of course sections for the majority of Open Seats courses, like AP Biology, and inability to enroll in core courses limited participation.

Guidance counselors reported less student interest in the Open Seats courses in the fourth program year because of fewer course offerings. One counselor noted that a popular language course had fewer available openings in year 4; thus, fewer students across the RCI could enroll. Stakeholders reported that although course offerings expanded over time, seat availability for courses restricted participation.

\section{Key Findings}

Open Seats fell short of the performance measure of enrolling 125 students in the first and second years of the program. It also fell short of overall participation goal of 1,077 students earning a passing grade by end of the program — 999 students successfully completed an Open Seats course. Yet the vast majority of students enrolled in an Open Seats course completed it successfully (on average, 91 percent). Schools had some challenges accommodating Open Seats courses because of variations in master schedules throughout the region, as well as travel time to and from schools. Guidance counselors also reported that some students were not interested in taking a course using IVC. 
Open Seats did expand course offerings for students. Students could enroll in courses, such as foreign language, college preparation, or ROTC, that were not offered in their districts. Students could participate in advanced coursework, such as AP courses. Stakeholders identified the opportunity for students to engage in advanced coursework as a key strength of the Open Seats program. Limited sections of Open Seats courses reportedly prohibited the participation of students in the program.

Most students who enrolled in a course in a series progressed through to the subsequent courses. Most students who enrolled in Mandarin Chinese I, for example, also took Mandarin Chinese II. There were also strong return rates in other foreign-language, college-preparation, and ROTC courses. Students often recruited their peers for Open Seats courses.

Stakeholders strongly supported the Open Seats program. It provided opportunities to engage students in courses of interest and provided advanced coursework for all students in the region. RCI administrators and superintendents began sustainability planning for Open Seats in year 4 of the RCI. 


\section{Performance of Dual Enrollment}

This chapter describes the participation and attainment of performance goals for the Dual Enrollment program. Participation increased sharply at first, and again in later years of the program. Stakeholders noted that there were ample funding and synergies with a statewide program, which aided implementation, and that student recruitment was an ongoing challenge. After reviewing details of participation trends and stakeholder insights, we summarize our key findings for the Dual Enrollment program.

\section{Participation in Dual Enrollment}

Dual Enrollment offered tenth- to 12th-grade students opportunities take college courses. Student participation in Dual Enrollment increased annually, with the most dramatic increase in participation in the second year of the RCI. There was also an increase in participation from year 4 to year 5, but year 5 actually reflects two school years of participation. By the end of the RCI, 1,782 students participated in the program. Of the 1,782 participants 1,585 students earned a passing grade in the course (see Table 6.1). A passing grade in Dual Enrollment is a C or better for the final course grade. On average, 89 percent of students participating in Dual Enrollment successfully completed a course. Variation in final performance in program courses was minimal, ranging from 87 to 98 percent. Though participation increased each year through year 4 , the rate of growth was less dramatic in later years (combined years 5 and 6 participation). In respective years 4 and 5, participation decreased. By year 4 of the program, all eligible districts in the RCI were enrolling students in the Dual Enrollment program. 
Table 6.1. Student Performance in Dual Enrollment by Year

\begin{tabular}{|c|c|c|c|c|c|c|c|c|}
\hline Program Year & Year 1 & Year 2 & Year 3 & Year 4 & Year 5 & Year 6 & $\begin{array}{l}\text { Years } \\
5 \& 6^{\mathrm{A}}\end{array}$ & Total \\
\hline School Year(s) & $\begin{array}{c}2007- \\
2008\end{array}$ & $\begin{array}{c}2008- \\
2009\end{array}$ & $\begin{array}{c}2009- \\
2010\end{array}$ & $\begin{array}{c}2010- \\
2011\end{array}$ & $\begin{array}{c}2011- \\
2012\end{array}$ & $\begin{array}{c}2012- \\
2013\end{array}$ & $\begin{array}{c}2011- \\
2013\end{array}$ & \\
\hline $\begin{array}{l}\text { Number of students } \\
\text { participating }\end{array}$ & 50 & 309 & 372 & 403 & 385 & 263 & 648 & 1,782 \\
\hline $\begin{array}{l}\text { Number of students } \\
\text { earning a passing } \\
\text { grade }\end{array}$ & 47 & 269 & 339 & 394 & 334 & 238 & 572 & 1,585 \\
\hline $\begin{array}{l}\text { Percentage of } \\
\text { students earning a } \\
\text { passing grade }\end{array}$ & 94 & 87 & 91 & 98 & 87 & 90 & 88 & 89 \\
\hline $\begin{array}{l}\text { Annual percentage } \\
\text { growth in successful } \\
\text { course completion }\end{array}$ & - & 472 & 26 & 16 & -15 & -29 & 45 & - \\
\hline $\begin{array}{l}\text { Annual change in } \\
\text { successful course } \\
\text { completion (number } \\
\text { of students) }\end{array}$ & - & 222 & 70 & 55 & -60 & -96 & 178 & - \\
\hline
\end{tabular}

${ }^{\mathrm{A}} \mathrm{RCl}$ administrators received direction from the VPSC program officer to report year 5 and the NCE in the aggregate. For consistency, we aggregated data from year 5 and the NCE to determine attainment of the performance measures related to annual growth and annual increases in successful course completion.

\section{Performance Goal Attainment}

The objective for Dual Enrollment program is to increase the number of high school students successfully completing grant-funded college courses (i.e., courses for which tuition costs are covered by the VPSC grant through the RCI) by offering courses provided by postsecondary institutions. There were also two student performance measures: (1) the number of eligible tenthto 12 th-grade students earning a $\mathrm{C}$ or better in college courses would increase by 5 percent in the first year of the grant and (2) the number of students earning a $\mathrm{C}$ or better would increase by at least 150 students per year, beginning in 2009 (year 3; see Table 6.2).

Table 6.2. Dual Enrollment Performance Measures and Objectives

\begin{tabular}{|l|l|c|}
\hline $\begin{array}{l}\text { Type of } \\
\text { Measure }\end{array}$ & Description of Goal & Goal Attainment \\
\hline Performance & $\begin{array}{l}\text { The number of eligible tenth- to 12th-grade students }(6,284) \text { earning a C or } \\
\text { better in college courses will increase by 5 percent in the first year of the grant. }\end{array}$ & Not achieved \\
\hline Performance & $\begin{array}{l}\text { The number of students earning a C or better would increase by at least 150 } \\
\text { students per year, beginning in 2009 (year 3). }\end{array}$ & Not achieved \\
\hline Objective & $\begin{array}{l}\text { Increase the number of students successfully completing grant-funded college } \\
\text { courses in high school by offering courses provided by multiple postsecondary } \\
\text { institutions. }\end{array}$ & Achieved \\
\hline
\end{tabular}

The RCI did not achieve the goal of increasing participation in the Dual Enrollment program by 5 percent in the first year of the grant. Fifty students participated in the Dual Enrollment 
program in the first year. This is significantly below the expected enrollment of 6,284 students to achieve the 5-percent growth goal (see Table 6.1).

RCI had mixed success in growing the successful completion of the program by 150 students annually, beginning in year 3 . The number of students earning a passing grade did not grow by 150 students in the third to fourth program years. The successful completion of Dual Enrollment courses grew by 70 students from years 2 to 3; from years 3 to 4 , the number of students successfully completing courses increased by 55 students. Growth from year 4 to the combined years 5 and 6 exceeded the growth goal, with 178 more students earning a passing grade; however, annual participation declined in year 5 compared with year 4 and in year 5 compared with year 6. Overall, the RCI did meet the growth goals for participation and successful course completion beginning in the third program year.

Stakeholders reported that the number of postsecondary institutions offering RCI Dual Enrollment courses expanded during the program. This achieves the performance objective. Although courses were offered in multiple postsecondary institutions and the majority of students successfully completed the courses, students tended to enroll in the same postsecondary institutions each year. According to stakeholders, the proximity of the high school to a college campus affected students' selection of Dual Enrollment courses.

\section{Performance Factors}

Stakeholders identified ample funding and synergies with a similar statewide program as implementation strengths, and student recruitment were identified as an implementation challenge.

\section{Implementation Strengths}

The Commonwealth of Pennsylvania has provided funding for the statewide Dual Enrollment program since the 2005-2006 school year, prior to the inception of the RCI, for higherperforming students. By contrast, the RCI Dual Enrollment program encouraged districts to focus on low-performing and disengaged students who might also be the first in their families to attend college. Funding for the statewide Dual Enrollment program was discontinued by 20102011, year 4 of the RCI program.

Nevertheless, the statewide Dual Enrollment program helped lay a foundation for the RCI Dual Enrollment program in two ways. First, districts and universities reported preexisting networks and relationships that had been established for the state's Dual Enrollment program and that allowed a smooth transition to the RCI program. Second, the RCI Dual Enrollment program did not require any new training in the district or among its university partners, though in later years teachers participated in trainings that were required for teaching dual credit courses in the high school. 
The RCI Dual Enrollment program was well funded and had the capacity to serve three times as many students as enrolled in it. Having sufficient funding for Dual Enrollment was unusual for stakeholders. Despite more than adequate levels of funding, most guidance counselors found it challenging to remember that funding was not limited, and they remained cautious in recruiting students. Guidance counselors did not want to disappoint students, particularly low- or underperforming and disengaged students. One said:

I have a hard time believing the funding exists from year to year. Each year we received less money from the state until there was nothing for Dual Enrollment. I am still in the mind-set that I cannot say much about the program at the end of the school year. I am not used to money not being a limitation. It is awesome that we do not have to worry about the money; I am just not used to it.

Students could participate in the Dual Enrollment program for more than one year-e.g., enrolling in the 10th grade and then for each of the subsequent two years. Students were free to select courses of interest to them.

The RCI provided opportunities for high school teachers to receive the accreditation necessary to teach college classes at the high school. This expanded the Dual Enrollment program. The RCI provided financial support for teachers to attend the training to receive accreditation. This helped overcome early challenges that stakeholders in some schools reported regarding the time students would need to travel to college courses or finding available times for courses of interest. High school teachers also partnered with college professors to create hybrid courses located at the high school. College professors taught a course on the high school campus some days, while high school teachers provided content support on the remaining days. Students had some exposure to the college schedule but also had the opportunity to receive ongoing monitoring from the high school, which supported students' performance.

Some postsecondary institutions partnered closely with RCI administrators and stakeholders to design implementation models for Dual Enrollment that expanded students' ability to participate in the program. Dual Enrollment providers represented a broad range of institutions, including traditional four-year colleges, two-year colleges, technical schools, and other certification programs.

Stakeholders agreed that low or underperforming students benefited from the opportunity to take college courses in high school. Principals and guidance counselors reported that some students gained confidence in their skills, improving students' perceptions of their ability to enroll in college. Superintendents agreed that students experienced success in Dual Enrollment courses, which could influence postsecondary decisions, particularly for low- or underperforming and disengaged students.

Stakeholders highlighted individual students who changed their mind about postsecondary coursework. One guidance counselor commented, "[Student] said college was not happening and now [student] is asking me about which types of colleges she might be able to take more classes [with]." Dual Enrollment provided exposure to students that stakeholders deemed "very 
important." Stakeholders noted that schools would not have provided low- and underperforming students the exposure without this program, because the state and district did not target these students for Dual Enrollment.

Superintendents sought to sustain the Dual Enrollment program, suggesting strong buy-in for the program near the end of the program. Districts with accredited Dual Enrollment teaching staff planned to continue offering college courses at the high school and would open the classes to students from other districts as part of Open Seats.

\section{Implementation Challenges}

Student recruitment was a challenge for Dual Enrollment; as noted, considerably more students were eligible to participate in the program than enrolled in it. As also noted, guidance counselors expressed concerns about adequate funding for the program, which resulted in cautious recruitment efforts. Guidance counselors recruited cautiously in the final year of the program with the assumption that schools could not sustain Dual Enrollment without RCI funding.

Guidance counselors reported the eligibility of students in their schools as a key recruitment challenge. Students eligible for state-funded Dual Enrollment, who were high-performing students, were not eligible for the RCI Dual Enrollment program, which targeted low- or underperforming and disengaged students. Guidance counselors expressed discomfort informing some students that they were "too high performing" for the RCI program, and high-performing students did not understand why they were ineligible for it. Many guidance counselors expressed reluctance to recruit broadly in the school because a portion of the school was ineligible to participate, especially given that ineligible students were those most interested in Dual Enrollment. The RCI program did deem students who were first in their families to attend college (and who might otherwise be less likely to enroll and persist in college) as eligible regardless of their academic performance, and counselors understood this eligibility.

Stakeholders reported that low- and underperforming students were less willing than expected to enroll in Dual Enrollment courses occurring outside the high school campus. One guidance counselor explained:

The paperwork was complete and submitted, but her friend decided not to take the class so she would not take the class. She was afraid to go to the campus and take the class on her own, even though she has been to the campus many times before. It [the campus] is just down the street.

Many superintendents, principals, and guidance counselors perceived that lack of confidence among low- or underperforming or disengaged students resulted in reluctance to take risks. Stakeholders noted that participation in a Dual Enrollment course entailed academic and social risk, while adding that having college classes on high school campuses helped some students overcome their hesitancy. 
Many guidance counselors, as well as some principals and superintendents, identified the academic performance of the target population of students for the RCI (low performing or disengaged) as a challenge for program participation. Some college courses of interest had performance requirements. For example, students must pass a placement exam to take a Pennsylvania State University English course. Students who did not pass the placement exam were ineligible for the course. Some students, when informed of ineligibility, were often not willing to enroll in the same course offered by a different postsecondary institution.

\section{Key Findings}

Participation and successful completion of Dual Enrollment courses increased by the targeted percentages over time, but the program did not meet its goal of increasing the number of students successfully completing a course by 150 students per year beginning in year 3 . The RCI offered courses at multiple postsecondary institutions and expanded offerings over the lifetime of the grant, resulting in the attainment of the performance objective.

On average, 89 percent of students who enrolled in a Dual Enrollment course successfully completed it each year of the program.

Student recruitment was a considerable challenge. Though the program was well funded, guidance counselors and principals were cautious to enroll students, particularly given the ineligibility of high-performing students. At the same time, low- and underperforming students were less interested in enrolling in college courses, and some students did not participate because their friends did not.

To combat student hesitancy to enroll in Dual Enrollment courses, high schools offered Dual Enrollment courses on their campuses. College professors, as well as high school teachers accredited for college instruction, taught such courses. The RCI also funded training for high school teachers to gain the required accreditation.

Stakeholders agreed that the Dual Enrollment program was an important opportunity for lowand underperforming or disengaged students. In some cases, students who successfully completed a college course gained confidence in their ability to enroll in postsecondary certification or degree programs.

Districts planned to continue offering college courses delivered by accredited high school teachers beyond the RCI. Without RCI funding, schools could not afford for students to enroll in courses offered on college campuses. 


\section{Performance of Cyber Learning}

This chapter describes the participation and attainment of performance goals for the Cyber Learning program. The Cyber Learning program had relatively modest enrollment at first, but there was rapid expansion in the fourth and fifth years of the program. Stakeholders suggested that opportunities to "test drive" Cyber Learning opportunities and the support offered to students in these courses were among the program's strengths, but initial reluctance by students to enroll in such opportunities posed an early challenge. In reviewing key findings, we note that Cyber Learning did not lead to an exodus of students from traditional settings, as had been feared.

\section{Participation in Cyber Learning}

The Cyber Learning program offered students an opportunity to take courses online. Table 7.1 presents data on participation and performance in the Cyber Learning program. Over the period of the RCI, 1,664 students completed an RCI Cyber Learning course, and 72 percent of these students earned a passing grade ( $\mathrm{D}$ or above). The increase in the number of students enrolled in the Cyber Learning program in the fourth year was attributed to an increase in the number of teachers designing cyber courses and then supplementing traditional instruction with the online courses. Successful course-completion rates were highest in the later years of the program, when more than 75 percent of students earned a passing grade in the course (year 4 and combined years 5 and 6).

Table 7.1. Student Performance in Cyber Learning Courses by Year

\begin{tabular}{|c|c|c|c|c|c|c|c|c|}
\hline Program Year & Year 1 & Year 2 & Year 3 & Year 4 & Year 5 & Year 6 & $\begin{array}{l}\text { Years } \\
5 \& 6^{A} \\
\end{array}$ & Total \\
\hline School Year(s) & $\begin{array}{c}2007- \\
2008\end{array}$ & $\begin{array}{c}2008- \\
2009\end{array}$ & $\begin{array}{c}2009- \\
2010\end{array}$ & $\begin{array}{c}2010- \\
2011\end{array}$ & $\begin{array}{c}2011- \\
2012\end{array}$ & $\begin{array}{c}2012- \\
2013\end{array}$ & $\begin{array}{c}2011- \\
2013\end{array}$ & \\
\hline $\begin{array}{l}\text { Number of students } \\
\text { participating }\end{array}$ & 112 & 118 & 145 & 306 & 451 & 532 & 983 & 1,664 \\
\hline $\begin{array}{l}\text { Number of students } \\
\text { earning a passing } \\
\text { grade }\end{array}$ & 48 & 72 & 93 & 234 & 302 & 451 & 753 & 1,200 \\
\hline $\begin{array}{l}\text { Percentage of } \\
\text { students earning a } \\
\text { passing grade }\end{array}$ & 43 & 61 & 64 & 76 & 67 & 85 & 77 & 72 \\
\hline
\end{tabular}

${ }^{A} \mathrm{RCl}$ administrators received direction from the VPSC program office to report year 5 and the NCE in the aggregate. We aggregate years 5 and the NCE to determine attainment of the performance measures for the percentage of students earning a passing grade. 


\section{Performance Goal Attainment}

To assess performance of the Cyber Learning program, we assessed six performance goals, related to the number of students completing a cyber course and to the proportion of students earning a passing grade in such a course in each year of the program. Each of these goals is presented in Table 7.2 and we report on attainment of each individually.

Table 7.2. Cyber Learning Performance Measures and Objectives

\begin{tabular}{|l|l|c|}
\hline $\begin{array}{l}\text { Type of } \\
\text { Measure }\end{array}$ & Description of Goal & Goal Attainment \\
\hline Performance & $\begin{array}{l}\text { Two percent of students (in Beaver County, 252) enrolled in a course will earn a } \\
\text { passing grade in at least one cyber service choice in the first year of the grant } \\
\text { period. }\end{array}$ & Not achieved \\
\hline Performance & $\begin{array}{l}\text { Five percent of students (603) enrolled in a course will earn a passing grade in at } \\
\text { least one cyber service choice in the second year of the grant period. }\end{array}$ & Not achieved \\
\hline Performance & $\begin{array}{l}\text { Twenty-five percent of students (3,150) enrolled in a course will earn a passing } \\
\text { grade in at least one cyber service choice in the third year of the grant period. }\end{array}$ & Not achieved \\
\hline Performance & $\begin{array}{l}\text { Fifty percent of students (6,300) enrolled in a course will earn a passing grade in } \\
\text { at least one cyber service choice in the fourth year of the grant period. }\end{array}$ & Not achieved \\
\hline Performance & $\begin{array}{l}\text { Seventy percent of students (8,820) enrolled in a course will earn a passing grade } \\
\text { in at least one cyber service choice in the final year of the grant period. }\end{array}$ & Not achieved \\
\hline Objective & $\begin{array}{l}\text { Utilize the newly installed fiber-optic network to increase the number of students } \\
\text { completing a cyber course. }\end{array}$ & Achieved \\
\hline
\end{tabular}

NOTE: The total number of seventh- to 12th-grade students enrolled at participating districts in the first program year was used as the denominator when setting goals for performance measures.

The Cyber Learning program failed to meet its first goal, to have 2 percent of students in Beaver County (252 students) earn a passing grade in at least one Cyber Learning course in the first year of the RCI. The actual number of students participating in the Cyber Learning program in year 1 was 112 , less than half of the target.

The remaining performance measures focus on increases in the percentage of students earning a passing grade in the course. In no year of the program did the number of students participating in Cyber Learning meet or exceed the planned enrollment necessary to attain the performance measures. The planned number of students earning a passing grade in year 2 was 603, while 72 students actually earned a passing grade; in year 3, the planned number of students earning a passing grade was 3,150 , but only 93 students actually did (Table 7.1 ). Thus, using actual participation figures to measure attainment the program does not achieve any of the performance measures. Though the actual number of students earning a passing grade was far below the planned number, the percentage of students participating in Cyber Learning and received a passing grade ranged from 43 to 85 percent (Table 7.1). Most students participating in Cyber Learning courses earned a passing grade.

The RCI achieved its performance objective to use the fiber-optic network to increase the number of students completing a cyber course. The program achieved this goal by using a 
preexisting fiber-optic network. Cyber Learning relied on the fiber-optic network to deliver course content online to students throughout the region. Stakeholders reported that the fiber-optic network was the foundation for the program, without which students would not have been able to enroll, and that the network supported all student participation in Cyber Learning courses.

\section{Performance Factors}

The following section highlights the strengths and challenges in implementing the Cyber Learning program, according to stakeholders.

\section{Implementation Strengths}

The program enabled students to decide how to receive instruction. Students interested in cyber learning could enroll in one or more courses online to determine whether the instructional model was a fit for their learning style. Guidance counselors identified students who "test drove" a cyber schedule, a schedule that included cyber and traditional classes. At the close of the course, some students proceeded with online learning — adding additional cyber courses to their schedules or transitioning to full cyber schedules - while others discontinued cyber courses. Students determined their schedules based on their interests or success with the Cyber Learning program. Many students opted for a hybrid schedule, a combination of traditional and online courses. Students reportedly had more control in their educational experiences.

Stakeholders perceived the additional support available to students in Cyber Learning classrooms as a key contributor to program success. One superintendent commented, "We see more students passing classes and staying on pace to complete a class in a semester now that students come here." A principal said, "Teachers might not like the duty [because it requires more engagement than cafeteria duty or study hall], but it is making a big difference for our students, so it is worth it." The Cyber Learning program offered many supports to students to ensure the successful completion of online courses.

\section{Implementation Challenges}

Stakeholders admitted that the Cyber Learning program was important but concerning to them at its inception. Many were "afraid" or "nervous" that a considerable number of students would enroll in the Cyber Learning program full time. A few feared a "mass exodus" from their schools. Of the 10,786 students eligible to participate in the Cyber Learning program in year 5 of the RCI, 4 percent enrolled in the program; aggregated years 5 and 6 participation was 9 percent of eligible students. In retrospect, stakeholders identified their concerns as unfounded. They agreed that students in need of varied and different learning opportunities received the supports they needed through the Cyber Learning program, and districts "kept" students who might have enrolled in cyber charter schools if not for the program. 
Some districts opted to purchase cyber courses independent of the RCI. Students' participation and performance in online courses purchased with district funds and without RCI funding cannot be included in the performance-measure calculation. In interviews, stakeholders from schools that purchased courses independently identified a number of reasons for their decision, including satisfaction with the rigor of the courses, with minimal investments of time from their teachers and sustainability planning. RCI administrators discussed course satisfaction with stakeholders and initiated courses from an additional provider for districts moving forward (years 5 and 6).

A few stakeholders reported that the independent purchase of cyber courses was an effort to sustain the Cyber Learning program after the RCI ends. Students in these stakeholders' schools wanted to persist with online learning, and districts committed to sustain such opportunities. Despite RCI administrators regularly addressing in meetings and email communication the availability of courses after the conclusion of the RCI, stakeholders were unclear about the regulations. RCI administrators combated the challenge by engaging in a broad communication campaign, outlining the availability of courses in future years. Though the level of commitment of stakeholders to the Cyber Learning program was a strength of the program overall, reluctance to recruit for the program resulted in missed performance targets.

\section{Key Findings}

The Cyber Learning program used preexisting investments in a fiber-optic network throughout Beaver County to deliver online courses to students and achieved a performance goal by doing so. Student participation in the program increased annually; however, participation each year did not meet the enrollment targets outlined in the performance measures. Of the students participating in a Cyber Learning course, most earned a passing grade.

Lower-than-expected participation may be related to the reluctance of stakeholders to recruit students to the program. Stakeholders initially hesitated to support the Cyber Learning program, fearing that it might lead to an exodus of students from schools. These fears proved unfounded, as fewer than 5 percent of eligible students participated in the program by the end of the RCI.

Cyber Learning reportedly offered students more control of their education experiences. Students selected the number of classes, courses, pace of instruction or course completion, and persistence with cyber courses.

Despite recruitment challenges in the program, stakeholders agreed that the Cyber Learning program was important to the students and committed to sustain the program without VPSC funds. 


\section{Performance of Academies for Success}

This chapter describes the participation and attainment of performance goals for the Academies for Success program. This program had several false starts and did not enroll students until the fifth year of the overall initiative. As a result, we are unable to examine its achievement of many of the goals originally envisioned for it. Nevertheless, we do examine how well it achieved its ultimate goals, as well as the strengths and challenges of implementation, and key findings of this effort for those who may seek to launch a similar program.

\section{Participation in Academies for Success}

The level of participation in Academies for Success was low. In total, only 18 students enrolled in the Leadership Academy in the sixth year of program implementation. Participating students represented eight school districts. As a reminder, students did not enroll in the program until the 2012-2013 school year, the year of the NCE.

\section{Performance Goal Attainment}

The RCI team set goals and objectives to measure performance of the Academies for Success by end of the funding period (end of the NCE for the purposes of reporting). Table 8.1 presents the three performance measures and one objectives for the Academies for Success program.

Table 8.1. Academies for Success Performance Measures and Objectives

\begin{tabular}{|l|l|c|}
\hline $\begin{array}{l}\text { Type of } \\
\text { Measure }\end{array}$ & Description of Goal & Goal Attainment \\
\hline Performance & $\begin{array}{l}\text { By the end of the final year, students who participate in the Academies for } \\
\text { Success will have a dropout rate of less than 10 percent. }\end{array}$ & Achieved \\
\hline Performance & $\begin{array}{l}\text { By the end of the final year, 100 percent of the students attending the } \\
\text { Academies for Success will reach proficiency in math by the 11th grade, as } \\
\text { measured by the PSSA. }\end{array}$ & Not achieved \\
\hline Performance & $\begin{array}{l}\text { By the end of the final year, 100 percent of the students attending the } \\
\text { Academies for Success will reach proficiency in reading by the 11th grade, as } \\
\text { measured by the PSSA. }\end{array}$ & $\begin{array}{c}\text { Not achieved } \\
\text { Objective }\end{array}$ \\
$\begin{array}{l}\text { Increase the academic achievement in math and reading for students } \\
\text { performance in their home districts. }\end{array}$ & \\
\hline
\end{tabular}

NOTES: The end of the final year includes the NCE year. ED approved NCE funds for the Academies for Success program and directed $\mathrm{RCl}$ administrators to aggregate performance in the NCE year with year 5 for reporting purposes. 
Academies for Success achieved the performance goal of a dropout rate of less than 10 percent. In fact, none of the students participating dropped out of the program, or school. The two academic measures specify measurement according to the 4Sight exam, a benchmark assessment, in preparation for the PSSA in the spring of that year. We assessed reading and mathematics performance using PSSA performance because 4Sight data were not available. The program did not achieve performance measures specific to mathematics or reading proficiency as measured on the PSSA; only four students tested in reading, of whom only two demonstrated proficiency, and 11 students tested in mathematics in the NCE year, of whom only five demonstrated proficiency. Limited data for the participants and implementation create challenges for assessing the attainment of the achievement performance goals and, in turn, the performance objective. Because the program did not achieve the performance measure related to the objective, we report the objective as not achieved.

\section{Performance Factors}

From 2007 to 2008, the RCI team and partnering superintendents worked to determine a direction for Academies for Success. The RCI team and governing board struggled to identify an appropriate approach to Academies for Success because of disagreements over the target population, where the program should be housed, and the academic foci.

To gain an understanding of parents' and students' potential needs for the program, BVIU staff held an initial focus group in spring 2009, which included low-performing or disengaged students and their parents, as selected by guidance counselors and principals. This discussion led the RCI director, the governing board, and the SAC to develop the Choice Academies.

Lack of participation in the program led RCI administrators, BVIU leaders, and superintendents to investigate other foci for the Academies for Success program. In the SAC and governing board meetings during the fourth year of the RCI, RCI administrators, BVIU leaders, and superintendents routinely discussed their perceptions of how the ROTC course in the Open Seats program affected students at risk of dropping out or failing, as well as how the course affected low- and underperforming and higher-achieving students. These discussions led the SAC and governing board to ask RCI administrators to investigate the option of Academies for Success integrating ROTC into a program. Students' interest in and commitment to ROTC drove the design of the new Academy for Success, dubbed the Leadership Academy, in year 5. RCI administrators and superintendents convened planning meetings with ROTC leadership throughout the fifth year of the program to design a program that met the requirements of ROTC, expanded the Open Seats course for students, and provided rigorous coursework. Students enrolled in the Leadership Academy during the year of the NCE. 


\section{Implementation Strengths}

The Leadership Academy was built on students' interest and desire to participate in ROTC and a program aimed at preparation for military careers. Stakeholders identified the need for the program using participation data from the Open Seats program and conversations with students. Although the initiation of Academies for Success and participation occurred in the last years of funding, the RCI designed and enrolled students in the program quickly.

At the close of year 6, some students from the Leadership Academy attended a meeting with superintendents, BVIU leaders, and RCI administrators to share experiences and answer questions about the program. Each student discussed the importance of the Leadership Academy. One said:

I felt isolated and alone my freshman year. I did not go to school regularly and when I did, I was not paying attention. I hated it. I planned to drop out as soon as I could. I wanted to go on homebound [instruction]. The military seemed interesting to me so I decided to try ROTC when I could not go on homebound. I started in the ROTC program in the morning. I rode the bus to practice. I made friends, felt happier. I tried a little more when I was at school, but I missed the friends I made at ROTC. They checked on me, offered support, but I still felt alone. Now, in the Leadership Academy, I am very happy. Dropping out is not an option. I am a leader. I am responsible for a team of people and they depend on me. I feel connected and supported. I spend all of my time with the unit. I am going to graduate from high school and I plan to join the military. I know that I can use the money from the military to go to college later; I plan to do that now. The Leadership Academy changed my life. I do not know where I would be if [I] was not in the Leadership Academy, but it would not be here. Thank you for this program.

Superintendents committed to sustain the Leadership Academy without RCI funding.

\section{Implementation Challenges}

The RCI initially offered three other Academies for Success, called Choice Academies. Though stakeholders reported recruiting students for Choice Academies, students did not enroll. Many stakeholders perceived that the focus areas of the Choice Academies did not align with student interests, even though focus groups of students shaped their development.

Measuring the impact of Academies for Success is also a challenge. In the meeting with superintendents, BVIU leaders, and RCI administrators, students described the impact of the Leadership Academy on their social-emotional states and changes in their engagement with school since enrollment in the program. Nevertheless, changes in students' willingness to attend school, their persistence in the face of academic adversity, and their plans to graduate are not measured on the PSSA, which provides the primary measures of program-goal achievement. Students' willingness to engage curriculum also may not immediately improve their academic performance. 


\section{Key Findings}

The RCI planned for the Academies for Success program to offer a number of focused and targeted programs to students. Yet there was only one program, the Leadership Academy, in the term of the RCI. Eighteen students participated in the Leadership Academy and, in turn, the program during the NCE year (2012-2013 school year), with 100 percent of participants completing it - i.e., not withdrawing from or discontinuing participation during the school year. The Leadership Academy did not, however, meet academic proficiency goals, as measured by PSSA scores, for these students.

In meetings with superintendents, BVIU leaders, and RCI administrators, Leadership Academy students contended that the academy was critical in helping them stay in school and plan for the future. They also claimed that several social, emotional, and nonacademic benefits were not captured in the performance measures for the program or the outcome evaluation. RCI stakeholders agreed that Academies for Success supported students at greater risk of dropping out. Superintendents committed to sustaining the Leadership Academy following the conclusion of the RCI. 


\section{Overall Performance of the $\mathrm{RCl}$}

This chapter begins by describing the attainment of performance goals that apply to the overall initiative. We then address implementation strengths and challenges related to these performance goals. In order to summarize the overall success of implementing the initiative, we list all performance measures and objectives for the RCI and the attainment of each goal. We conclude the chapter with a summary of key findings for RCI implementation.

\section{Attainment of Broad Performance Goals}

A number of performance objectives and measures are specific not to RCI programs but to the RCI more broadly. Broad performance objectives are related to two of the four activities for implementation, including training and PD for school staff in participating RCI districts and disseminating information about the RCI to parents and students. This section reports the attainment of these performance objectives by the end of VPSC funding. Table 9.1 identifies performance goals that are not associated with an individual RCI program.

Table 9.1. Overall RCI Performance Goals

\begin{tabular}{|l|l|c|}
\hline $\begin{array}{l}\text { Type of } \\
\text { Measure }\end{array}$ & Description of Goal & Goal Attainment \\
\hline Objective & $\begin{array}{l}\text { Professional development: Embed appropriate professional development } \\
\text { for administrators, guidance counselors, and faculty in each of the four } \\
\text { choice programs to support the development of live and cyber courses. } \\
\text { This will be held regularly on a sustained basis and will be based on state } \\
\text { standards. }\end{array}$ & Achieved \\
\hline Performance & $\begin{array}{l}\text { Professional development: By the end of the 2008-2009 school year } \\
\text { (year 2), the content-area faculty teams will have developed a total of } \\
\text { eight live and/or cyber courses in the core curriculum. }\end{array}$ & Achieved \\
\hline Performance & $\begin{array}{l}\text { Professional development: By the end of the 2009-2010 school year } \\
\text { (year 3), the content-area faculty teams will have developed a total of } \\
\text { eight life and/or cyber courses in the core curriculum. }\end{array}$ & Achieved \\
\hline Objective & $\begin{array}{l}\text { Disseminating information: Conduct a countywide public-relations } \\
\text { campaign to increase parents' awareness of their school-choice options. }\end{array}$ & Achieved \\
\hline Performance & $\begin{array}{l}\text { Disseminating information: By the end of the RCl, at least 75 percent of } \\
\text { the total number of surveyed parents/guardians in the 15 middle and 14 } \\
\text { high schools will respond affirmatively to parent awareness surveys, in } \\
\text { the school district newsletters and websites, about school-choice options. }\end{array}$ & Not achieved \\
\hline
\end{tabular}




\section{Professional Development}

RCI administrators embedded PD for administrators, guidance counselors, and faculty in each of the four programs. Professional development began in the first year of funding for the Open Seats, Dual Enrollment, and Cyber Learning programs. PD relevant to administrators and guidance counselors tended to occur quarterly. Reports indicate that PD occurred at least twice a year and offerings tended to persist over many weeks; these reports on PD offerings for teachers and participation in these offerings were given during conversations between the evaluation team and RCI administrators, and some observations of PD and reports on activities were discussed during governing board meetings. PD for Academies for Success began in the later years of the program, with the creation of the Leadership Academy.

There are two performance measures related to teacher training. These goals are specific to the second and third years of the RCI and focus on the development of live courses (i.e., Open Seats courses) or cyber courses (i.e., courses conducted online at least in part) in the core curriculum. Performance measures aimed for the development of eight courses in core subjects per year. The RCI exceeded this metric: Teachers attending training developed more than eight courses annually, ultimately developing more than 30 courses.

\section{Disseminating Information About the RCI to Parents and Students}

RCI administrators conducted a countywide public-relations campaign to increase parents' awareness of program options. The campaign included a number of approaches. The RCI and all participating districts posted information about the RCI on their websites, with a link to the RCI website. A banner promoting the RCI hung in the local mall. Radio advertisements on a number of stations serving the region informed listeners about the program. Administrators also promoted the RCI in materials distributed to parents and students throughout the county. RCI administrators contracted with a cable provider to release commercials; individuals could click a button on their remotes for additional information, enabling administrators to follow up directly with households expressing interest in the RCI.

Nevertheless, parents' knowledge of the RCI appeared to remain low in the fourth year of funding. A postcard survey sent to parents had a response rate of only 19 percent. Given the low response rate, survey findings may not be representative of parents in the region; the findings are suggestive at best. Among those who did respond to the survey, only 33 percent said that they had heard of the RCI, far below the 75-percent recognition goal of the program, while 78 percent had heard of the BVIU. Responding parents were more familiar with some programs than others, as shown in Figure 9.1. Most reported knowing about Cyber Learning, and one in three said that they knew about Dual Enrollment, but far fewer knew about Open Seats and Academies for Success. More than one in three parents were not familiar with any of the programs. Similarly, parents reported that their oldest school-aged child was more likely to have heard of Cyber Learning and Dual Enrollment than they were to have heard of Open Seats or Academies for 
Success. RCI administrators also fielded a survey on their website, as well as on the websites of schools and publicized through school newsletters, to gauge awareness of the RCI at the end of the NCE. Of the 116 participants in the survey, 25 respondents knew of the RCI.

Figure 9.1. Parents' Awareness of RCI Programs

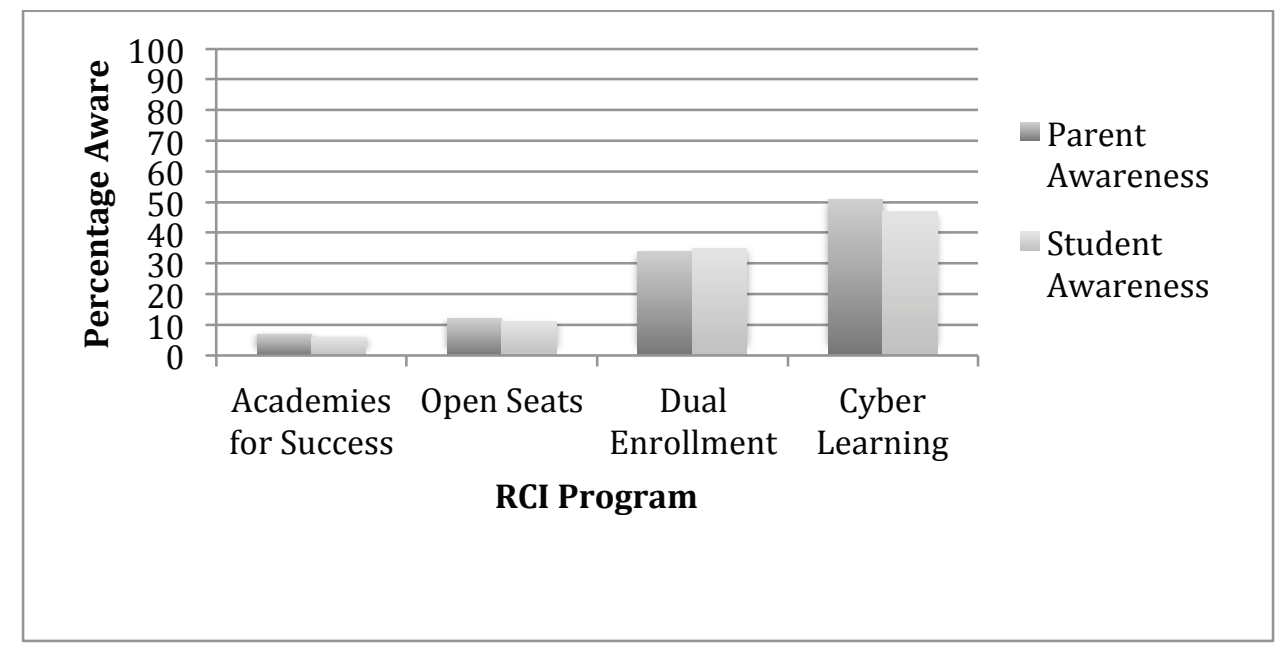

\section{Key Findings for Overall Performance of the $\mathrm{RCl}$}

Table 9.2 presents each performance goal and the measure to evaluate it, as well as whether the goal was attained.

The RCI attained few of the performance goals established by the BVIU leadership and RCI administrators in the final year of the initiative. Of the 21 goals and measures, the RCI attained eight. These eight measures did not rely on student participation in programs. The data gathered in this study indicate that RCI attained performance goals related to training teachers, executing a public relations campaign, utilizing a fiber optic network, providing transportation, and collaborating with postsecondary institutions. As discussed in earlier chapters, the programs had problems recruiting students, so that fewer participated than planned over the course of the RCI. Student participation is the primary hindrance in the initiative achieving its performance goals. 
Table 9.2. Attainment of RCI Performance Measures

\begin{tabular}{|c|c|c|c|}
\hline $\begin{array}{l}\text { RCI } \\
\text { Program }\end{array}$ & Type of Measure & Description of Goal & $\begin{array}{l}\text { Goal } \\
\text { Attainment }\end{array}$ \\
\hline \multirow[t]{3}{*}{$\begin{array}{l}\text { Open } \\
\text { Seats }\end{array}$} & Performance & $\begin{array}{l}\text { One percent of eligible students ( } 125 \text { students) will earn a passing } \\
\text { grade during the first year of the grant and the second year of the } \\
\text { grant. }\end{array}$ & $\begin{array}{l}\text { Not } \\
\text { achieved }\end{array}$ \\
\hline & Performance & $\begin{array}{l}\text { The number of participating students will increase so that, by } 2012 \text {, } \\
10 \text { percent of the target group of students will earn a passing grade } \\
\text { in an IVC course and/or physically transfer to another school } \\
\text { program. }\end{array}$ & $\begin{array}{l}\text { Not } \\
\text { achieved }\end{array}$ \\
\hline & Objective & $\begin{array}{l}\text { Provide bus transportation, reimburse mileage, and offer courses via } \\
\text { IVC for students to transfer from one school to another to participate } \\
\text { in courses or entire programs based on students' educational } \\
\text { needs. }\end{array}$ & Achieved \\
\hline \multirow[t]{3}{*}{$\begin{array}{l}\text { Dual } \\
\text { Enrollment }\end{array}$} & Performance & $\begin{array}{l}\text { The number of eligible } 10 \text { th- to } 12 \text { th-grade students }(6,284) \text { earning } \\
\text { a C or better in college courses will increase by } 5 \text { percent in the first } \\
\text { year of the grant. }\end{array}$ & $\begin{array}{l}\text { Not } \\
\text { achieved }\end{array}$ \\
\hline & Performance & $\begin{array}{l}\text { The number of students earning a C or better would increase by at } \\
\text { least } 150 \text { students per year, beginning in } 2009 \text { (year } 3 \text { ). }\end{array}$ & $\begin{array}{l}\text { Not } \\
\text { achieved }\end{array}$ \\
\hline & Objective & $\begin{array}{l}\text { Increase the number of students successfully completing grant- } \\
\text { funded college courses in high school by offering courses provided } \\
\text { by multiple postsecondary institutions. }\end{array}$ & Achieved \\
\hline \multirow[t]{6}{*}{$\begin{array}{l}\text { Cyber } \\
\text { Learning }\end{array}$} & Performance & $\begin{array}{l}\text { Two percent of students (in Beaver County, 252) enrolled in a } \\
\text { course will earn a passing grade in at least one cyber service choice } \\
\text { in the first year of the grant period. }\end{array}$ & $\begin{array}{l}\text { Not } \\
\text { achieved }\end{array}$ \\
\hline & Performance & $\begin{array}{l}\text { Five percent of students (603) enrolled in a course will earn a } \\
\text { passing grade in at least one cyber service choice in the second } \\
\text { year of the grant period. }\end{array}$ & $\begin{array}{l}\text { Not } \\
\text { achieved }\end{array}$ \\
\hline & Performance & $\begin{array}{l}\text { Twenty-five percent of students }(3,150) \text { enrolled in a course will earn } \\
\text { a passing grade in at least one cyber service choice in the third year } \\
\text { of the grant period. }\end{array}$ & $\begin{array}{l}\text { Not } \\
\text { achieved }\end{array}$ \\
\hline & Performance & $\begin{array}{l}\text { Fifty percent of students }(6,300) \text { enrolled in a course will earn a } \\
\text { passing grade in at least one cyber service choice in the fourth year } \\
\text { of the grant period. }\end{array}$ & $\begin{array}{l}\text { Not } \\
\text { achieved }\end{array}$ \\
\hline & Performance & $\begin{array}{l}\text { Seventy percent of students }(8,820) \text { enrolled in a course will earn a } \\
\text { passing grade in at least one cyber service choice in the final year of } \\
\text { the grant period. }\end{array}$ & $\begin{array}{l}\text { Not } \\
\text { achieved }\end{array}$ \\
\hline & Objective & $\begin{array}{l}\text { Utilize the newly installed fiber-optic network to increase the number } \\
\text { of students completing a cyber course. }\end{array}$ & Achieved \\
\hline \multirow[t]{4}{*}{$\begin{array}{l}\text { Academies } \\
\text { for } \\
\text { Success }\end{array}$} & Performance & $\begin{array}{l}\text { By the end of the final year, students who participate in the } \\
\text { Academies for Success will have a dropout rate of less than } 10 \\
\text { percent. }\end{array}$ & Achieved \\
\hline & Performance & $\begin{array}{l}\text { By the end of the final year, } 100 \text { percent of the students attending } \\
\text { the Academies for Success will reach proficiency in math by the } \\
11 \text { th grade, as measured by the PSSA. }\end{array}$ & $\begin{array}{l}\text { Not } \\
\text { achieved }\end{array}$ \\
\hline & Performance & $\begin{array}{l}\text { By the end of the final year, } 100 \text { percent of the students attending } \\
\text { the Academies for Success will reach proficiency in reading by the } \\
11 \text { th grade, as measured by the PSSA. }\end{array}$ & $\begin{array}{l}\text { Not } \\
\text { achieved }\end{array}$ \\
\hline & Objective & $\begin{array}{l}\text { Increase the academic achievement in math and reading for } \\
\text { students participating in the Academies for Success, as compared }\end{array}$ & $\begin{array}{l}\text { Not } \\
\text { achieved }\end{array}$ \\
\hline
\end{tabular}




\begin{tabular}{|c|c|c|c|}
\hline $\begin{array}{l}\text { RCI } \\
\text { Program }\end{array}$ & Type of Measure & Description of Goal & $\begin{array}{c}\text { Goal } \\
\text { Attainment }\end{array}$ \\
\hline & & with their prior performance in their home districts. & \\
\hline \multirow[t]{5}{*}{$\mathrm{RCl}$ overall } & Objective & $\begin{array}{l}\text { Professional development: Embed appropriate professional } \\
\text { development for administrators, guidance counselors, and faculty in } \\
\text { each of the four choice programs to support the development of live } \\
\text { and cyber courses. This will be held regularly on a sustained basis } \\
\text { and will be based on state standards. }\end{array}$ & Achieved \\
\hline & Performance & $\begin{array}{l}\text { Professional development: By the end of the } 2008-2009 \text { school year } \\
\text { (year 2), the content-area faculty teams will have developed a total } \\
\text { of eight live and/or cyber courses in the core curriculum. }\end{array}$ & Achieved \\
\hline & Performance & $\begin{array}{l}\text { Professional development: By the end of the } 2009-2010 \text { school year } \\
\text { (year } 3 \text { ), the content-area faculty teams will have developed a total } \\
\text { of eight live and/or cyber courses in the core curriculum. }\end{array}$ & Achieved \\
\hline & Objective & $\begin{array}{l}\text { Disseminating information: Conduct a countywide public-relations } \\
\text { campaign to increase parents' awareness of their school-choice } \\
\text { options. }\end{array}$ & Achieved \\
\hline & Performance & $\begin{array}{l}\text { Disseminating information: By the end of the } \mathrm{RCI} \text {, at least } 75 \\
\text { percent of the total number of surveyed parents/guardians in the } 15 \\
\text { middle and } 14 \text { high schools will respond affirmatively to parent } \\
\text { awareness surveys, in the school-district newsletters and websites, } \\
\text { about school-choice options. }\end{array}$ & $\begin{array}{c}\text { Not } \\
\text { achieved }\end{array}$ \\
\hline
\end{tabular}

\section{Overall Performance Factors}

We asked stakeholders their perceptions of influences on RCI performance and goals, including particular strengths and challenges and how they affected the attainment of performance goals, and broad activities that supported implementation, as identified in the RCI logic model (see Chapter Two). Stakeholders cited communication and leadership support of the program but noted that there was initial resistance.

\section{Implementation Strengths}

According to stakeholders, RCI administrators facilitated communication and implementation and were key to the perceived success of the initiative. Superintendents consistently described administrators as "tireless" in their efforts to offer the programs and expand participation annually. RCI administrators "immediately responded" at nearly all hours to requests for assistance, information, and questions about the availability of services. District leaders described high levels of support for their districts, schools, school staff, and students. One superintendent said:

If the RCI does not meet all of it goals, it is because we [districts] did not do our part. They [RCI administrators] could not have done anything more to get us [districts] to participate. [Administrators] pushed for change when we were resistant and got us to work together in ways I never thought possible. The cohesion of superintendents across the county never could have occurred in this way without the RCI and efforts of [RCI administrators]. I never thought this was possible. 
Principals and guidance counselors also described RCI administrators as the primary levers of success. RCI administrators offered consistent support to principals and guidance counselors by answering questions about students who might have participate in the programs, identifying the appropriate courses for students interested in program participation, providing ongoing support to students enrolled in programs, and consistently communicating about students' performance. School staff felt "fully informed" about the programs and success of their students participating in programs. Stakeholders described RCI administrators as "diligent," "passionate," "patient," "committed to the success of the RCI," and committed to expanding opportunities for all students in the county. Stakeholders agreed that RCI administrators appropriately pushed schools to enroll students in RCI programs.

Many superintendents identified the impact on district leadership as one of the most significant contributions of the RCI. On average, superintendents met monthly for governing board and SAC meetings. Each agenda included time for reporting on the performance of the $\mathrm{RCI}$ and discussion of future directions. These meetings created a collaborative environment, a culture of shared decisionmaking, and expectations to continue the structure and function of leadership meetings beyond the RCI. As one superintendent said:

I rarely spoke with others [superintendents] when I was unsure of what to do. Now I openly share the challenge in our meetings and ask my colleagues how they might address a challenge. I never thought I would share things in that way. It might have taken us four years to get on board, but there is no going back now.

Superintendents throughout the county planned to continue participation in meetings and committees created through the RCI. The structure and function of leadership teams would exist beyond the initiative. Superintendents tended to identify the transformation in partnership between districts as a critical and unexpected impact of the initiative.

\section{Implementation Challenges}

All stakeholders agreed that some aspects of the RCI program were initially resisted by district staff, including administrators and counselors. Resistance was a considerable hurdle for RCI administrators. In particular, interviewees noted resistance to the requirement of the grant for low -or underperforming disengaged students to participate in the program, as opposed to high-performing students. Stakeholders were reluctant to enroll students in Open Seats, fearing that they might adversely affect class size or a school's ability to maintain full course loads for their teachers. There was also resistance to the Cyber Learning program. School staff feared that the program would result in a "mass exodus" of students to Cyber Learning. When asked about the participation rates in the performance goals, stakeholders agreed that the performance measures submitted to evaluate the program were unrealistic. Stakeholders perceived that the participation rates were unrealistic from the outset.

Though RCI administrators combated the challenges, stakeholders agreed that participation was low in the early years of the program because they required time and evidence that the RCI 
would not negatively affect districts. The participation requirement of the grant for low- or underperforming students in Dual Enrollment persisted as an area of dissatisfaction through the final year of the RCI. Nevertheless, stakeholders consistently recognized that RCI administrators were "not at fault" for the restriction and that RCI administrators only sought to ensure that districts participating in the program complied with regulations.

Stakeholders reported limited efforts to recruit students for programs in the later years of the grant because of questions regarding sustainability without VPSC funds. As a result, schools did not bolster recruitment even after their concerns about negative impact decreased. Limited recruitment resulted in slower program growth, even when some performance measures required more growth in student participation.

Though RCI administrators sought many ways to market the initiative to families, knowledge and awareness of the RCI remained low. The extent to which families received communication from the marketing campaign is unclear. Overall, recruitment was a challenge for the RCI. 


\section{Relationship of Participation in the RCI to Student Outcomes}

In this chapter, we examine the association between RCI implementation and student outcomes. We begin the chapter by describing RCI participation by district and year, because the years covered in the impact analysis are limited. The impact analysis covers years 1 to 4 of the RCI; the initial timeline of VPSC funding and available data sources did not allow for inclusion of year 5 and NCE data.

\section{Descriptive Summary of RCI Participation}

In total, 1,960 students from 16 districts took RCI courses from the 2007-2008 to 2010-2011 school years. The total number of RCI participating students across all RCI districts increased from 165 in the first program year to 864 in the fourth program year.

Most RCI participants ( 86 percent) participated in the RCI for only one year. Fourteen percent of RCI participants participated in the program in more than one year; less than 1 percent did so for more than two years. Figure 10.1 shows the percentage of RCI participants by the program years they participated in the RCI.

Figure 10.1. Percentage of RCI Participants by the Years Students Participated in the RCI

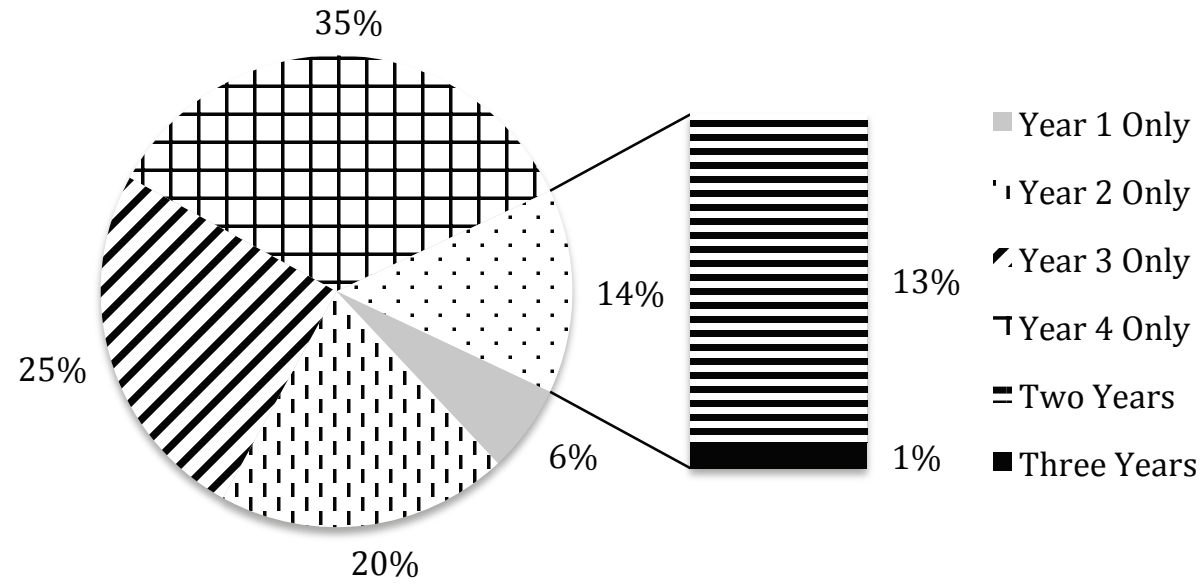

More than 90 percent of participants took courses through one RCI program. About 45 percent of participants only participated in Dual Enrollment. One in four participants used only Cyber Learning, and one in five enrolled only in the Open Seats program. Less than one in ten participated in more than one program, and less than one in 100 participated in more than two 
programs. Figure 10.2 shows the percentage of RCI participants by the number of programs they participated in.

Figure 10.2. Percentage of RCI Participants by the Number of Programs Students Participated In

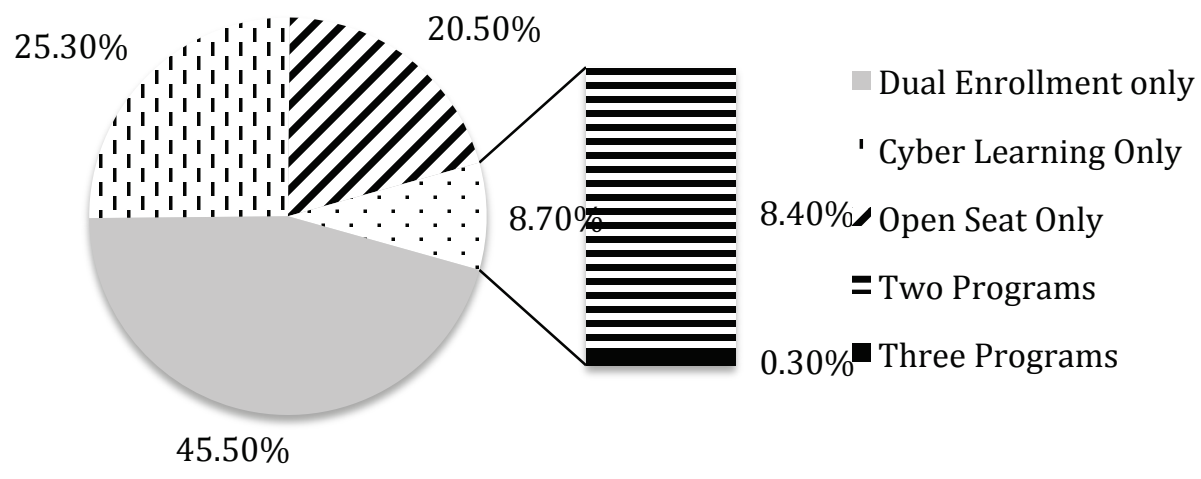

Sixty-five percent of participants took mathematics or English Language Arts-related courses through RCI programs. The percentage of RCI participants who ever took mathematics or English Language Arts courses through RCI programs varied from 50 to 72 percent over the four program years.

\section{Trends in Student Achievement and Engagement}

To discern achievement changes during the project, we examined trends in students' performance on the PSSA mathematics and reading tests in RCI districts from 2007-2008 to 2010-11, or program years 1 to 3 . Because the RCI focused on high school students, and because only 11 th-grade students took the PSSA achievement tests, we examined the percentage of 11 thgrade students who scored at or above the proficient level on the PSSA mathematics and reading tests during program years (see Table 10.1).

About 60 percent of 11th-grade students scored at or above the proficient level on the PSSA mathematics test in RCI districts during the first four program years, with 65 to 69 percent doing so in reading. There was an increase in reading proficiency between the second and third years, but factors other than RCI may have contributed to such an increase. 
Table 10.1. Trends in the Percentage of 11th-Grade Student Scoring at or Above the Proficient Level on the PSSA Mathematics and Reading Tests in RCI Districts, 2007-2008 to 2010-2011

\begin{tabular}{|l|l|l|l|l|l|l|l|l|}
\hline & \multicolumn{5}{|c|}{ Mathematics } & \multicolumn{5}{c|}{ Reading } \\
\cline { 2 - 10 } Year & Percentage & Std. Dev. & Min (\%) & Max (\%) & Percentage & Std. Dev. & Min (\%) & Max (\%) \\
\hline $\begin{array}{l}2007- \\
2008\end{array}$ & 60 & 13.59 & 31 & 76 & 67 & 11.40 & 45 & 85 \\
\hline $\begin{array}{l}2008- \\
2009\end{array}$ & 59 & 14.44 & 22 & 78 & 65 & 14.25 & 31 & 83 \\
\hline $\begin{array}{l}2009- \\
2010\end{array}$ & 60 & 16.72 & 13 & 76 & 69 & 14.22 & 29 & 84 \\
\hline $\begin{array}{l}2010-20 \\
11\end{array}$ & 59 & 13.87 & 30 & 75 & 69 & 9.89 & 42 & 77 \\
\hline
\end{tabular}

NOTE: There were $16 \mathrm{RCl}$ districts during 2007-2010 and 15 during 20010-2011.

To examine whether RCI solely caused this increase, we would need data on the percentage of students who scored at or above the proficient level on the PSSA mathematics and reading tests had RCI not been implemented. Because such data are not available, we examine the percentage of 11th-grade students who scored at or above the proficient level on the PSSA mathematics and reading tests in non-RCI districts in Pennsylvania during the same period. The results, summarized in Figure 10.3, suggest that RCI districts did not improve as much as nonRCI districts on these scores. Because non-RCI districts in Pennsylvania serve only as a proxy comparison group for RCI districts, more-detailed analyses comparing RCI districts with similar non-RCI districts are required to assess the association between the RCI and student achievement.

Figure 10.3. Trends in the Percentage of Students Scoring at or Above the Proficient Level on the PSSA Mathematics and Reading Tests for RCI and Non-RCI Districts, 2007-2008 to 2010-2011

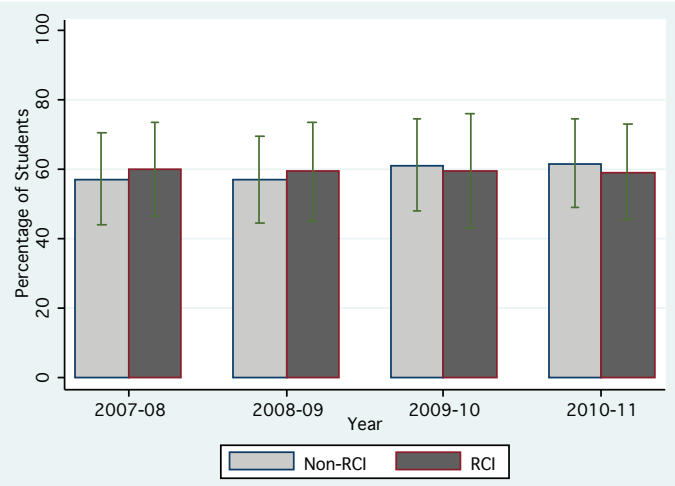

Mathematics

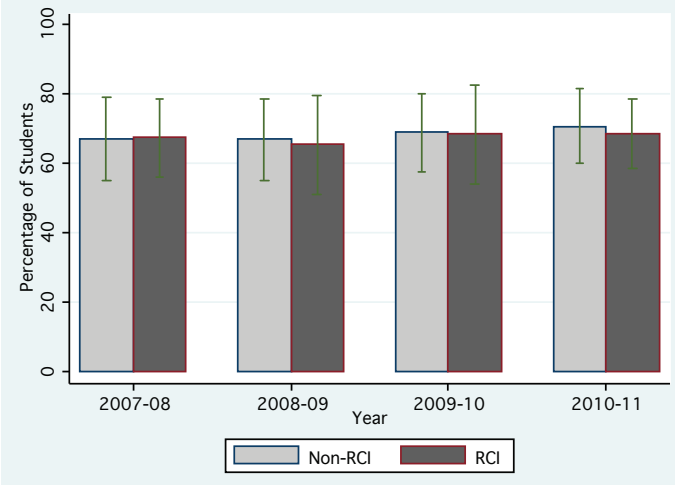

Reading

NOTES: The height of the bars represents the average district-level percentage of students who scored at or above the proficient level on the PSSA mathematics and reading tests. The error bar represents the standard deviation of the district-level percentage of students who scored at or above the proficient level on the PSSA mathematics and reading tests in a particular year. The number of $\mathrm{RCl}$ districts was 16 during 2007-2010 and 15 during $2010-2011$. The number of non-RCI districts in Pennsylvania was 483 from 2007 to 2011. 
To examine the trend in student engagement during the four program years, we focused on students' dropout and graduation rates from 2007-2008 to 2009-2010. Table 10.2 indicates that mean dropout rates appear to have decreased more in RCI districts than in others, while Table 10.3 indicates that graduation rates increased more in RCI districts. Because non-RCI districts only serve as a proxy comparison group for RCI districts, it is unclear whether differences other than the RCI initiative contributed to the different changes in mean dropout and graduation rates.

Table 10.2. Trends in Dropout Rates Among Students at Grades 7-12 in RCl and Non-RCl Districts, 2007-08 to 2009-10

\begin{tabular}{|l|c|c|c|c|c|c|c|c|}
\hline & \multicolumn{4}{|c|}{ RCI Districts } & \multicolumn{4}{c|}{ Non-RCI Districts } \\
\cline { 2 - 9 } Year & $\begin{array}{c}\text { Mean } \\
(\%)\end{array}$ & Std. Dev. & Min (\%) & $\begin{array}{c}\text { Max } \\
(\%)\end{array}$ & $\begin{array}{c}\text { Mean } \\
(\%)\end{array}$ & Std. Dev. & Min (\%) & Max (\%) \\
\hline $\begin{array}{l}2007- \\
2008\end{array}$ & 1.23 & 1.25 & 0 & 3.99 & 1.22 & 1.14 & 0 & 14.75 \\
\hline $\begin{array}{l}2008- \\
2009\end{array}$ & 1.06 & 0.81 & 0 & 3.41 & 1.10 & 0.97 & 0 & 9.41 \\
\hline $\begin{array}{l}2009- \\
2010\end{array}$ & 1.00 & 0.94 & 0 & 2.98 & 1.14 & 1.00 & 0 & 11.39 \\
\hline
\end{tabular}

NOTES: Dropout rate data came from PDE. According to PDE, a dropout student is someone who, for any reason other than death, leaves school before graduation without transferring to another school or institution. The dropout rate is calculated by dividing the total count of dropout students by the fall enrollment for the same school year. The dropout rate is calculated for students at grades 7-12. Dropout-rate data were available for 2007-2008 to 20092010. The number of $\mathrm{RCl}$ districts included in the analysis was 16 in the first and second program years and 14 in the third program year. The number of non- $\mathrm{RCl}$ districts included in the analysis was 484 for all three program years.

Table 10.3. Trends in Graduation Rates in RCI and Non-RCI Districts, 2007-2008 to 2009-2010

\begin{tabular}{|l|c|c|c|c|c|c|c|c|}
\hline & \multicolumn{4}{|c|}{ RCI Districts } & \multicolumn{4}{c|}{ Non-RCI Districts } \\
\cline { 2 - 9 } & $\begin{array}{c}\text { Mean } \\
\text { Y\%) }\end{array}$ & Std. Dev. & Min (\%) & $\begin{array}{c}\text { Max } \\
(\%)\end{array}$ & $\begin{array}{c}\text { Mean } \\
(\%)\end{array}$ & Std. Dev. & Min (\%) & Max (\%) \\
\hline $\begin{array}{l}2007- \\
2008\end{array}$ & 79 & 10 & 63 & 93 & 85 & 11 & 36 & 100 \\
\hline $\begin{array}{l}2008- \\
2009\end{array}$ & 79 & 12 & 51 & 92 & 85 & 11 & 40 & 100 \\
\hline $\begin{array}{l}2009- \\
2010\end{array}$ & 83 & 13 & 55 & 100 & 85 & 10 & 49 & 100 \\
\hline
\end{tabular}

NOTES: Graduation-rate data came from PDE. PDE considers a high school graduate as a student who has received a diploma. Students who earned high school credentials by obtaining a GED diploma are not considered graduates for the purpose of the graduate data. PDE does not provide information regarding how graduation rates are calculated. Graduation rates were available for 2007-2008, 2008-2009, and 2009-2010. The number of RCl districts included in the analysis was 15 in the first and second program years, and 13 in the third program year. The number of non- $\mathrm{RCl}$ districts included in the analysis was 482 for all three program years.

\section{Relationship of RCI Participation to Student Outcomes}

Achievement analysis, described in the appendix, tested whether participation, as measured by the individual- and district-level participation measures, is related to student achievement and engagement, after controlling for student demographic characteristics, preimplementation test scores, and other predictors of future achievement and engagement. These analyses included 
only students for whom complete data on these variables were available. The appendix contains details about the models we implemented, the variables included in the models, and analysis results.

\section{Relationship of RCI Participation to Student Achievement}

In total, seven cohorts of students had the chance to participate in the RCI from 2007-2008 to 2010-2011, including cohorts B to H (see Chapter Three, Table 3.1, for additional information about the cohorts). Because PSSA scores are only available for 11th-grade students at the high school level, we conducted analyses on the relationship of RCI participation to student achievement for only four cohorts of students: C, D, E, and F. Although these four cohorts had different years of exposure to the RCI, most students participated in the RCI program for only one year. Thus, analyses on these four cohorts examined the association between one year of RCI participation and student achievement.

Table 10.4 summarizes the type of analyses conducted for each cohort. All four cohorts were examined in the district-level analysis. Cohorts D, E, and F were examined in the student-level analysis. Cohort $\mathrm{C}$ was not examined in the student-level analysis because of limited number of RCI participants with the required data. None of these analyses of student-achievement measures found any significant relationship between RCI participation and student performance on the PSSA mathematics and reading achievement tests.

Table 10.4. Summary of Achievement Analyses

\begin{tabular}{|l|c|c|c|c|}
\hline \multirow{2}{*}{ Level of Analysis } & \multicolumn{3}{|c|}{ Cohort } & E \\
\cline { 2 - 5 } & C & D & & \\
\hline Student level & & & & \\
\hline
\end{tabular}

NOTES: Shaded cells indicate cohorts on which student- or district-level achievement analyses were conducted. None of the analyses found a significant relationship between $\mathrm{RCl}$ participation and student achievement outcomes. Refer to Table 3.1 for additional information about the cohorts and the appendix for technical details about the methods and models used for analyses.

\section{Relationship of RCI Participation to Student Engagement}

We analyzed the impact of the RCI on student engagement for seven cohorts of students, cohorts B to H. Student-level engagement measures include students' attendance rates and the number of advanced courses a student took. District-level measures were dropout and graduation rates. Table 10.5 summarizes the level of analysis conducted on each cohort. None of these analyses of student-engagement measures found any significant relationship between RCI participation and student engagement. 
Table 10.5. Summary of Engagement Analyses

\begin{tabular}{|c|c|c|c|c|c|c|c|c|}
\hline \multirow[b]{2}{*}{ Level of Analysis } & \multirow[b]{2}{*}{ Outcome Variable } & \multicolumn{6}{|c|}{ Cohort } & \multirow[b]{2}{*}{$\mathbf{H}$} \\
\hline & & B & C & D & $E$ & $\mathbf{F}$ & $\mathbf{G}$ & \\
\hline Student level & Attendance rate & & & & & & & \\
\hline & Advanced course & & & & & & & \\
\hline District level & Dropout rate & & & & & & & \\
\hline & Graduation rate & & & & & $\mathrm{N} / \mathrm{A}$ & $\mathrm{N} / \mathrm{A}$ & $\mathrm{N} / \mathrm{A}$ \\
\hline
\end{tabular}

NOTES. Shaded cells indicate cohorts on which student- or district-level engagement analyses were conducted. None of the analyses found a significant relationship between $\mathrm{RCl}$ participation and student engagement measures. Refer to Table 3.1 for additional information about the cohorts and the appendix for technical details about the methods and models used for analyses. Cohorts F, G, and $\mathrm{H}$ were not included in the analysis of graduation rates because these cohorts of students had not reached grade 12 by the fourth program year.

\section{Key Findings}

This chapter examined the relationship between students' participation in the RCI and student outcomes at the individual and district levels for the first four program years. We matched RCI students and districts with similar non-RCI students and districts and examined whether the former had higher student achievement and greater student engagement, after controlling for observable, potential contributors to student achievement and engagement. We also examined whether RCI students and districts made greater gains on student achievement and engagement than their non-RCI counterparts.

None of these analyses found any significant relationship between RCI participation and student outcomes at the individual or district level. However, these results do not enable us to draw any overall conclusions about the association between RCI participation and student outcomes because of limitations in the data available for analysis and measures of participation, the low and inconsistent participation in the RCI, and limitations in the outcome measures to capture the impact of the RCI. 


\section{Key Findings and Recommendations}

This evaluation describes the RCI, a large-scale initiative designed and implemented in 16 school districts in Beaver County and one school district in Lawrence County. The RCI sought to expand school choice for students in grades 7 to 12 in each of these districts by offering four programs: Open Seats, Dual Enrollment, Cyber Learning, and Academies for Success. Using measures developed prior to the start of the RCI, we evaluated the performance of the individual programs and the RCI overall. We also identified aspects of implementation that facilitated or hindered the performance of the RCI. This chapter summarizes the key findings related to the performance measures, the impact evaluation of the RCI as it relates to student outcomes, and implications of the initiative.

\section{The RCI Did Not Achieve the Majority of the Performance Measures}

The RCI did not achieve the majority of the performance and objective measures. Of the 21 measures, it achieved eight by the end of the funding period. The RCI was most successful in achieving the objective measures - activities that did not rely on student participation. An example of an objective is providing transportation to students participating in Open Seats courses. Performance measures almost always depended on the number of students participating in a program and the performance of students in those courses. There are two key barriers to the attainment of the goals: student recruitment and student participation in the RCI.

\section{Student Recruitment}

Student recruitment was a challenge for the RCI. There were a number of reasons why the $\mathrm{RCI}$ struggled to recruit students. The program targeted students from low-performing districts and low-performing or disengaged students in all other districts. RCI administrators communicated the target population to schools and consistently provided definitions for identifying these students. However, the definition did not provide explicit data indicators or benchmarks to identify students who were "not reaching their fullest potential." School stakeholders reported "erring on the side of caution" when recruiting a student for the RCI. If they were not confident a student was not meeting his or her "full potential," staff did not recruit the student.

The requirement to enroll low- or underperforming students or disengaged students created recruitment challenges for the Dual Enrollment program. School stakeholders were hesitant to recruit the target population of students for the program because they may experience failure in the course. There was concern that failure in the course could result in students' negatively perceiving their readiness and plans for postsecondary education. Schools also hesitated to 
recruit students for the Dual Enrollment program because high-achieving students could not participate in the program. Stakeholders from schools expressed concern about informing parents that students could not exercise the option because they were too high performing.

Districts were also reluctant to recruit students for the Cyber Learning program. In the early years of the RCI, school stakeholders feared that the program would result in a "mass exodus" of students from the traditional school. They perceived that the majority of students would exercise the choice to complete all courses online and would not attend school. Low student attendance could have resulted in staffing changes and an "empty" school building.

RCI administrators executed a media campaign to inform parents and students in the region of the RCI. They implemented a number of strategies and expanded their efforts over the RCI period. Although data must be interpreted with caution, a survey of households with parents in grades 7 to 12 revealed low knowledge and awareness of the RCI. This suggests that the primary mechanism for student recruitment was school stakeholders. And these stakeholders reported cautious and narrow efforts to recruit students to the RCI.

\section{Student Participation}

A number of factors negatively affected student participation outside of recruitment efforts. Open Seats participation was limited by master schedules. Districts in the region did not run a uniform schedule. Lack of compatible schedules limited the number of schools, and, in turn, courses, available to students. Time required to physically travel between schools prohibited students from taking some classes. Though IVC circumvented travel time, guidance counselors reported that students did not want to take a course using this technology. Students' preference for traditional instruction surpassed their interest in taking the course. Limited sections for Open Seats courses also created scheduling challenges. There were a few sections of advanced courses or levels of foreign language during the day. It was not always possible to build a students' schedule around a class with only one section offering.

Participation in Dual Enrollment was sometimes limited by the characteristics of the target population, specifically low-performing and disengaged students. School stakeholders reported that these students struggled with placement tests required for courses at some schools. Rather than taking the course at a different postsecondary institution, students did not participate in the program. In some cases, the target student population was unwilling to take a course on a college campus without a peer.

Finally, student participation was lower than planned, and many performance measures were based on planned participation in the first program year. As an example, the RCI planned for 125 students to participate in the Open Seats program and earn a passing grade in the course in year 1. Actual enrollment for year 1 of the program was one student. It was not possible to achieve the goal even though the student earned a passing grade, because the number of participating students was far below the expected level. Measures for the subsequent years planned for growth in the number of participants, using 125 students as the baseline. Student participation increased 
each year. However, the gap between the planned and actual participation was quite large and would have persisted even if the number of students participating increased by the planned amount. According to stakeholders, the performance goals were unattainable from the outset of the initiative.

\section{The RCl's Impact on Student Outcomes Is Not Evident in the Limited Available Data}

Stakeholders perceived that the RCI provided critical opportunities to students. Yet few students in the region participated in these opportunities each year or for more than one year. That is, participation was low and inconsistent. We were not able to measure the impact of the initiative on all participants because most participating districts did not provide student-level data for analysis. Insufficient data limited the statistical power of our analyses and therefore our ability to identify program effects.

Overall, we did not find a discernible effect on student outcomes at the school and district levels. One possible reason for this is that the PSSA, which we used to measure effects, does not measure changes in students' willingness to attend school, persistence in the face of academic adversity, or plans to graduate. Furthermore, students' willingness to engage with curriculum did not result in immediate changes in their academic performance, particularly for low- or underperforming, disengaged students. At the same time, given data limitations, as well as measurements that were not ideally suited for targeted program outcomes, it is unlikely that we could have detected any program effects on student outcomes.

\section{Stakeholders Perceive That the RCl Affected the Region}

The RCI did not attain most of its performance goals, and the initiative did not have a discernible impact on student outcomes. Yet throughout the final three years of the initiative, stakeholders reported that the RCI and its programs provided important opportunities to students. Each program was valuable in supporting the needs of students. Stakeholders also agreed that the initiative transformed partnerships between districts in the region, including greater communication and collaboration between districts. They identified the transformation as one of the greatest successes of the RCI. Stakeholders reported that the RCI and the work of its administrators transformed the climate and culture of the county. Districts committed to sustaining three of the four RCI programs without external funding. Continued collaboration of this type requires considerable partnership and cohesion between districts that are not required to work together. Though districts were hesitant to participate in the RCI early on, their decision to sustain the majority of the programs without external funding indicates strong commitment and support. 


\section{Recommendations}

Findings from this project lead to three recommendations regarding the design and implementation of similar programs in the future: Test feasibility prior to full implementation, develop a strong multitiered communication strategy, and establish a rigorous data collection system.

\section{Feasibility Test}

It is important to test the feasibility of designed program features and the implementation plan before the full implementation of the program. This feasibility study should examine the demand for the expected program, readiness and capacity of participating organizations, and problems that may arise during the implementation.

For the case of the RCI, a feasibility study might have helped guide the design of the program. For instance, a survey of the target student population and parents might have been carried out to assess the demand for Cyber Learning courses, perceptions of course taking through virtual-learning technologies, or the academic readiness of the target population for college-level courses at higher-education institutions. Results from this survey could have helped RCI administrators better design recruitment strategies for the RCI and set up more-appropriate program performance goals.

A survey or interviews of district stakeholders during the program design stage could have helped the program designers assess districts' readiness for participating in the initiative and sharing students. Survey and interview results could have helped the designers assess districts' capacity in providing the data required for the evaluation and plan for supporting participating districts with the collection of student administrative data.

In addition, a thorough analysis of the challenges that may arise during the implementation of RCI programs at the program design stage may have helped identify problems, such as school stakeholders' concerns about funding sources and the lack of comparable schedules across participating districts.

\section{Communication Strategy}

A strong multitiered communication strategy to communicate program information to the target student population and parents may help recruit students directly for the program and counter the potential difficulty in recruiting students through school stakeholders. The RCI implemented a marketing campaign throughout the region and asked participating schools to recruit students for the program. Yet participation rates in the program were very low. While there is strong evidence that low participation is related to lack of widespread recruitment efforts from districts, low participation may also be due to lack of knowledge and awareness of the initiative among families and students in the region. The enacted approach to recruitment may not have built sufficient knowledge and awareness of the RCI. Further, recruiting the target 
population of students for initiatives such as the RCI may present particular challenges. Experts in communication may support the development of effective campaigns that appeal to the target population and encourage recruitment.

\section{Data Collection System}

It is important to have a rigorous data collection system. Although RCI administrators worked with technology specialists to develop a data management system to monitor program implementation, the system experienced errors at the data-entry stage, which proved costly. Despite efforts to clean these data, questions remained about the accuracy of the data available for program evaluation purposes. Using a dashboard system from the beginning to monitor the implementation and facilitate communication with stakeholders may help improve the program implementation and its potential impact. This dashboard system requires careful design to make sure it provides information that program administrators need to assess the implementation of the program and the evaluation of the program. It may also provide channels to solicit feedback from a large number of stakeholders in a timely manner, such as online surveys of school staff members and students.

The design of this dashboard system should include various types of expertise, including the program administrators, district and school administrators and data specialists, technology specialists, the school staff who will be responsible for data entry, and the program evaluator. It is also important to build in data-auditing functions or activities in the design and use of this dashboard system to ensure that the program implementation data captured by this system are accurate. 


\section{Appendix: Student Outcome Analysis Methods and Results}

This appendix contains additional information related to the student outcome analysis discussed in Chapter Ten, including the methods used to conduct student outcome analysis and detailed results.

\section{Analytic Approach}

We used a quasi-experimental design to examine the association between RCI participation and student outcomes. Specifically, we used propensity score matching to identify equivalent comparison groups at the district and student levels and analyzed differences between the RCI group and comparison group on each outcome variable of interest in each program year. In order to control for the influence of any unobserved variables on the relationship between RCI participation and student outcomes, we also used a difference-in-difference approach and compared RCI districts and students with their corresponding comparison groups on the change in the target student outcomes between the baseline year (i.e., 2006-2007) and each of the first four program years.

To conduct propensity score matching, we estimated the propensity score of each district and student to participate in the RCI based on observable, available district and student characteristics. The propensity score represents the probability of a district or student being assigned to the RCI group, conditional on a set of observed covariates. The following logistic model was used to estimate propensity scores:

$$
\ln \left(\frac{P}{1-P}\right)=X_{i j} \beta_{j}
$$

where $P$ denotes $P\left(W_{i}\right)$, representing the conditional probability of a district or a student participating in the RCI. $W_{i}=1$ if a district or a student participated in the RCI, and $W_{i}=0$ otherwise. $X_{i j}$ represents a vector of $j$ observed covariates that were used to estimate the conditional probability of a district or student being in the RCI group for district or student $i$. $\beta_{j}$ represents the corresponding regression coefficient vector for $j$ covariates in $X$.

At the district level, covariates used to estimate the propensity scores include district-level demographic, achievement, and economic characteristics in the baseline year (i.e., the 20062007 school year, the year before the start of the RCI). These covariates include the percentage of 11th-grade students who scored at or above the proficiency level on the PSSA mathematics and reading tests, enrollment size, the percentages of boys and black and Hispanic students, the percentage of students eligible for free and reduced-price lunch, total expenditures per student, the dropout rate for students at grades 7-12, and the graduation rate for 12th-grade students.

At the student level, covariates used to estimate the propensity scores include student gender, ethnicity, and eligibility for free and reduced-price lunch and individual education programs and 
student outcome variables in the baseline year, including scaled scores on the PSSA mathematics and reading achievement tests, attendance rates, and enrollment in advanced courses.

After we obtained the propensity scores for individual districts or students, we identified an equivalent comparison group for RCI districts and students using the generated propensity scores as weights. Once we achieved equivalence between the RCI group and comparison groups, we estimated the average treatment effect on the treated (ATT; Angrist \& Pischke, 2008) on each target student outcome in each program year and the growth in each target student outcome between the baseline year and each program year at the district and students levels.

\section{Implementation of the Analysis Approaches}

For the student sample, we conducted multiple imputations to deal with the issue of missing values (Schafer, 1999). Variables used for multiple imputation included gender, ethnicity, and eligibility for free and reduced-price lunch and individual education programs. Missing values in students' scaled scores on the PSSA mathematics and reading tests at grades 11, 8, and 7; attendance rates in the prior school year; and enrollment in advanced courses were imputed. Because the multiple imputation method is based on a series of assumptions about the missing values and the soundness of the imputation model, there is potential risk of introducing additional bias in the results when using this approach. We implemented the analysis approach on both the subsample of students with complete data required for analysis and the imputed sample and compared the results between two sets of samples to test the sensitivity of findings.

We implemented these analyses in the twang package (Griffin et al., 2014) in $R$ (R Core Team, 2014). The twang package was developed specifically for weighting and analysis of observational data for causal inferences.

As we conducted multiple tests on the differences between RCI districts and students and comparison groups, we used the Benjamini and Hochberg (1995) method to control for the false significant rate, at 5 percent across all tests.

\section{Results}

\section{District-Level Results}

Table A.1 shows the evidence of equivalence between the RCI and identified comparison groups before the implementation of the program at the district level. We identified ten variables to match RCI and non-RCI districts before the implementation of the RCI. Before propensity score weighting, the difference between the RCI group and the unweighted comparison group on graduation rate was significant $(p=0.04)$, and difference in the percentage of Hispanic students was close to being significant $(p=0.08)$. Differences in other matching variables were unsignificant before propensity score weighting. After propensity score weighting, none of the 
differences between two groups was significant, which indicates that equivalence was established between two groups. 
Table A.1. Equivalence Between RCl and Comparison Districts at Baseline

\begin{tabular}{|c|c|c|c|c|c|c|c|c|c|c|}
\hline \multirow[b]{2}{*}{ Variables Used for Propensity Score Matching } & \multicolumn{2}{|c|}{$\mathrm{RCI}$} & \multicolumn{4}{|c|}{$\begin{array}{l}\text { Comparison Group After } \\
\text { Propensity Score Weighting }\end{array}$} & \multicolumn{4}{|c|}{$\begin{array}{l}\text { Comparison Group Before } \\
\text { Propensity Score Weighting }\end{array}$} \\
\hline & Mean & SD & Mean & SD & $\begin{array}{l}\text { STD } \\
\text { EFF } \\
\text { SIZE }\end{array}$ & $p$ & Mean & SD & $\begin{array}{l}\text { STD } \\
\text { EFF } \\
\text { SIZE }\end{array}$ & $p$ \\
\hline $\begin{array}{l}\text { Percentage of } 11 \text { th graders who scored at or above the proficiency level } \\
\text { on PSSA reading test in the 2006-2007 school year }\end{array}$ & 69.42 & 7.95 & 69.44 & 9.42 & -0.00 & 0.99 & 67.52 & 9.97 & 0.24 & 0.36 \\
\hline $\begin{array}{l}\text { Percentage of } 11 \text { th graders who scored at or above the proficiency level } \\
\text { on PSSA mathematics test in the 2006-2007 school year }\end{array}$ & 56.49 & 11.32 & 55.61 & 11.27 & 0.08 & 0.79 & 53.23 & 11.64 & 0.29 & 0.27 \\
\hline Enrollment size in the 2006-2007 school year & $1,786.73$ & 668.73 & $1,799.79$ & 704.90 & -0.02 & 0.94 & $1,807.32$ & 886.74 & -0.03 & 0.91 \\
\hline Percentage of boys in the 2006-2007 school year & 0.50 & 0.07 & 0.51 & 0.02 & -0.19 & 0.45 & 0.51 & 0.02 & -0.18 & 0.47 \\
\hline Percentage of black students in the 2006-2007 school year & 0.12 & 0.20 & 0.09 & 0.16 & 0.17 & 0.52 & 0.04 & 0.10 & 0.40 & 0.12 \\
\hline Percentage of Hispanic students in the 2006-2007 school year & 0.00 & 0.01 & 0.00 & 0.01 & -0.14 & 0.64 & 0.01 & 0.01 & -0.45 & 0.08 \\
\hline $\begin{array}{l}\text { Percentage of students eligible for free and reduced-price lunch in the } \\
2006-2007 \text { school year }\end{array}$ & 0.34 & 0.18 & 0.32 & 0.15 & 0.11 & 0.70 & 0.32 & 0.14 & 0.14 & 0.58 \\
\hline Total expenditure per student in the 2006-07 school year & $12,018.20$ & $3,149.16$ & $11,190.01$ & $2,408.60$ & 0.26 & 0.32 & $\begin{array}{c}11,237.4 \\
4\end{array}$ & $2,446.92$ & 0.25 & 0.33 \\
\hline Dropout rate in the 2006-2007 school year & 1.25 & 0.73 & 1.27 & 0.85 & -0.02 & 0.94 & 1.15 & 0.85 & 0.14 & 0.59 \\
\hline Graduation rate in the 2006-2007 school year & 0.80 & 0.11 & 0.82 & 0.10 & -0.20 & 0.47 & 0.85 & 0.09 & -0.51 & 0.04 \\
\hline
\end{tabular}

NOTES: SD = standard deviation; STD EFF SIZE = standardized effect size. N_RCI = 16. N_Comparison = 252. Certain restrictions were applied to the percentage of Hispanic students and the enrollment size to make the pool of comparison districts was more similar to the pool of RCI districts. 
Tables A.2 shows the raw and adjusted $p$-values for RCI participation in the district-level analysis. None of the analyses found any effect of RCI participation at the district level.

Table A.2. Results of the ATT Analysis at the District Level

\begin{tabular}{|c|c|c|c|}
\hline Outcome Variable Included in the Analysis & Est. Coef. & Std. Err. & p.adjust \\
\hline $\begin{array}{l}\text { Percentage of } 11 \text { th graders who scored at or above the proficiency level in PSSA } \\
\text { mathematics test in the } 2010-2011 \text { school year }\end{array}$ & -2.99 & 4.09 & 0.992 \\
\hline $\begin{array}{l}\text { Percentage of } 11 \text { th graders who scored at or above the proficiency level in PSSA } \\
\text { mathematics test in the 2009-2010 school year }\end{array}$ & -2.12 & 4.87 & 0.992 \\
\hline $\begin{array}{l}\text { Percentage of } 11 \text { th graders who scored at or above the proficiency level in PSSA } \\
\text { mathematics test in the } 2008-2009 \text { school year }\end{array}$ & 2.53 & 3.95 & 0.992 \\
\hline $\begin{array}{l}\text { Percentage of } 11 \text { th graders who scored at or above the proficiency level in PSSA } \\
\text { mathematics test in the } 2007-2008 \text { school year }\end{array}$ & 2.58 & 3.68 & 0.992 \\
\hline $\begin{array}{l}\text { Percentage of 11th graders who scored at or above the proficiency level in PSSA reading } \\
\text { test in the 2010-2011 school year }\end{array}$ & -1.66 & 2.95 & 0.992 \\
\hline $\begin{array}{l}\text { Percentage of } 11 \text { th graders who scored at or above the proficiency level in PSSA reading } \\
\text { test in the 2009-2010 school year }\end{array}$ & -0.74 & 4.06 & 0.992 \\
\hline $\begin{array}{l}\text { Percentage of } 11 \text { th graders who scored at or above the proficiency level in PSSA reading } \\
\text { test in the 2008-2009 school year }\end{array}$ & 0.98 & 3.91 & 0.992 \\
\hline $\begin{array}{l}\text { Percentage of 11th graders who scored at or above the proficiency level in PSSA reading } \\
\text { test in the 2007-2008 school year }\end{array}$ & 0.45 & 3.16 & 0.992 \\
\hline Dropout rate in the 2009-2010 school year & 0.00 & 0.00 & 0.994 \\
\hline Dropout rate in the 2008-2009 school year & 0.00 & 0.00 & 0.994 \\
\hline Dropout rate in the 2007-2008 school year & 0.00 & 0.00 & 0.992 \\
\hline Graduation rate in the 2009-2010 school year & -0.01 & 0.04 & 0.992 \\
\hline Graduation rate in the $2008-2009$ school year & -0.04 & 0.03 & 0.992 \\
\hline Graduation rate in the 2009-2010 school year & -0.03 & 0.03 & 0.992 \\
\hline $\begin{array}{l}\text { Difference in the percentage of } 11 \text { th graders who scored at or above the proficiency level } \\
\text { in the PSSA mathematics test between the baseline and 2007-2008 school year }\end{array}$ & 1.70 & 3.37 & 0.992 \\
\hline $\begin{array}{l}\text { Difference in the percentage of } 11 \text { th graders who scored at or above the proficiency level } \\
\text { in the PSSA mathematics test between the baseline and 2008-2009 school year }\end{array}$ & 1.65 & 2.85 & 0.992 \\
\hline $\begin{array}{l}\text { Difference in the percentage of } 11 \text { th graders who scored at or above the proficiency level } \\
\text { in the PSSA mathematics test between the baseline and 2009-2010 school year }\end{array}$ & -2.89 & 4.18 & 0.992 \\
\hline $\begin{array}{l}\text { Difference in the percentage of } 11 \text { th graders who scored at or above the proficiency level } \\
\text { in the PSSA mathematics test between the baseline and 2010-2011 school year }\end{array}$ & -3.77 & 3.10 & 0.992 \\
\hline $\begin{array}{l}\text { Difference in the percentage of } 11 \text { th graders who scored at or above the proficiency level } \\
\text { in the PSSA reading test between the baseline and } 2007-2008 \text { school year }\end{array}$ & 0.47 & 2.73 & 0.992 \\
\hline $\begin{array}{l}\text { Difference in the percentage of } 11 \text { th graders who scored at or above the proficiency level } \\
\text { in the PSSA reading test between the baseline and 2008-2009 school year }\end{array}$ & 1.00 & 3.57 & 0.992 \\
\hline $\begin{array}{l}\text { Difference in the percentage of } 11 \text { th graders who scored at or above the proficiency level } \\
\text { in the PSSA reading test between the baseline and 2009-2010 school year }\end{array}$ & 0.03 & 3.49 & 0.994 \\
\hline $\begin{array}{l}\text { Difference in the percentage of } 11 \text { th graders who scored at or above the proficiency level } \\
\text { in the PSSA reading test between the baseline and 2010-2011 school year }\end{array}$ & -0.89 & 3.06 & 0.992 \\
\hline Difference in the dropout rate between the baseline and the 2007-2008 school year & 0.49 & 0.49 & 0.992 \\
\hline Difference in the dropout rate between the baseline and the 2008-2009 school year & 0.49 & 0.49 & 0.992 \\
\hline Difference in the dropout rate between the baseline and the 2009-2010 school year & 0.61 & 0.54 & 0.992 \\
\hline Difference in the graduation rate between the baseline and the 2007-2008 school year & -0.01 & 0.02 & 0.992 \\
\hline Difference in the graduation rate between the baseline and the 2008-2009 school year & -0.02 & 0.02 & 0.992 \\
\hline Difference in the graduation rate between the baseline and the 2009-2010 school year & 0.01 & 0.03 & 0.992 \\
\hline
\end{tabular}




\section{Student-Level Results}

Tables A.3.-A.22. show the means and standard deviations of the covariates included in the analysis before and after propensity score matching and the standardized differences between two groups and the associated $p$-values. These tables show that equivalence was established between the RCI participants and comparison groups in each analysis at the student level through propensity score matching.

Tables A.23.-A.24. summarize the results of the ATT analyses at the student level. Analyses on the associations between RCI participation and 11th-grade RCI participants' PSSA scores in 2008-2009 and 2007-2008 could not be conducted because of the small number of participants with PSSA test scores at grades 8 and 11. Overall, none of the analyses found a significant positive association between RCI participation and student outcomes. The analyses using historical comparison groups found that RCI participants in 2009-2010 and 2010-2011 enrolled in fewer advanced courses, and 11th-grade participants in 2009-2010 had smaller gains in their PSSA reading scores between grade 8 and 11 than their historical counterparts. However, such findings were not consistently found in the analyses using contemporary comparison students. Given other concerns about the adequacy of data available to support a thorough analysis of the associations between RCI participation and student outcomes, we concluded that these few negative findings did not necessarily represent the true impact of RCI participation on student outcomes. 
Table A.3. Equivalence Between 11th Grade RCI Participants in 2010-2011 and the Contemporary-Comparison Students at Baseline

\begin{tabular}{|c|c|c|c|c|c|c|c|c|c|c|}
\hline \multirow[b]{2}{*}{ Variables Used for Propensity Score Matching } & \multicolumn{2}{|c|}{$\mathbf{R C l}$} & \multicolumn{4}{|c|}{$\begin{array}{l}\text { Comparison Group After } \\
\text { Propensity Score Weighting }\end{array}$} & \multicolumn{4}{|c|}{$\begin{array}{l}\text { Comparison Group Before } \\
\text { Propensity Score Weighting }\end{array}$} \\
\hline & Mean & SD & Mean & SD & $\begin{array}{l}\text { STD } \\
\text { EFF } \\
\text { SIZE }\end{array}$ & $p$ & Mean & SD & $\begin{array}{l}\text { STD } \\
\text { EFF } \\
\text { SIZE }\end{array}$ & $p$ \\
\hline Scale score on the PSSA reading test in the 2006-2007 school year & $1,395.07$ & 309.58 & $1,402.91$ & 308.70 & -0.03 & 0.88 & $1,350.27$ & 301.73 & 0.14 & 0.30 \\
\hline $\begin{array}{l}\text { Scale score on the PSSA mathematics test in the 2006-2007 school } \\
\text { year }\end{array}$ & $1,384.98$ & 297.36 & $1,370.67$ & 265.95 & 0.05 & 0.75 & $1,305.86$ & 285.47 & 0.27 & 0.06 \\
\hline Male & 0.57 & 0.49 & 0.55 & 0.50 & 0.04 & 0.79 & 0.48 & 0.50 & 0.18 & 0.17 \\
\hline Nonwhite student & 0.34 & 0.47 & 0.29 & 0.46 & 0.10 & 0.48 & 0.26 & 0.44 & 0.17 & 0.18 \\
\hline Eligible for free and reduced-price lunch & 0.36 & 0.48 & 0.62 & 0.49 & 0.06 & 0.70 & 0.42 & 0.49 & -0.14 & 0.29 \\
\hline Eligible for individual education program & 0.10 & 0.30 & 0.10 & 0.30 & -0.00 & 1.00 & 0.16 & 0.37 & -0.20 & 0.20 \\
\hline
\end{tabular}

NOTES: SD = standard deviation; STD EFF SIZE = standardized effect size. N_RCI = 70. N_Comparison $=349$. 
Table A.4. Equivalence Between 11th-Grade RCI Participants in 2009-2010 and the Contemporary-Comparison Students at Baseline

\begin{tabular}{|c|c|c|c|c|c|c|c|c|c|c|}
\hline \multirow[b]{2}{*}{ Variables Used for Propensity Score Matching } & \multicolumn{2}{|c|}{$\mathbf{R C l}$} & \multicolumn{4}{|c|}{$\begin{array}{l}\text { Comparison Group After } \\
\text { Propensity Score Weighting }\end{array}$} & \multicolumn{4}{|c|}{$\begin{array}{l}\text { Comparison Group Before } \\
\text { Propensity Score Weighting }\end{array}$} \\
\hline & Mean & SD & Mean & SD & $\begin{array}{l}\text { STD } \\
\text { EFF } \\
\text { SIZE }\end{array}$ & $p$ & Mean & SD & $\begin{array}{l}\text { STD } \\
\text { EFF } \\
\text { SIZE }\end{array}$ & $p$ \\
\hline Scale score on the PSSA reading test in the 2006-2007 school year & $1,397.56$ & 187.55 & $1,405.63$ & 187.46 & -0.04 & 0.73 & $1,393.11$ & 302.98 & 0.02 & 0.86 \\
\hline $\begin{array}{l}\text { Scale score on the PSSA mathematics test in the 2006-2007 school } \\
\text { year }\end{array}$ & $1,487.81$ & 226.76 & $1,501.49$ & 224.98 & -0.06 & 0.66 & $1,411.41$ & 307.62 & 0.34 & 0.01 \\
\hline Male & 0.64 & 0.48 & 0.64 & 0.48 & 0.01 & 0.91 & 0.47 & 0.50 & 0.36 & 0.00 \\
\hline Nonwhite student & 0.30 & 0.46 & 0.25 & 0.43 & 0.09 & 0.46 & 0.18 & 0.39 & 0.25 & 0.01 \\
\hline Eligible for free and reduced-price lunch & 0.58 & 0.49 & 0.58 & 0.49 & 0.01 & 0.97 & 0.63 & 0.48 & -0.10 & 0.33 \\
\hline Eligible for individual education program & 0.04 & 0.20 & 0.05 & 0.21 & -0.02 & 0.83 & 0.15 & 0.36 & -0.58 & 0.00 \\
\hline
\end{tabular}

NOTES: SD = standard deviation; STD EFF SIZE = standardized effect size. N_RCI = 98. N_Comparison $=535$. 
Table A.5. Equivalence Between RCI Participants in 2010-2011 and the Contemporary-Comparison Students at Baseline for Analyses on Attendance Rate

\begin{tabular}{|c|c|c|c|c|c|c|c|c|c|c|}
\hline \multirow[b]{2}{*}{ Variables Used for Propensity Score Matching } & \multicolumn{2}{|c|}{$\mathrm{RCl}$} & \multicolumn{4}{|c|}{$\begin{array}{l}\text { Comparison Group After } \\
\text { Propensity Score Weighting }\end{array}$} & \multicolumn{4}{|c|}{$\begin{array}{l}\text { Comparison Group Before } \\
\text { Propensity Score Weighting }\end{array}$} \\
\hline & Mean & SD & Mean & SD & \begin{tabular}{|l} 
STD \\
EFF \\
SIZE
\end{tabular} & $p$ & Mean & SD & $\begin{array}{l}\text { STD } \\
\text { EFF } \\
\text { SIZE }\end{array}$ & $p$ \\
\hline Attendance rate at baseline & 0.95 & 0.06 & 0.96 & 0.05 & -0.06 & 0.56 & 0.95 & 0.06 & -0.00 & 0.96 \\
\hline Male & 0.59 & 0.49 & 0.59 & 0.49 & -0.00 & 0.98 & 0.48 & 0.50 & 0.21 & 0.02 \\
\hline Nonwhite student & 0.31 & 0.46 & 0.29 & 0.45 & 0.05 & 0.59 & 0.29 & 0.45 & 0.04 & 0.62 \\
\hline Eligible for free and reduced-price lunch & 0.65 & 0.48 & 0.65 & 0.48 & 0.00 & 0.99 & 0.55 & 0.50 & 0.21 & 0.02 \\
\hline Eligible for individual education program & 0.07 & 0.26 & 0.07 & 0.26 & -0.00 & 0.98 & 0.16 & 0.36 & -0.32 & 0.01 \\
\hline
\end{tabular}

NOTES: SD = standard deviation; STD EFF SIZE = standardized effect size. N_RCI = 139. N_Comparison $=1,510$.

Table A.6. Equivalence Between RCI Participants in 2009-2010 and the Contemporary-Comparison Students at Baseline for Analyses on Attendance Rate

\begin{tabular}{|c|c|c|c|c|c|c|c|c|c|c|}
\hline \multirow[b]{2}{*}{ Variables Used for Propensity Score Matching } & \multicolumn{2}{|c|}{$\mathbf{R C I}$} & \multicolumn{4}{|c|}{$\begin{array}{l}\text { Comparison Group After } \\
\text { Propensity Score Weighting }\end{array}$} & \multicolumn{4}{|c|}{$\begin{array}{l}\text { Comparison Group Before } \\
\text { Propensity Score Weighting }\end{array}$} \\
\hline & Mean & SD & Mean & SD & $\begin{array}{l}\text { STD } \\
\text { EFF } \\
\text { SIZE }\end{array}$ & $p$ & Mean & SD & $\begin{array}{l}\text { STD } \\
\text { EFF } \\
\text { SIZE }\end{array}$ & $p$ \\
\hline Attendance rate at baseline & 0.77 & 0.38 & 0.78 & 0.37 & -0.01 & 0.94 & 0.63 & 0.44 & 0.37 & 0.00 \\
\hline Male & 0.58 & 0.49 & 0.58 & 0.49 & 0.01 & 0.89 & 0.48 & 0.50 & 0.20 & 0.01 \\
\hline Nonwhite student & 0.25 & 0.43 & 0.25 & 0.44 & -0.01 & 0.94 & 0.18 & 0.39 & 0.16 & 0.03 \\
\hline Eligible for free and reduced-price lunch & 0.59 & 0.49 & 0.59 & 0.49 & 0.01 & 0.94 & 0.63 & 0.48 & -0.08 & 0.32 \\
\hline Eligible for individual education program & 0.04 & 0.20 & 0.04 & 0.21 & -0.01 & 0.95 & 0.14 & 0.34 & -0.44 & 0.00 \\
\hline
\end{tabular}

NOTES: SD = standard deviation; STD EFF SIZE = standardized effect size. N_RCI $=159$. N_Comparison $=2,408$. 
Table A.7. Equivalence Between RCI Participants in 2008-2009 and the Contemporary-Comparison Students at Baseline for Analyses on Attendance Rate

\begin{tabular}{|c|c|c|c|c|c|c|c|c|c|c|}
\hline \multirow[b]{2}{*}{ Variables Used for Propensity Score Matching } & \multicolumn{2}{|c|}{$\mathrm{RCl}$} & \multicolumn{4}{|c|}{$\begin{array}{l}\text { Comparison Group After } \\
\text { Propensity Score Weighting }\end{array}$} & \multicolumn{4}{|c|}{$\begin{array}{l}\text { Comparison Group Before } \\
\text { Propensity Score Weighting }\end{array}$} \\
\hline & Mean & SD & Mean & SD & $\begin{array}{l}\text { STD } \\
\text { EFF } \\
\text { SIZE }\end{array}$ & $p$ & Mean & SD & $\begin{array}{l}\text { STD } \\
\text { EFF } \\
\text { SIZE }\end{array}$ & $p$ \\
\hline Attendance rate at baseline & 0.95 & 0.05 & 0.95 & 0.04 & -0.08 & 0.41 & 0.95 & 0.04 & -0.08 & 0.37 \\
\hline Male & 0.64 & 0.48 & 0.63 & 0.48 & 0.01 & 0.91 & 0.47 & 0.50 & 0.35 & 0.00 \\
\hline Nonwhite student & 0.06 & 0.24 & 0.06 & 0.24 & -0.00 & 0.98 & 0.16 & 0.37 & -0.39 & 0.00 \\
\hline Eligible for free and reduced-price lunch & 0.76 & 0.43 & 0.76 & 0.42 & -0.00 & 0.96 & 0.68 & 0.47 & 0.20 & 0.04 \\
\hline Eligible for individual education program & 0.10 & 0.30 & 0.10 & 0.30 & 0.01 & 0.88 & 0.14 & 0.35 & -0.13 & 0.21 \\
\hline
\end{tabular}

NOTES: SD = standard deviation; STD EFF SIZE = standardized effect size. N_RCI = 93. N_Comparison $=2,320$.

Table A.8. Equivalence Between RCI Participants in 2007-2008 and the Contemporary-Comparison Students at Baseline for Analyses on Attendance Rate

\begin{tabular}{|c|c|c|c|c|c|c|c|c|c|c|}
\hline \multirow[b]{2}{*}{ Variables Used for Propensity Score Matching } & \multicolumn{2}{|c|}{$\mathbf{R C I}$} & \multicolumn{4}{|c|}{$\begin{array}{l}\text { Comparison Group After } \\
\text { Propensity Score Weighting }\end{array}$} & \multicolumn{4}{|c|}{$\begin{array}{l}\text { Comparison Group Before } \\
\text { Propensity Score Weighting }\end{array}$} \\
\hline & Mean & SD & Mean & SD & $\begin{array}{l}\text { STD } \\
\text { EFF } \\
\text { SIZE }\end{array}$ & $p$ & Mean & SD & $\begin{array}{l}\text { STD } \\
\text { EFF } \\
\text { SIZE }\end{array}$ & $p$ \\
\hline Attendance rate at baseline & 0.92 & 0.09 & 0.93 & 0.08 & -0.14 & 0.40 & 0.94 & 0.05 & -0.31 & 0.05 \\
\hline Male & 0.60 & 0.49 & 0.60 & 0.49 & 0.00 & 0.98 & 0.48 & 0.50 & 0.26 & 0.08 \\
\hline Nonwhite student & 0.15 & 0.35 & 0.12 & 0.33 & 0.07 & 0.64 & 0.06 & 0.23 & 0.26 & 0.01 \\
\hline Eligible for free and reduced-price lunch & 0.69 & 0.46 & 0.73 & 0.44 & -0.10 & 0.48 & 0.77 & 0.42 & -0.18 & 0.18 \\
\hline Eligible for individual education program & 0.15 & 0.35 & 0.15 & 0.36 & -0.02 & 0.89 & 0.15 & 0.35 & -0.01 & 0.97 \\
\hline
\end{tabular}

NOTES: SD = standard deviation; STD EFF SIZE = standardized effect size. N_RCI = 48. N_Comparison $=2,982$. 
Table A.9. Equivalence Between RCI Participants in 2010-2011 and the Contemporary-Comparison Students at Baseline for Analyses on Advanced Course Enrollment

\begin{tabular}{|c|c|c|c|c|c|c|c|c|c|c|}
\hline \multirow[b]{2}{*}{ Variables Used for Propensity Score Matching } & \multicolumn{2}{|c|}{$\mathrm{RCI}$} & \multicolumn{4}{|c|}{$\begin{array}{l}\text { Comparison Group After } \\
\text { Propensity Score Weighting }\end{array}$} & \multicolumn{4}{|c|}{$\begin{array}{l}\text { Comparison Group Before } \\
\text { Propensity Score Weighting }\end{array}$} \\
\hline & Mean & SD & Mean & SD & $\begin{array}{l}\text { STD } \\
\text { EFF } \\
\text { SIZE }\end{array}$ & $p$ & Mean & SD & $\begin{array}{l}\text { STD } \\
\text { EFF } \\
\text { SIZE }\end{array}$ & $p$ \\
\hline The number of advanced course enrolled at baseline & 0.03 & 0.16 & 0.03 & 0.16 & -0.00 & 1.00 & 0.09 & 0.29 & -0.38 & 0.00 \\
\hline Male & 0.59 & 0.49 & 0.59 & 0.49 & 0.00 & 0.99 & 0.48 & 0.50 & 0.21 & 0.02 \\
\hline Nonwhite student & 0.31 & 0.46 & 0.31 & 0.46 & 0.00 & 0.99 & 0.29 & 0.45 & 0.04 & 0.62 \\
\hline Eligible for free and reduced-price lunch & 0.65 & 0.48 & 0.65 & 0.48 & 0.00 & 0.98 & 0.55 & 0.50 & 0.21 & 0.02 \\
\hline Eligible for individual education program & 0.07 & 0.26 & 0.07 & 0.26 & 0.00 & 0.96 & 0.16 & 0.36 & -0.32 & 0.01 \\
\hline
\end{tabular}

NOTES: SD = standard deviation; STD EFF SIZE = standardized effect size. N_RCI = 139. N_Comparison =1,510.

Table A.10. Equivalence Between RCI Participants in 2009-2010 and the Contemporary-Comparison Students at Baseline for Analyses on Advanced Course Enrollment

\begin{tabular}{|c|c|c|c|c|c|c|c|c|c|c|}
\hline \multirow[b]{2}{*}{ Variables Used for Propensity Score Matching } & \multicolumn{2}{|c|}{$\mathrm{RCI}$} & \multicolumn{4}{|c|}{$\begin{array}{l}\text { Comparison Group After } \\
\text { Propensity Score Weighting }\end{array}$} & \multicolumn{4}{|c|}{$\begin{array}{l}\text { Comparison Group Before } \\
\text { Propensity Score Weighting }\end{array}$} \\
\hline & Mean & SD & Mean & SD & $\begin{array}{l}\text { STD } \\
\text { EFF } \\
\text { SIZE }\end{array}$ & $p$ & Mean & SD & $\begin{array}{l}\text { STD } \\
\text { EFF } \\
\text { SIZE }\end{array}$ & $p$ \\
\hline The number of advanced course enrolled at baseline & 0.15 & 0.49 & 0.15 & 0.49 & 0.00 & 0.99 & 0.14 & 0.41 & 0.02 & 0.80 \\
\hline Male & 0.58 & 0.49 & 0.58 & 0.49 & -0.00 & 1.00 & 0.48 & 0.50 & 0.20 & 0.01 \\
\hline Nonwhite student & 0.25 & 0.43 & 0.25 & 0.44 & -0.01 & 0.94 & 0.18 & 0.39 & 0.16 & 0.03 \\
\hline Eligible for free and reduced-price lunch & 0.59 & 0.49 & 0.59 & 0.49 & 0.00 & 0.96 & 0.63 & 0.48 & -0.08 & 0.32 \\
\hline Eligible for individual education program & 0.04 & 0.20 & 0.04 & 0.21 & -0.00 & 0.99 & 0.14 & 0.34 & -0.44 & 0.00 \\
\hline
\end{tabular}

NOTES: SD = standard deviation; STD EFF SIZE = standardized effect size. N_RCI = 159. N_Comparison $=2,408$. 
Table A.11. Equivalence Between RCI Participants in 2008-2009 and the Contemporary-Comparison Students at Baseline for Analyses on Advanced Course Enrollment

\begin{tabular}{|c|c|c|c|c|c|c|c|c|c|c|}
\hline \multirow[b]{2}{*}{ Variables Used for Propensity Score Matching } & \multicolumn{2}{|c|}{$\mathrm{RCl}$} & \multicolumn{4}{|c|}{$\begin{array}{l}\text { Comparison Group After } \\
\text { Propensity Score Weighting }\end{array}$} & \multicolumn{4}{|c|}{$\begin{array}{l}\text { Comparison Group Before } \\
\text { Propensity Score Weighting }\end{array}$} \\
\hline & Mean & SD & Mean & SD & $\begin{array}{l}\text { STD } \\
\text { EFF } \\
\text { SIZE }\end{array}$ & $p$ & Mean & SD & $\begin{array}{l}\text { STD } \\
\text { EFF } \\
\text { SIZE }\end{array}$ & $p$ \\
\hline The number of advanced course enrolled at baseline & 0.46 & 0.83 & 0.46 & 0.82 & 0.00 & 0.99 & 0.27 & 0.60 & 0.24 & 0.03 \\
\hline Male & 0.65 & 0.48 & 0.65 & 0.48 & 0.01 & 0.95 & 0.46 & 0.50 & 0.41 & 0.00 \\
\hline Nonwhite student & 0.02 & 0.15 & 0.02 & 0.15 & 0.00 & 0.99 & 0.14 & 0.35 & -0.78 & 0.00 \\
\hline Eligible for free and reduced-price lunch & 0.80 & 0.40 & 0.80 & 0.40 & 0.01 & 0.94 & 0.72 & 0.45 & 0.20 & 0.10 \\
\hline Eligible for individual education program & 0.12 & 0.32 & 0.12 & 0.32 & 0.00 & 0.99 & 0.15 & 0.35 & -0.10 & 0.42 \\
\hline
\end{tabular}

NOTES: SD = standard deviation; STD EFF SIZE = standardized effect size. N_RCI = 93. N_Comparison = 2,320.

Table A.12. Equivalence Between RCI Participants in 2007-2008 and the Contemporary-Comparison Students at Baseline for Analyses on Advanced Course Enrollment

\begin{tabular}{|c|c|c|c|c|c|c|c|c|c|c|}
\hline \multirow[b]{2}{*}{ Variables Used for Propensity Score Matching } & \multicolumn{2}{|c|}{$\mathbf{R C l}$} & \multicolumn{4}{|c|}{$\begin{array}{l}\text { Comparison Group After } \\
\text { Propensity Score Weighting }\end{array}$} & \multicolumn{4}{|c|}{$\begin{array}{l}\text { Comparison Group Before } \\
\text { Propensity Score Weighting }\end{array}$} \\
\hline & Mean & SD & Mean & SD & \begin{tabular}{|l} 
STD \\
EFF \\
SIZE
\end{tabular} & $\mathbf{P}$ & Mean & SD & $\begin{array}{l}\text { STD } \\
\text { EFF } \\
\text { SIZE }\end{array}$ & $\mathbf{P}$ \\
\hline The number of advanced course enrolled at baseline & 0.10 & 0.30 & 0.10 & 0.30 & -0.00 & 0.98 & 0.17 & 0.55 & -0.24 & 0.19 \\
\hline Male & 0.59 & 0.49 & 0.59 & 0.49 & -0.00 & 1.00 & 0.48 & 0.50 & 0.22 & 0.17 \\
\hline Nonwhite student & 0.13 & 0.33 & 0.12 & 0.32 & 0.03 & 0.85 & 0.07 & 0.26 & 0.16 & 0.20 \\
\hline Eligible for free and reduced-price lunch & 0.64 & 0.48 & 0.65 & 0.48 & -0.02 & 0.90 & 0.74 & 0.44 & -0.21 & 0.15 \\
\hline Eligible for individual education program & 0.18 & 0.38 & 0.17 & 0.38 & 0.02 & 0.89 & 0.15 & 0.36 & 0.07 & 0.67 \\
\hline
\end{tabular}

NOTES: SD = standard deviation; STD EFF SIZE = standardized effect size. N_RCI = 48. N_Comparison $=2,982$. 
Table A.13. Equivalence Between 11th-Grade RCI Participants in 2010-2011 and the Historical-Comparison Students

\begin{tabular}{|c|c|c|c|c|c|c|c|c|c|c|}
\hline \multirow[b]{2}{*}{ Variables Used for Propensity Score Matching } & \multicolumn{2}{|c|}{ RCI } & \multicolumn{4}{|c|}{$\begin{array}{l}\text { Comparison Group After } \\
\text { Propensity Score Weighting }\end{array}$} & \multicolumn{4}{|c|}{$\begin{array}{l}\text { Comparison Group Before } \\
\text { Propensity Score Weighting }\end{array}$} \\
\hline & Mean & SD & Mean & SD & $\begin{array}{l}\text { STD } \\
\text { EFF } \\
\text { SIZE }\end{array}$ & $p$ & Mean & SD & $\begin{array}{l}\text { STD } \\
\text { EFF } \\
\text { SIZE }\end{array}$ & $p$ \\
\hline Scale score on the PSSA reading test at grade 8 & $1,407.16$ & 217.45 & $1,397.84$ & 223.26 & 0.04 & 0.82 & $1,257.91$ & 265.73 & 0.69 & 0.00 \\
\hline Scale score on the PSSA mathematics test at grade 8 & $1,511.90$ & 284.40 & $1,490.81$ & 316.77 & 0.07 & 0.74 & $1,255.35$ & 288.03 & 0.90 & 0.00 \\
\hline Male & 0.57 & 0.49 & 0.61 & 0.49 & -0.07 & 0.63 & 0.50 & 0.50 & 0.15 & 0.23 \\
\hline Nonwhite student & 0.34 & 0.47 & 0.33 & 0.47 & 0.02 & 0.91 & 0.24 & 0.42 & 0.23 & 0.04 \\
\hline Eligible for free and reduced-price lunch & 0.64 & 0.48 & 0.61 & 0.49 & 0.06 & 0.72 & 0.73 & 0.45 & -0.18 & 0.12 \\
\hline Eligible for individual education program & 0.10 & 0.30 & 0.09 & 0.28 & 0.04 & 0.79 & 0.06 & 0.24 & 0.12 & 0.23 \\
\hline
\end{tabular}

NOTES: SD = standard deviation; STD EFF SIZE = standardized effect size. N_RCI = 70. N_Comparison $=963$. 
Table A.14. Equivalence Between 11th-Grade RCI Participants in 2009-2010 and the Historical-Comparison Students

\begin{tabular}{|c|c|c|c|c|c|c|c|c|c|c|}
\hline \multirow[b]{2}{*}{ Variables Used for Propensity Score Matching } & \multicolumn{2}{|c|}{$\mathrm{RCI}$} & \multicolumn{4}{|c|}{$\begin{array}{l}\text { Comparison Group After } \\
\text { Propensity Score Weighting }\end{array}$} & \multicolumn{4}{|c|}{$\begin{array}{l}\text { Comparison Group Before } \\
\text { Propensity Score Weighting }\end{array}$} \\
\hline & Mean & SD & Mean & SD & $\begin{array}{l}\text { STD } \\
\text { EFF } \\
\text { SIZE }\end{array}$ & $p$ & Mean & SD & $\begin{array}{l}\text { STD } \\
\text { EFF } \\
\text { SIZE }\end{array}$ & $p$ \\
\hline Scale score on the PSSA reading test at grade 8 & $1,397.56$ & 187.55 & $1,370.47$ & 202.78 & 0.14 & 0.28 & $1,266.49$ & 271.43 & 0.70 & 0.00 \\
\hline Scale score on the PSSA mathematics test at grade 8 & $1,487.81$ & 226.76 & $1,456.83$ & 260.02 & 0.14 & 0.38 & $1,271.58$ & 290.17 & 0.95 & 0.00 \\
\hline Male & 0.64 & 0.48 & 0.58 & 0.49 & 0.13 & 0.30 & 0.50 & 0.50 & 0.30 & 0.01 \\
\hline Nonwhite student & 0.30 & 0.46 & 0.29 & 0.45 & 0.02 & 0.86 & 0.17 & 0.38 & 0.27 & 0.00 \\
\hline Eligible for free and reduced-price lunch & 0.58 & 0.49 & 0.59 & 0.49 & -0.01 & 0.93 & 0.79 & 0.41 & -0.42 & 0.00 \\
\hline Eligible for individual education program & 0.04 & 0.20 & 0.04 & 0.19 & 0.01 & 0.88 & 0.06 & 0.23 & -0.07 & 0.55 \\
\hline
\end{tabular}

NOTES: SD = standard deviation; STD EFF SIZE = standardized effect size. N_RCI = 98. N_Comparison $=1,387$. 
Table A.15. Equivalence Between RCI Participants in 2010-2011 and the Historical-Comparison Students for Analyses on Attendance Rate

\begin{tabular}{|c|c|c|c|c|c|c|c|c|c|c|}
\hline \multirow[b]{2}{*}{ Variables Used for Propensity Score Matching } & \multicolumn{2}{|c|}{$\mathrm{RCI}$} & \multicolumn{4}{|c|}{$\begin{array}{l}\text { Comparison Group After } \\
\text { Propensity Score Weighting }\end{array}$} & \multicolumn{4}{|c|}{$\begin{array}{l}\text { Comparison Group Before } \\
\text { Propensity Score Weighting }\end{array}$} \\
\hline & Mean & SD & Mean & SD & \begin{tabular}{|l} 
STD \\
EFF \\
SIZE
\end{tabular} & $p$ & Mean & SD & $\begin{array}{l}\text { STD } \\
\text { EFF } \\
\text { SIZE }\end{array}$ & $P$ \\
\hline Attendance rate in the previous school year & 0.91 & 0.17 & 0.93 & 0.09 & -0.11 & 0.28 & 0.94 & 0.06 & -0.14 & 0.10 \\
\hline Male & 0.59 & 0.49 & 0.58 & 0.49 & 0.02 & 0.82 & 0.48 & 0.50 & 0.22 & 0.01 \\
\hline Nonwhite student & 0.31 & 0.46 & 0.29 & 0.45 & 0.04 & 0.66 & 0.26 & 0.44 & 0.10 & 0.23 \\
\hline Eligible for free and reduced-price lunch & 0.65 & 0.48 & 0.65 & 0.48 & 0.00 & 0.98 & 0.67 & 0.47 & -0.06 & 0.52 \\
\hline Eligible for individual education program & 0.07 & 0.26 & 0.07 & 0.26 & -0.00 & 1.00 & 0.07 & 0.25 & 0.03 & 0.77 \\
\hline
\end{tabular}

NOTES: SD = standard deviation; STD EFF SIZE = standardized effect size. N_RCI = 139. N_Comparison $=2,092$.

Table A.16. Equivalence Between RCI Participants in 2009-2010 and the Historical-Comparison Students for Analyses on Attendance Rate

\begin{tabular}{|c|c|c|c|c|c|c|c|c|c|c|}
\hline \multirow[b]{2}{*}{ Variables Used for Propensity Score Matching } & \multicolumn{2}{|c|}{$\mathrm{RCI}$} & \multicolumn{4}{|c|}{$\begin{array}{l}\text { Comparison Group After } \\
\text { Propensity Score Weighting }\end{array}$} & \multicolumn{4}{|c|}{$\begin{array}{l}\text { Comparison Group Before } \\
\text { Propensity Score Weighting }\end{array}$} \\
\hline & Mean & SD & Mean & SD & $\begin{array}{l}\text { STD } \\
\text { EFF } \\
\text { SIZE }\end{array}$ & $p$ & Mean & SD & $\begin{array}{l}\text { STD } \\
\text { EFF } \\
\text { SIZE }\end{array}$ & $P$ \\
\hline Attendance rate in the previous school year & 0.95 & 0.04 & 0.95 & 0.04 & -0.01 & 0.90 & 0.94 & 0.05 & 0.12 & 0.15 \\
\hline Male & 0.58 & 0.49 & 0.59 & 0.49 & -0.00 & 0.98 & 0.48 & 0.50 & 0.21 & 0.01 \\
\hline Nonwhite student & 0.25 & 0.43 & 0.25 & 0.43 & 0.01 & 0.92 & 0.19 & 0.39 & 0.15 & 0.04 \\
\hline Eligible for free and reduced-price lunch & 0.59 & 0.49 & 0.61 & 0.49 & -0.04 & 0.66 & 0.76 & 0.43 & -0.34 & 0.00 \\
\hline Eligible for individual education program & 0.04 & 0.20 & 0.05 & 0.21 & -0.02 & 0.82 & 0.07 & 0.25 & -0.10 & 0.28 \\
\hline
\end{tabular}

NOTES: SD = standard deviation; STD EFF SIZE = standardized effect size. N_RCI $=159$. N_Comparison $=3,010$. 
Table A.17. Equivalence Between RCI Participants in 2008-2009 and the Historical-Comparison Students for Analyses on Attendance Rate

\begin{tabular}{|c|c|c|c|c|c|c|c|c|c|c|}
\hline \multirow[b]{2}{*}{ Variables Used for Propensity Score Matching } & \multicolumn{2}{|c|}{$\mathrm{RCI}$} & \multicolumn{4}{|c|}{$\begin{array}{l}\text { Comparison Group After } \\
\text { Propensity Score Weighting }\end{array}$} & \multicolumn{4}{|c|}{$\begin{array}{l}\text { Comparison Group Before } \\
\text { Propensity Score Weighting }\end{array}$} \\
\hline & Mean & SD & Mean & SD & \begin{tabular}{|l} 
STD \\
EFF \\
SIZE
\end{tabular} & $p$ & Mean & SD & $\begin{array}{l}\text { STD } \\
\text { EFF } \\
\text { SIZE }\end{array}$ & $p$ \\
\hline Attendance rate in the previous school year & 0.94 & 0.05 & 0.95 & 0.05 & -0.06 & 0.54 & 0.94 & 0.05 & -0.04 & 0.69 \\
\hline Male & 0.64 & 0.48 & 0.62 & 0.48 & 0.03 & 0.78 & 0.48 & 0.50 & 0.33 & 0.00 \\
\hline Nonwhite student & 0.06 & 0.24 & 0.07 & 0.26 & -0.03 & 0.75 & 0.16 & 0.36 & -0.39 & 0.00 \\
\hline Eligible for free and reduced-price lunch & 0.76 & 0.43 & 0.79 & 0.41 & -0.06 & 0.51 & 0.77 & 0.42 & -0.02 & 0.83 \\
\hline Eligible for individual education program & 0.10 & 0.30 & 0.10 & 0.30 & 0.01 & 0.90 & 0.07 & 0.26 & 0.09 & 0.24 \\
\hline
\end{tabular}

NOTES: SD = standard deviation; STD EFF SIZE = standardized effect size. N_RCI = 126. N_Comparison = 3,621.

Table A.18. Equivalence Between RCI Participants in 2007-2008 and the Historical-Comparison Students for Analyses on Attendance Rate

\begin{tabular}{|c|c|c|c|c|c|c|c|c|c|c|}
\hline \multirow[b]{2}{*}{ Variables Used for Propensity Score Matching } & \multicolumn{2}{|c|}{$\mathbf{R C I}$} & \multicolumn{4}{|c|}{$\begin{array}{l}\text { Comparison Group After } \\
\text { Propensity Score Weighting }\end{array}$} & \multicolumn{4}{|c|}{$\begin{array}{l}\text { Comparison Group Before } \\
\text { Propensity Score Weighting }\end{array}$} \\
\hline & Mean & SD & Mean & SD & $\begin{array}{l}\text { STD } \\
\text { EFF } \\
\text { SIZE }\end{array}$ & $p$ & Mean & SD & $\begin{array}{l}\text { STD } \\
\text { EFF } \\
\text { SIZE }\end{array}$ & $p$ \\
\hline Attendance rate in the previous school year & 0.92 & 0.09 & 0.93 & 0.07 & -0.18 & 0.25 & 0.95 & 0.05 & -0.33 & 0.03 \\
\hline Male & 0.60 & 0.49 & 0.58 & 0.49 & 0.05 & 0.75 & 0.48 & 0.50 & 0.24 & 0.10 \\
\hline Nonwhite student & 0.14 & 0.35 & 0.12 & 0.32 & 0.07 & 0.62 & 0.04 & 0.21 & 0.28 & 0.00 \\
\hline Eligible for free and reduced-price lunch & 0.70 & 0.46 & 0.74 & 0.44 & -0.09 & 0.50 & 0.87 & 0.34 & -0.36 & 0.00 \\
\hline Eligible for individual education program & 0.14 & 0.35 & 0.13 & 0.34 & 0.02 & 0.86 & 0.08 & 0.26 & 0.19 & 0.09 \\
\hline
\end{tabular}

NOTES: SD = standard deviation; STD EFF SIZE = standardized effect size. N_RCI = 50. N_Comparison $=3,240$. 
Table A.19. Equivalence Between RCI Participants in 2010-2011 and the Historical-Comparison Students for Analyses on Advanced Course Enrollment

\begin{tabular}{|c|c|c|c|c|c|c|c|c|c|c|}
\hline \multirow[b]{2}{*}{ Variables Used for Propensity Score Matching } & \multicolumn{2}{|c|}{$\mathrm{RCl}$} & \multicolumn{4}{|c|}{$\begin{array}{l}\text { Comparison Group After } \\
\text { Propensity Score Weighting }\end{array}$} & \multicolumn{4}{|c|}{$\begin{array}{l}\text { Comparison Group Before } \\
\text { Propensity Score Weighting }\end{array}$} \\
\hline & Mean & SD & Mean & SD & \begin{tabular}{|l} 
STD \\
EFF \\
SIZE
\end{tabular} & $p$ & Mean & SD & $\begin{array}{l}\text { STD } \\
\text { EFF } \\
\text { SIZE }\end{array}$ & $p$ \\
\hline The number of advanced courses enrolled in the previous school year & 0.01 & 0.09 & 0.01 & 0.08 & 0.02 & 0.81 & 0.10 & 0.41 & -1.09 & 0.00 \\
\hline Male & 0.59 & 0.49 & 0.59 & 0.49 & -0.00 & 0.99 & 0.48 & 0.50 & 0.22 & 0.01 \\
\hline Nonwhite student & 0.31 & 0.46 & 0.31 & 0.46 & 0.00 & 0.98 & 0.26 & 0.44 & 0.10 & 0.23 \\
\hline Eligible for free and reduced-price lunch & 0.65 & 0.48 & 0.65 & 0.48 & -0.00 & 0.99 & 0.67 & 0.47 & -0.06 & 0.52 \\
\hline Eligible for individual education program & 0.07 & 0.26 & 0.07 & 0.26 & 0.00 & 0.99 & 0.07 & 0.25 & 0.03 & 0.77 \\
\hline
\end{tabular}

NOTES: SD = standard deviation; STD EFF SIZE = standardized effect size. N_RCI = 139. N_Comparison = 2,092.

Table A.20. Equivalence Between RCI Participants in 2009-2010 and the Historical-Comparison Students for Analyses on Advanced Course Enrollment

\begin{tabular}{|c|c|c|c|c|c|c|c|c|c|c|}
\hline \multirow[b]{2}{*}{ Variables Used for Propensity Score Matching } & \multicolumn{2}{|c|}{$\mathbf{R C l}$} & \multicolumn{4}{|c|}{$\begin{array}{l}\text { Comparison Group After } \\
\text { Propensity Score Weighting }\end{array}$} & \multicolumn{4}{|c|}{$\begin{array}{l}\text { Comparison Group Before } \\
\text { Propensity Score Weighting }\end{array}$} \\
\hline & Mean & SD & Mean & SD & \begin{tabular}{|l} 
STD \\
EFF \\
SIZE
\end{tabular} & $p$ & Mean & SD & $\begin{array}{l}\text { STD } \\
\text { EFF } \\
\text { SIZE }\end{array}$ & $p$ \\
\hline The number of advanced courses enrolled in the previous school year & 0.40 & 0.92 & 0.31 & 0.76 & 0.10 & 0.50 & 0.08 & 0.35 & 0.35 & 0.00 \\
\hline Male & 0.58 & 0.49 & 0.57 & 0.49 & 0.03 & 0.77 & 0.48 & 0.50 & 0.21 & 0.01 \\
\hline Nonwhite student & 0.25 & 0.43 & 0.24 & 0.42 & 0.04 & 0.67 & 0.19 & 0.39 & 0.15 & 0.04 \\
\hline Eligible for free and reduced-price lunch & 0.59 & 0.49 & 0.60 & 0.49 & -0.03 & 0.76 & 0.76 & 0.43 & -0.34 & 0.00 \\
\hline Eligible for individual education program & 0.04 & 0.20 & 0.04 & 0.20 & 0.02 & 0.81 & 0.07 & 0.25 & -0.10 & 0.29 \\
\hline
\end{tabular}

NOTES: SD = standard deviation; STD EFF SIZE = standardized effect size. N_RCI = 159. N_Comparison $=3,010$. 
Table A.21. Equivalence Between RCI Participants in 2008-2009 and the Historical-Comparison Students for Analyses on Advanced Course Enrollment

\begin{tabular}{|c|c|c|c|c|c|c|c|c|c|c|}
\hline \multirow[b]{2}{*}{ Variables Used for Propensity Score Matching } & \multicolumn{2}{|c|}{$\mathbf{R C l}$} & \multicolumn{4}{|c|}{$\begin{array}{l}\text { Comparison Group After } \\
\text { Propensity Score Weighting }\end{array}$} & \multicolumn{4}{|c|}{$\begin{array}{l}\text { Comparison Group Before } \\
\text { Propensity Score Weighting }\end{array}$} \\
\hline & Mean & SD & Mean & SD & \begin{tabular}{|l} 
STD \\
EFF \\
SIZE
\end{tabular} & $p$ & Mean & SD & $\begin{array}{l}\text { STD } \\
\text { EFF } \\
\text { SIZE }\end{array}$ & $P$ \\
\hline The number of advanced courses enrolled in the previous school year & 0.84 & 1.20 & 0.52 & 0.92 & 0.26 & 0.12 & 0.07 & 0.32 & 0.65 & 0.00 \\
\hline Male & 0.64 & 0.48 & 0.61 & 0.49 & 0.06 & 0.67 & 0.48 & 0.50 & 0.34 & 0.00 \\
\hline Nonwhite student & 0.06 & 0.23 & 0.04 & 0.20 & 0.05 & 0.54 & 0.15 & 0.35 & -0.39 & 0.01 \\
\hline Eligible for free and reduced-price lunch & 0.76 & 0.43 & 0.76 & 0.42 & -0.02 & 0.87 & 0.78 & 0.42 & -0.05 & 0.63 \\
\hline Eligible for individual education program & 0.10 & 0.30 & 0.10 & 0.30 & 0.00 & 0.99 & 0.07 & 0.26 & 0.10 & 0.26 \\
\hline
\end{tabular}

NOTES: SD = standard deviation; STD EFF SIZE = standardized effect size. N_RCI = 126. N_Comparison $=3,621$.

Table A.22. Equivalence Between RCI Participants in 2007-2008 and the Historical-Comparison Students for Analyses on Advanced Course Enrollment

\begin{tabular}{|c|c|c|c|c|c|c|c|c|c|c|}
\hline \multirow[b]{2}{*}{ Variables Used for Propensity Score Matching } & \multicolumn{2}{|c|}{$\mathbf{R C l}$} & \multicolumn{4}{|c|}{$\begin{array}{l}\text { Comparison Group After } \\
\text { Propensity Score Weighting }\end{array}$} & \multicolumn{4}{|c|}{$\begin{array}{l}\text { Comparison Group Before } \\
\text { Propensity Score Weighting }\end{array}$} \\
\hline & Mean & SD & Mean & SD & \begin{tabular}{|l} 
STD \\
EFF \\
SIZE
\end{tabular} & $p$ & Mean & SD & $\begin{array}{l}\text { STD } \\
\text { EFF } \\
\text { SIZE }\end{array}$ & $p$ \\
\hline The number of advanced courses enrolled in the previous school year & 0.58 & 1.12 & 0.43 & 0.77 & 0.14 & 0.39 & 0.06 & 0.32 & 0.47 & 0.00 \\
\hline Male & 0.58 & 0.49 & 0.58 & 0.49 & 0.00 & 1.00 & 0.48 & 0.50 & 0.21 & 0.19 \\
\hline Nonwhite student & 0.12 & 0.33 & 0.12 & 0.32 & 0.01 & 0.93 & 0.14 & 0.35 & -0.07 & 0.70 \\
\hline Eligible for free and reduced-price lunch & 0.68 & 0.47 & 0.69 & 0.46 & -0.01 & 0.97 & 0.78 & 0.42 & -0.20 & 0.16 \\
\hline Eligible for individual education program & 0.07 & 0.26 & 0.07 & 0.26 & -0.00 & 0.99 & 0.07 & 0.26 & -0.00 & 0.98 \\
\hline
\end{tabular}

NOTES: SD = standard deviation; STD EFF SIZE = standardized effect size. N_RCI = 41. N_Comparison $=3,373$. 
Table A.23. ATT Analysis Results at the Student Level Using Contemporary-Comparison Group

\begin{tabular}{|c|c|c|c|c|c|}
\hline Outcome Variable Included in the Analysis & $\begin{array}{l}\text { Program } \\
\text { Year }\end{array}$ & $\begin{array}{l}\text { Grade Levels } \\
\text { Included in } \\
\text { the Analysis }\end{array}$ & Coe.Est & Std.Err. & p.adjust \\
\hline Scaled score on PSSA mathematics test & 2010-2011 & 11 & 38.69 & 42.94 & 0.65 \\
\hline Scaled score on PSSA reading test & 2010-2011 & 11 & 32.60 & 41.25 & 0.71 \\
\hline Scaled score on PSSA mathematics test & $2009-2010$ & 11 & 24.57 & 28.05 & 0.65 \\
\hline Scaled score on the PSSA reading test & $2009-2010$ & 11 & 2.22 & 36.91 & 0.97 \\
\hline Attendance rate & 2010-2011 & $9-12$ & 0.01 & 0.01 & 0.45 \\
\hline Attendance rate & $2009-2010$ & $9-12$ & 0.01 & 0.00 & 0.27 \\
\hline Attendance rate & 2008-2009 & $9-12$ & -0.01 & 0.01 & 0.45 \\
\hline Attendance rate & $2007-2008$ & $9-12$ & -0.02 & 0.01 & 0.37 \\
\hline The number of advanced courses attended & 2010-2011 & $9-12$ & 0.00 & 0.01 & 0.80 \\
\hline The number of advanced courses attended & 2009-2010 & $9-12$ & 0.03 & 0.02 & 0.37 \\
\hline The number of advanced courses attended & 2008-2009 & $9-12$ & 0.29 & 0.12 & 0.12 \\
\hline The number of advanced courses attended & $2007-2008$ & $9-12$ & -0.16 & 0.24 & 0.71 \\
\hline $\begin{array}{l}\text { Differences in the scaled score on PSSA } \\
\text { mathematics test between grades } 8 \text { and } 11\end{array}$ & 2010-2011 & 11 & 26.76 & 39.22 & 0.71 \\
\hline $\begin{array}{l}\text { Differences in the scale score on PSSA reading } \\
\text { test between grades } 8 \text { and } 11\end{array}$ & $2010-2011$ & 11 & 12.42 & 43.96 & 0.83 \\
\hline $\begin{array}{l}\text { Differences in the scaled score on PSSA } \\
\text { mathematics test between grades } 8 \text { and } 11\end{array}$ & $2009-2010$ & 11 & 24.22 & 17.74 & 0.41 \\
\hline $\begin{array}{l}\text { Differences in the scaled score on the PSSA } \\
\text { reading test between grades } 8 \text { and } 11\end{array}$ & 2009-2010 & 11 & 23.30 & 34.28 & 0.71 \\
\hline $\begin{array}{l}\text { Differences in attendance rate between the } \\
\text { baseline year and the 2010-2011 school year }\end{array}$ & 2010-2011 & $9-12$ & 0.01 & 0.01 & 0.51 \\
\hline $\begin{array}{l}\text { Differences in attendance rate between the } \\
\text { baseline year and the 2009-2010 school year }\end{array}$ & 2009-2010 & $9-12$ & 0.01 & 0.03 & 0.83 \\
\hline $\begin{array}{l}\text { Differences in attendance rate between the } \\
\text { baseline year and the 2008-2009 school year }\end{array}$ & 2008-2009 & $9-12$ & 0.00 & 0.01 & 0.71 \\
\hline $\begin{array}{l}\text { Differences in attendance rate between the } \\
\text { baseline year and the 2007-2008 school year }\end{array}$ & 2007-2008 & $9-12$ & -0.01 & 0.01 & 0.71 \\
\hline $\begin{array}{l}\text { Differences in the number of advanced courses } \\
\text { enrolled between the baseline year and the } \\
\text { 2010-2011 school year }\end{array}$ & 2010-2011 & $9-12$ & 0.01 & 0.02 & 0.80 \\
\hline $\begin{array}{l}\text { Differences in the number of advanced courses } \\
\text { enrolled between the baseline year and the } \\
2009-2010 \text { school year }\end{array}$ & 2009-2010 & $9-12$ & 0.03 & 0.05 & 0.71 \\
\hline $\begin{array}{l}\text { Differences in the number of advanced courses } \\
\text { enrolled between the baseline year and the } \\
2008-2009 \text { school year }\end{array}$ & 2008-2009 & $9-12$ & 0.28 & 0.18 & 0.37 \\
\hline $\begin{array}{l}\text { Differences in the number of advanced courses } \\
\text { enrolled between the baseline year and the } \\
\text { 2007-2008 school year }\end{array}$ & $2007-2008$ & $9-12$ & -0.10 & 0.28 & 0.80 \\
\hline
\end{tabular}


Table A.24. Results of the ATT Analysis at the Student Level Using Historical-Comparison Group

\begin{tabular}{|c|c|c|c|c|c|}
\hline Outcome Variable Included in the Analysis & $\begin{array}{c}\text { Program } \\
\text { Year }\end{array}$ & $\begin{array}{c}\text { Grade Levels } \\
\text { Included in the } \\
\text { Analysis } \\
\end{array}$ & Coe.Est & Std.Err. & p.adjust \\
\hline Scaled score on PSSA mathematics test & 2010-2011 & 11 & -25.02 & 51.15 & 0.75 \\
\hline Scaled score on the PSSA reading test & $2010-2011$ & 11 & -30.01 & 45.70 & 0.71 \\
\hline Scaled score on PSSA mathematics test & 2009-2010 & 11 & -6.41 & 30.01 & 0.87 \\
\hline Scaled score on the PSSA reading test & 2009-2010 & 11 & -73.36 & 32.91 & 0.18 \\
\hline Attendance rate & 2010-2011 & $9-12$ & 0.00 & 0.01 & 0.99 \\
\hline Attendance rate & 2009-2010 & $9-12$ & 0.00 & 0.00 & 0.71 \\
\hline Attendance rate & 2008-2009 & $9-12$ & -0.01 & 0.01 & 0.34 \\
\hline Attendance rate & $2007-2008$ & $9-12$ & -0.03 & 0.02 & 0.37 \\
\hline The number of advanced courses attended & 2010-2011 & $9-12$ & -0.31 & 0.02 & 0.00 \\
\hline The number of advanced courses attended & 2009-2010 & $9-12$ & -0.24 & 0.03 & 0.00 \\
\hline The number of advanced courses attended & 2008-2009 & $9-12$ & 0.16 & 0.11 & 0.40 \\
\hline The number of advanced courses attended & $2007-2008$ & $9-12$ & 0.31 & 0.25 & 0.45 \\
\hline $\begin{array}{l}\text { Differences in the scaled score on PSSA } \\
\text { mathematics test between grades } 8 \text { and } 11\end{array}$ & $2010-2011$ & 11 & -51.09 & 33.66 & 0.37 \\
\hline $\begin{array}{l}\text { Differences in the scale score on PSSA } \\
\text { reading test between grades } 8 \text { and } 11\end{array}$ & $2010-2011$ & 11 & -77.88 & 46.36 & 0.37 \\
\hline $\begin{array}{l}\text { Differences in the scaled score on PSSA } \\
\text { mathematics test between grades } 8 \text { and } 11\end{array}$ & 2009-2010 & 11 & -28.36 & 16.83 & 0.37 \\
\hline $\begin{array}{l}\text { Differences in the scaled score on the PSSA } \\
\text { reading test between grades } 8 \text { and } 11\end{array}$ & 2009-2010 & 11 & -86.89 & 22.47 & 0.00 \\
\hline $\begin{array}{l}\text { Differences in attendance rate between the last } \\
\text { school year and the current school year }\end{array}$ & 2010-2011 & $9-12$ & 0.02 & 0.01 & 0.37 \\
\hline $\begin{array}{l}\text { Differences in attendance rate between the last } \\
\text { school year and the current school year }\end{array}$ & 2009-2010 & $9-12$ & 0.00 & 0.00 & 0.71 \\
\hline $\begin{array}{l}\text { Differences in attendance rate between the last } \\
\text { school year and the current school year }\end{array}$ & 2008-2009 & $9-12$ & -0.01 & 0.01 & 0.45 \\
\hline $\begin{array}{l}\text { Differences in attendance rate between the last } \\
\text { school year and the current school year }\end{array}$ & 2007-2008 & $9-12$ & -0.01 & 0.01 & 0.62 \\
\hline $\begin{array}{l}\text { Differences in the number of advanced courses } \\
\text { enrolled between the last school year and the } \\
\text { current school year }\end{array}$ & 2010-2011 & $9-12$ & -0.31 & 0.02 & 0.00 \\
\hline $\begin{array}{l}\text { Differences in the number of advanced courses } \\
\text { enrolled between the last school year and the } \\
\text { current school year }\end{array}$ & 2009-2010 & $9-12$ & -0.32 & 0.05 & 0.00 \\
\hline $\begin{array}{l}\text { Differences in the number of advanced courses } \\
\text { enrolled between the last school year and the } \\
\text { current school year }\end{array}$ & 2008-2009 & $9-12$ & 0.12 & 0.09 & 0.39 \\
\hline $\begin{array}{l}\text { Differences in the number of advanced courses } \\
\text { enrolled between the last school year and the } \\
\text { current school year }\end{array}$ & 2007-2008 & $9-12$ & 0.17 & 0.30 & 0.71 \\
\hline
\end{tabular}

NOTES: For analyses on the differences in attendance rates and the number of advanced courses enrolled using historical-comparison students, we examined differences in one year due to the limited number of students in the historical-comparison group that had attendance and course enrollment data in more than two years. 


\section{References}

An, B. (2013). The influence of dual enrollment on academic performance and college readiness: Differences in socioeconomic status. Research in Higher Education, 54(4), 407-432.

Angrist, J. D., \& Pischke, J. (2008). Mostly harmless econometrics: An empiricist's companion. Princeton, NJ: Princeton University Press.

Beaver Valley Intermediate Unit. (2007). USDE interdistrict voluntary public school choice grant proposal. Monaca, PA: Author.

Benjamini, Y., \& Hochberg, Y. (1995). Controlling the false discovery rate: A practical and powerful approach to multiple testing. Journal of the Royal Statistical Society, Series B, 57, 289-300.

Bodilly, S. J., Keltner, B. R., Purnell, S. W., Reichardt, R., \& Ikemoto, G. S. (1998). Lessons from New American Schools' scale-up phase: Prospects for bringing designs to multiple schools. Santa Monica, CA: RAND Corporation, MR-942-NAS. As of March 8, 2011: http://www.rand.org/pubs/monograph_reports/MR942.html

Caparo, R. M., \& Slough, S. W. (2008). Why PBL? Why STEM? Why now? An introduction to project-based learning: An integrated science, technology, engineering, and mathematics (STEM) approach. In R. M. Capraro and S.W. Slough (Eds.), Project-based learning: An integrated science technology engineering and mathematics (STEM) approach (1-6). Rotterdam: Sense.

Carlson, D., Lavery, L., \& Witte, J. F. 2011. The determinants of interdistrict open enrollment flows: Evidence from two states. Educational Evaluation and Policy Analysis, 33(1), 76-94.

Clark, A. C., \& Ernst, J. V. (2007). A model for the integration of science, technology, engineering and mathematics. The Technology, 66(4), 24-26.

Cullen, J. B., Jacob, B., \& Levitt, S. (2005). The impact of school choice on student outcomes: An analysis of the Chicago Public Schools. Journal of Public Economics, 89(5-6), 729-760.

Data Recognition Corporation. (2011). Technical report for the 2011 Pennsylvania System of School Assessment. Maple Grove, MN: Author. As of November 23, 2015: http://www.education.pa.gov/Documents/K12/Assessment $\% 20$ and $\% 20$ Accountability/PSSA/Technical\%20Reports/2011\%20PSSA $\% 20$ Technical\%20Report.pdf

Dolmans, D., Grave, W. D., Wolfhagen, I. \& Vleuten, C. (2005). Problem based learning: Future challenges for educational practice and research. Medical Education, 39(7), 732-741. 
Dunphy, S. \& Hill, J. (2010). Explicitly differentiated eighth-grade reading instruction in a rural middle school seeking to reestablish adequate yearly progress benchmarks. International Journal of Education Leadership Preparation, 5(4).

Education Commission of the States. (2013). Open enrollment 50-state report. Denver, CO: Author. As of December 14, 2015: http://ecs.force.com/mbdata/mbtab8OE?sid=a0i70000006fu14\&rep=OE132T

Estacion, Cotner, B. A., D’Souza, S., Smith, C. A. S., \& Borman, K. M. (2011). Who enrolls in dual enrollment and other acceleration programs in Florida high schools? (Issues \& Answers Report, REL 2012-No. 119). Washington, DC: U.S. Department of Education, Institute of Education Sciences, National Center for Educaiton Evaluation and Regional Assistance, Regional Educational Laboratory Southeast.

Fullan, M. G., \& Miles, M. B. (1992). Getting reform right: What works and what doesn't. Phi Delta Kappan, 73(10), 744-752.

Goertz, M. E., Floden, R. E., \& O’Day, J. A. (1995). Studies of education reform: System reform. New Brunswick, NJ: Consortium for Policy Research in Education.

Griffin, B. A., Ridgeway, G., Morral, A. R., Burgette, L. F., Martin, C., Almirall, D., Ramchand, R., Jaycox, L. H., \& McCaffrey, D. F. (2014). Toolkit for Weighting and Analysis of Nonequivalent Groups (TWANG) website. Santa Monica, CA: RAND Corporation. As of November 23, 2015: http://www.rand.org/statistics/twang

Han, S., Capraro, R., \& Capraro, M. M. (2014). How science, technology, engineering, and mathematics (STEM) project-based learning (PBL) affects high, middle, and low achievers differently: The impact of student factors on achievement. International Journal of Science and Mathematics Education, 13(5), 1089-1113.

Hanushek, E. A. (1989). The impact of differential expenditures on school performance. Educational Researcher, 18(4), 45-65.

Hanushek, E. A. (1996) Measuring investment in education. Journal of Economic Perspectives, 10(4), 9-31.

Hedges, L. V., Laine, R. D., \& Greenwald, R. (2014). Does money matter? A meta-analysis of studies of the effects of differential school inputs on student outcomes (An exchange: Part 1). Educational Researcher, 23(3), 5-14.

Heinrich, C., Maffioli, A., \& Vazquez, G. (2010). A primer for applying propensity-score matching: Impact-evaluation guidelines. Washington, DC: The Inter-American Development Bank. 
Horan, C., Lavaroni, C. \& Beldon, P. (1996). Observation of the tinker tech program students for critical thinking and social participation behaviors. Novato: Buck Institute for Education.

Jimerson, L. (2002). Interdistrict open enrollment: The benign choice? The Clearing House, $76(1), 16-19$.

Kim, P., Hisook Kim, F., \& Karimi, A. (2012). Public online charter school students: Choices, perceptions, and traits. American Educational Research Journal, 49(3), 521-545.

Leithwood, K., Steinbach, R., \& Jantzi, D. (2002). School leadership and teachers' motivation to implement accountability policies. Educational Administration Quarterly, 38(1), 94-119.

Louis, K. S., \& Miles, M. B. (1990). Improving the urban high school: What works and why, New York: Teachers College Press.

Meade, T., \& Hoffman, E. (2007). CUNY College now: Extending the reach of dual enrollment. In N. Hoffman, J. Vargas, and M. Miller (Eds.), Minding the gap: Why integrating high school with college makes sense and how to do it. Cambridge, MA: Harvard Education Press.

Museus, S. D., Lutovsky, B. R., \& Colbeck, C. L. (2007). Access and equity in dual enrollment programs: Implications for policy formation. Higher Education in Review, 4, 1-19.

O’Dwyer, L. M., Carey, R., \& Kleiman, G. (2007). A study of the effectiveness of the Louisiana Algebra I online course. Journal of research on technology in education, 39(3), 289-306.

Public Law 107-110. (2002, January 8). No Child Left Behind Act of 2001.

Purkey, S. C., \& Smith, M. S. (1983). Effective schools: A review. Elementary School Journal, $83(4), 426-452$.

R Core Team. (2014). R: A language and environment for statistical computing. R Foundation for Statistical Computing. Vienna, Austria: Author. As of November 23, 2015 : http://www.R-project.org/

Schafer, J. L. (1999) Multiple imputation: A primer. Statistical Methods in Medical Research, 8, 3-15.

Selix, C. (2014). New dual-credit trends emerge as pioneering Post-Secondary Education Options turns 25. New York: The Heckinger Report. As of November 23, 2015: http://hechingerreport.org/content/new-dual-credit-trends-emerge-as-pioneering-postsecondary-education-options-turns-25_3238/

U.S. Census Bureau. (2010, November 4). State and county quickfacts: Beaver County, Pennsylvania. As of November 4, 2010:

http://quickfacts.census.gov/qfd/states/42/42007.html 
U.S. Department of Education, Office of Planning, Evaluation, and Policy Development. (2009). Evaluation of evidence-based practices in online learning: A meta-analysis and review of online learning studies. Washington, DC: Author.

U.S. Department of Labor, Bureau of Labor Statistics. (2009, September). Unemployment rates by county in Pennsylvania. Washington, DC: Author.

Welsch, D. M., Statz, B., \& Skidmore, M. (2010). An examination of inter- district public school transfers in Wisconsin. Economics of Education Review, 29(1), 126-137.

Witziers, B., Bosker R. J., \& Krüger M. L. (2003). Educational leadership and student achievement: The elusive search for an association. Educational Administration Quarterly, 39(3), 398-425.

Yell, M. L. (2006). The law and special education. Upper Saddle River, NJ: Pearson Merrill Prentice Hall.

Yin, R. K., \& Ahonen, P. S. (2008). Study of the Voluntary Public School Choice program: Final report. Washington, DC: U.S. Department of Education. 


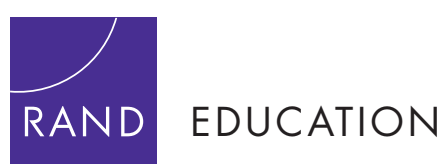

www.rand.org

$\$ 29.50$

ISBN-10 0-8330-9255-3

ISBN-13 978-0-8330-9255-7

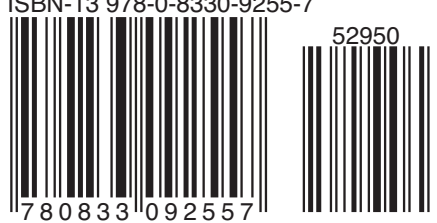

RR-1386-BVIU 